\title{
NEWLY RECOVERED MICRODATA ON U.S. MANUFACTURING PLANTS FROM THE 1950S AND 1960S:
}

\author{
SOME EARLY GLIMPSES
}

by

\author{
Randy A. Becker * \\ U.S. Bureau of the Census \\ and \\ Cheryl Grim * \\ U.S. Bureau of the Census
}

CES 11-29 September, 2011

The research program of the Center for Economic Studies (CES) produces a wide range of economic analyses to improve the statistical programs of the U.S. Census Bureau. Many of these analyses take the form of CES research papers. The papers have not undergone the review accorded Census Bureau publications and no endorsement should be inferred. Any opinions and conclusions expressed herein are those of the author(s) and do not necessarily represent the views of the U.S. Census Bureau. All results have been reviewed to ensure that no confidential information is disclosed. Republication in whole or part must be cleared with the authors.

To obtain information about the series, see www.census.gov/ces or contact Cheryl Grim, Editor, Discussion Papers, U.S. Census Bureau, Center for Economic Studies 2K130B, 4600 Silver Hill Road, Washington, DC 20233, CES.Papers.List@census.gov. 


\begin{abstract}
Longitudinally-linked microdata on U.S. manufacturing plants are currently available to researchers for 1963, 1967, and 1972-2009. In this paper, we provide a first look at recently recovered manufacturing microdata files from the 1950s and 1960s. We describe their origins and background, discuss their contents, and begin to explore their sample coverage. We also begin to examine whether the available establishment identifier(s) allow record linking. Our preliminary analyses suggest that longitudinally-linked Annual Survey of Manufactures microdata from the mid-1950s through the present - containing 16 years of additional data appears possible though challenging. While a great deal of work remains, we see tremendous value in extending the manufacturing microdata series back into time. With these data, new lines of research become possible and many others can be revisited.

* Various parts of this narrative have been presented in the past year at the Federal Reserve Board of Governors and the USDA's Economic Research Service, at sessions at the Comparative Analysis of Enterprise Data (CAED) conference and the RDC Annual Conference, and as part of a webinar broadcast by the Association of Public Data Users. We thank Mark Mildorf and Jason Chancellor for help converting the recovered data into SAS datasets, and Matthew Ashford, Joshua Coates, Henry Cross, and Justin Ladner for valuable research assistance. Any opinions and conclusions expressed herein are those of the authors and do not necessarily represent the views of the U.S. Census Bureau. All results have been reviewed to ensure that no confidential information is disclosed.
\end{abstract}




\section{Introduction}

Microdata on U.S. manufacturing plants have been available on a restricted basis through the U.S. Census Bureau and its Center for Economic Studies (CES) for nearly three decades. ${ }^{1}$ These research files currently contain data on all establishments surveyed in the Annual Survey of Manufactures $(1963,1967$, and 1972 to the present) and the much larger Census of Manufactures $\left(1963,1967\right.$, and every 5 years thereafter). ${ }^{2}$ Establishment identifiers allow these data to be linked to data from other manufacturing surveys collected by the Census Bureau. In addition, these identifiers have been made longitudinally-consistent, allowing for rich analyses of plant entry, exit, growth, and change. A vast array of economic research can be and has been done using these data.

A significant expansion of these already-valuable data now seems possible. In the last few years, CES unearthed large amounts of "new" manufacturing microdata from the Annual Survey of Manufactures (ASM) and Census of Manufactures (CM) of the 1950s and 1960s. In particular, we have recently uncovered and come to possess:

- Electronic files containing plant-level data from the individual ASMs of 1953-1964 and 1966-1971 (and sometimes multiple versions of a year's data).

- Electronic files created in the early-1960s containing longitudinally-linked, plant-level ASM data for 25 select 4-digit SIC industries for 1954-1961.

- Several hundred rolls of $16 \mathrm{~mm}$ microfilm containing images of (perhaps) all the completed survey forms from the 1954-1958 ASMs (a single "shuttle form") and the 1958 Census of Manufactures.

\footnotetext{
${ }^{1}$ Data are available to qualified researchers with approved projects through the Census Bureau's secure Research Data Center network. For more information, see http:/www.census.gov/ces/rdcresearch/index.html.

${ }^{2}$ Note that Annual Survey of Manufactures microdata are included within the Census of Manufactures microdata in those years.
} 
- Research datasets created decades ago by and for economic researchers affiliated with the Census Bureau, including Nancy and Richard Ruggles.

Figure 1 diagrams some of these newly uncovered ASM and CM microdata, and their relation to the ASM and CM microdata that are currently available at CES.

The electronic files were stored on tapes readable only by an old, archaic, and rather frail Unisys Clearpath IX 4400 mainframe that was a descendant of some of the earliest mainframes ever in existence. ${ }^{3}$ Indeed, some of the oldest data here were tabulated on a UNIVAC, of which the Census Bureau had two. ${ }^{4}$ Hundreds of person-hours were spent poring through old paper records of "data storage action requests" (DSAR) — an effort that revealed thousands of tapes worth of microdata that were eventually recovered, before the Unisys mainframe was decommissioned in 2010. Appendix A attempts to summarize the business microdata that were recovered. ${ }^{5}$ These can be classified into at least a few different types: data from surveys that are entirely new to CES; additional years of data from surveys that CES already had; and additional data items from surveys and years that CES already possessed. ${ }^{6}$ While much interesting historic microdata on manufacturers were recovered, including data on auxiliary establishments, $\mathrm{CM}$ special inquiries, class of customer, fixed base difference, industrial water use, and so forth, here we will focus only on the additional years of the ASM.

The challenges in moving these data to a modern computing platform were (and are) many. Among them, much of the data were stored in an arcane, proprietary file format (CENIO), which

\footnotetext{
${ }^{3}$ For another discussion of the historic data recovery effort, see Atrostic et al. (2010).

${ }^{4}$ In 1951, the Census Bureau purchased the very first UNIVAC computer ever produced (literally). The UNIVAC, the first electronic computer for commercial/civilian purposes, was designed by Eckert-Mauchly Computer Corporation, which was acquired by Remington Rand, which in turn was later acquired by the Sperry Corporation, which eventually merged with the Burroughs Corporation to form the Unisys Corporation. The decommissioning of this last Unisys Clearpath IX 4400 ("D machine") in the spring of 2010 ended an extraordinary 59-year chain of mainframe computing at the Census Bureau.

${ }_{6}^{5}$ A summary of recovered household microdata is available upon request.

${ }^{6}$ For the list of surveys and years that CES currently has and makes available, see http://www.census.gov/ces/dataproducts/.
} 
meant files could not simply be copied to another computer system. Further, the data within the files were completely unstructured, requiring a bit-by-bit, byte-by-byte, word-by-word record layout (on paper) to make sense of the data. In cases where a record layout no longer exists, the only hope is if a similar microdata file exists that might shed light on the contents and layout, and/or if the published aggregate data can somehow aid in reverse-engineering a record layout. Adding to the challenge, the vast majority of data employed now-esoteric, non-ASCII character sets, including FIELDATA, Excess-3 (XS3), Binary integer, and EBCDIC. ${ }^{7}$ For technical reasons, and to speed recovery, the data were read, converted to an ASCII equivalent, and written to a text file on the Unisys Clearpath, using two different assumptions: (1) the original data was all FIELDATA, and (2) the original data was all XS3. If there was a mix of character sets present within a file, which was not uncommon, ${ }^{8}$ then the resulting "gibberish" must be (re)converted to ASCII using the implied character mapping. ${ }^{9}$ It is worth noting that the knowledge and manpower necessary to overcome these various technical challenges, and to operate, maintain, and repair the Unisys Clearpath was incredibly scarce. While the vast majority of recovered data files are still in a rough state (i.e., text files in ASCII-FIELDATA and ASCII-XS3 format), and will likely remain so until demanded, the ASM files discussed in this paper have been converted to SAS datasets. ${ }^{10}$

In this paper, we begin to describe these newly uncovered ASM microdata. As Figure 1 suggests, there are at least five distinct pockets of "new" data, separated by both time and source, and we organize our discussion accordingly. For each of these different groups, we describe its

\footnotetext{
${ }^{7}$ Overall, most data was in FIELDATA, which was developed by the U.S. Army Signal Corps in the 1950s.

${ }^{8}$ For example, some of the data discussed in this paper came from files that were mix of XS3 and Binary integer.

${ }^{9}$ In cases where a record layout no longer exists - explaining variables, their positions, their lengths, and the character set(s) employed - we also have a Unisys-created text file displaying the first 100 records of a data file, employing 5 separate assumptions of character sets (FIELDATA, XS3, ASCII, Octal, and Decimal numeric). This can help us infer the proper character set and variable position and length.

${ }^{10}$ Opportunities exist to develop and use all the newly recovered microdata listed in Appendix A. For more information, contact the authors or ces.data.recovery.list@census.gov.
} 
origins and background (to the extent we can), discuss the set of variables contained therein, and begin to explore the sample coverage of each of these files, comparing establishment counts and aggregations of critical variables to those appearing in the ASM publications from the period. We also begin to examine the critical issue of whether the available establishment identifier(s) in these files allow both cross-sectional and longitudinal linking of records, including the linking of these historic ASM data to the "modern" longitudinally-linked manufacturing data that CES has long made available to researchers (i.e., those covering 1963, 1967, and 1972-present).

Our analyses show that longitudinally-linked microdata on manufactures, covering 1954 to the present, appear possible though very challenging. With the exception of a few years with fewer cases than we would expect (particularly 1953 and perhaps 1954), and 1965, for which we have no data at all, it appears possible that we have data on all ASM establishments over this period. The biggest challenge, no doubt, will be in constructing longitudinal links from these ASM files to the existing longitudinally-linked microdata - in particular, the CMs of 1963, 1967, and 1972. The naïvest of matching algorithms yields match rates of $75 \%$ to $96 \%$ for the ASM files in the 1960s and early 1970s. On an employment-weighted basis, these rates are $86 \%$ or better. Match rates decline, however, monotonically, as the time to the $1963 \mathrm{CM}$ increases falling to just $48 \%$ in 1954 (56\% on a weighted basis). ${ }^{11}$ These match rates can be improved upon through the use of multiple establishment identifiers and by other means (such as characteristics matching), but the task will prove challenging. Adding to the challenge is the tangle of (undocumented) files from 1954-1964. There are also the sobering (if sometimes vague) assessments offered by commentators from decades ago that led to the abandonment of these files in the late-1960s along with all efforts to longitudinally link them — assessments that

\footnotetext{
${ }^{11}$ For researchers interested in 25 select, largely capital-intensive industries, ASM data from 1954-1961 can be linked to the "modern" years at an $83 \%$ rate ( $93 \%$ on a weighted basis), and at a $100 \%$ rate for some industries.
} 
still held currency over a decade later when these files were explicitly ignored in favor of the more modern ASM and CM files, in an effort that was the basis for the longitudinally-linked manufacturing microdata we have today.

As will become obvious, a tremendous amount of work remains. However, we see great value in extending the manufacturing microdata series back into time. For the macroeconomists among us, these additional data contain a few more business cycles than currently available. These data would also allow the extension of gross job flows (job creation and destruction) series back into time. ${ }^{12}$ The 1950s and 1960s, in many ways, represents the "heyday" of U.S. manufacturing — before significant foreign competition, before the 1970s energy crisis, before modern environmental regulation, and so forth. With these data, new lines of research become possible, and many others can be revisited.

\section{The individual ASMs of 1966-1972}

The data in this group were recovered from the Unisys Clearpath by Alfred Nucci, then a CES staff member, in May 2006. ${ }^{13,14}$ Nucci recovered these files from the Unisys Clearpath in a manner different than that described in the previous section. He instead wrote COBOL programs that explicitly coded the record layout. These programs were executed on the Unisys and output as ASCII files. In November 2009 and January 2010 we pulled these same files using the alternative method described above - a more robust method - as insurance against possible

\footnotetext{
${ }^{12}$ The gross job flows data, described in Foster, Haltiwanger, and Kim (2006), can be found on John Haltiwanger's website: http://econweb.umd.edu/ haltiwan/. These data currently cover 1972-1998.

${ }^{13}$ Nucci retired just a few weeks later, so we were never able to discuss with him this work. All we have are the programs and datasets he left behind.

${ }^{14}$ CES already holds the 1967 and 1972 ASM data as part of the CM files from those years. Comparison of the recovered files to the existing $\mathrm{CM}$ files for these years offer opportunities for better understanding the recovered files as a whole.
} 
errors in these COBOL programs, or some other mishap. ${ }^{15}$ We have not yet worked with these alternate files or compared them to Nucci's.

By examining Nucci's programs, we know the tapes he pulled the data from and the names of the respective data files. We have since been able to identify most (but not yet all) of the DSARs that describe these files. This information is summarized in Table $1 .{ }^{16}$ At this point, our biggest concern is that the 1970 file may be missing 4,132 records that carried over onto a second tape. We are fairly confident that our data recovery efforts in 2009 captured these additional records, but we have not yet incorporated these additional observations. We are also a bit concerned (based solely on our observation of the names of the files in comparison to others) that the 1966 and 1971 files may not contain the final establishment-level data for those years.

The recovered ASM files contain much of the information collected on the ASM forms of the time. (For facsimiles of surveys forms from this period, one from each of the two ASM waves during this time (1965-68 and 1969-72), see Appendixes B and C.) For each year (19661972), the data include numerous output measures, including total value of shipments, value added, various inventories (total, finished products, work-in-progress, materials), and details at the product level, including value shipped and quantity shipped. The data also include employment measures, including total employment, production workers (by quarter), and manhours of production workers (by quarter). In addition to payroll measures, including total payroll

\footnotetext{
${ }^{15}$ We'll note that none of the relevant data storage action requests (DSARs) here contained a record layout. Nucci instead assumed/used an ASM record layout from the 1967 CM (see DSAR 79-112). For the most part, this seems to have been a decent assumption. However, we have identified some variables that are clearly not what the record layout would suggest - such as the issue with Serial_no, Type_3, and Rec_no, as noted below, and EIN and OLDID with no values.

${ }^{16}$ Besides those listed in this table, we recovered data from at least four other DSARs related to the ASMs from this period that also appear to be worth exploring. This includes DSAR 78-143 containing "1965 ASM - Sample Selection: 1965 ASM Sample Run 32 OUT 1 / UNIVLISTOUT and SAMPLLISTOUT"; 78-145 containing "1970 ASM - Sample Selection: Sampled Companies w/ Revised Weights"; 78-145 containing "1970 ASM - Sample Selection: Sampled Companies w/ Revised Weights"; and 78-149 containing "1971 ASM: Final Name and Address File".
} 
and the salaries and wages of production and non-production workers, these data also include supplemental labor costs - both legally-required and voluntary. Data on other production costs include the costs of materials and supplies, fuels, electricity, contract work, and so forth. The data also include details on capital expenditures (total, equipment, structures, new, and used), gross book value of capital assets (total, equipment, structure), rental payments (equipment, structures), and capital retirements. Kilowatt-hours of electricity purchased, generated, and sold/transferred are also here. Other notable variables include 4-digit SIC industry code, geographic codes, sample weight, and various identification numbers (including ID, Tab number, and PPN). ${ }^{17}$ The contents of these datasets, and all those discussed in this paper, are summarized in Table 2. Note that, with the exception of a number of key variables, we have not verified that all variables are filled with non-missing values in all years, let alone sensible values. This is a particular concern here since a surrogate record layout was used.

Table 3 shows the number of observations, the number of observations with positive payroll and employment, and the number of observations suggested by each year's ASM publications. ${ }^{18}$ In all years, the number of observations in these files exceed the numbers mentioned by the respective ASM publications. And the number of observations with positive payroll and employment also exceeds the numbers mentioned by the respective ASM publications in all years but 1970 and $1971 .{ }^{19}$ We previously noted that these Nucci files may be

\footnotetext{
${ }^{17}$ There appears to be at least one other identification number that currently (and erroneously) spans the variables Serial_no, Type_3, and Rec_no. It is a 10-digit ID-like number, but we do not know what it is exactly (because we do not have the appropriate record layout). This identification number's position is precisely where these other three variables are in the $1967 \mathrm{CM}$ record layout used and assumed by Nucci.

${ }^{18}$ Here, observations that were exact duplicates across all variables have been removed from these datasets, while ID-year duplicates with different data in any variables are retained. Also, observations with SIC industry codes outside of 2000-3999 have also been removed.

${ }^{19}$ The 1972 Census of Manufactures publication makes no mention of how many ASM cases there were in that year, though we might expect it to be between "about 65,000" and "about 70,000", which are the numbers mentioned in the 1971 and 1973 ASM publication, respectively. We will noted that close to 70,000 observations are flagged as ASM cases in the 1972 CM file maintained by CES.
} 
missing 4,132 records in 1970 that were subsequently recovered but not yet incorporated. We also noted a potential concern about the 1971 file. Further work will be needed to "prove in" these data.

We undertake a few preliminary longitudinal-linking exercises with these files. In particular, we attempt to longitudinally link adjacent years of these files together, as well as link these files to the longitudinally-linked manufacturing microdata that currently exists at CES. While there are a few establishment identifiers in these particular ASM files, for this initial exercise we will simply use the variable ID, a ten-digit number that uniquely identifies an establishment and has embedded in it a firm identifier common to all establishments within that firm (as it is in the "modern" files as well). Table 4 shows match rates on both an unweighted and employment-weighted basis.

In terms of linking adjacent years of these ASMs, a number of unweighted match rates are in the 80,90 , and 100 percent range, and the weighted match rates are even higher (not surprisingly). Two major exceptions here are the links between $1969 \&$ 1970, and $1971 \& 1972$. It is not obvious to us at this point why this should be the case.

To illustrate the importance of also utilizing some of the other establishment identifiers present, we took previously unmatched cases (through ID matching) and attempted to match by the 7-digit Tab number (TN) instead. This improved overall match rates by as much as 13 percentage points. ${ }^{20}$ We did not attempt any additional matching beyond this.

Table 4 also contains match rates of these ASM files to the existing longitudinally-linked microdata - in particular, the CMs of 1963,1967 , and 1972 . We see that, not surprisingly, the 1966 ASM matches better to the 1967 CM (84\%) than to the $1963 \mathrm{CM}$. Also not surprising, the

\footnotetext{
${ }^{20}$ In particular, the match rate between $1966 \& 1967,1967 \& 1968,1968 \& 1969,1969 \& 1970,1970 \& 1971$, and $1971 \& 1972$ improved by about 9, 5, 0, 5, 5, and 13 percentage points, respectively.
} 
1967 ASM matches better to the 1967 CM (91\%) than to the 1963 CM or 1972 CM. The 1968 and 1969 ASMs match better to the $1967 \mathrm{CM}(81 \%)$ than to the $1972 \mathrm{CM}$, while the 1970 and 1971 ASM match better to the $1972 \mathrm{CM}(77 \%$ and $91 \%)$ than the $1967 \mathrm{CM}$. For reasons we don't yet understand, the 1972 ASM matches better to the $1967 \mathrm{CM}(84 \%)$ than the $1972 \mathrm{CM}$ (52\%). This is not a large concern for us since we already have the universe of 1972 establishments in the CM. On an employment-weighted basis, the maximum match rates achieved are $91 \%, 97 \%, 91 \%, 88 \%, 86 \%$, and $96 \%$, for $1966-1971$, respectively. We'll note that these matches do not appear to be spurious - matched cases agree on county and 4-digit SIC in a very large proportion of cases.

As was the case earlier, the use of some of the other establishment identifiers to match unmatched cases proved successful. In particular, the use of TN raised the match to the 1963 CM, for the 1966 and 1967 ASMs, to 86\% and 72\%, respectively, on an unweighted basis, and $96 \%$ and $92 \%$ on a weighted basis. Meanwhile, the use of EIN (which is in the final nine digits of the ID for single-unit establishment/firms) improved the match rates of all the ASMs to the $1967 \mathrm{CM}$ - upwards of 2.3 percentage points in the cases of the 1966 and 1972 ASMs. Likewise, the use of EIN improved the match rates of all the ASMs to the $1972 \mathrm{CM}$, in the range of 1 to 3 percentage points. The other identification number noted above (that spans the variables Serial_no, Type_3, and Rec_no) also appears to play a useful role, particularly in matching the 1966 ASM to the $1963 \mathrm{CM}$. A more careful study and analyses of identifier matching will eventually need to be done.

In summary, using just simple ID-matching, between these ASM files and the existing longitudinally-linked microdata, we achieve an unweighted match rate ranging from $77 \%$ to $91 \%$, with a weighted match rate ranging from $86 \%$ to $97 \%$ (the nadir being 1970 in both 
instances). Of course a match rate of $100 \%$ is unrealistic here, since a non-trivial number of establishments die over time. Nevertheless, match rates can no doubt be improved by using some of the other establishment identifiers available (as we have already demonstrated). Broken links can also potentially be restored through "characteristics matching" which might, for example, rely on 4-digit SIC industry, county, and perhaps size class.

\section{The individual ASMs of 1954-1964 (the "Industrial Time Series" files)}

\subsection{Background}

The data in this group were recovered from the Unisys Clearpath in October 2009. The source of these data were the 38 unique files/tapes associated with Data Storage Action Request 79-089, of which only 37 were successfully recovered. ${ }^{21,22}$ The title given to these data on this DSAR (and its predecessors) was the "Industrial Time Series" or ITS, ${ }^{23}$ and the record layouts contained therein strongly suggest ASM data covering 1954-1964. Beyond that, the DSARs offer little clue of the story behind these files.

The earliest and most detailed account of this project that we have been able to (easily) find is a paper by Maxwell Conklin, then Chief of the Census Bureau's Industry Division, titled "Time Series for Individual Plants from the Annual Survey of Manufactures and Related Data" presented at a joint session of the American Economic Association and the American Statistical

\footnotetext{
${ }^{21}$ There are 76 files listed in DSAR 79-089. Of these, 38 files (half of the files) were known duplicates and recovery was not attempted unless the first copy of the file could not be recovered. It was standard practice during this period to make and store two copies of everything.

${ }^{22}$ This DSAR was executed in March 1979, after hundreds of UNISERVO III-A tapes associated with DSAR 68130, 69-068, 69-069, 69-070, 69-071, 69-091, 69-092, 69-093, 69-095 and 69-096 (dating from the winter of 196869) were copied to UNISERVO VIII-C 9 track tapes. It is these early DSARs that contain the record layouts needed to read the data files and convert them to ASCII. The DSAR for 68-130 has not been found.

${ }^{23}$ For better or worse, this is what we have come to call these files, though it appears that these data had no proper name at the time, at least not one that was used consistently. Old working papers and other documents tended to refer to these data as the time series file, the time series project, or similar (e.g., Jordan 1965, Krishna 1967, Klotz 1970, Kallek 1982). Only in these DSARs, and in a Request for Records Disposition Authority (SF-115) filed with the National Archives in 1982, are these data ever called the ITS.
} 
Association on December 30, 1964. Conklin describes a project to construct longitudinally linked data on manufacturing establishments and the hopes underlying this effort - in particular, that such data would help in the development of "new and improved measures that would throw light on the forces changing the structural characteristics of industry." Besides data from multiple ASMs, these files would also contain additional data items available only in the CMs (e.g., exports, installed horsepower) or in special supplemental surveys, as well as derived items (e.g., average hourly earnings) and data on the parent company (e.g., R\&D expenditures, integration/diversification, profitability, concentration). Conklin states that with these data, "the dynamics of a manufacturing plant can be introduced to the computer record as a basis for its classification and analysis", and he lists a number of specific examples. In addition, he notes the potential "for testing and developing models dealing with the components of growth or decline, investment functions, economies of scale, elements of changes in productivity, and so forth."

In his paper, Conklin presents a number of experimental tables and charts, and describes some eight other projects that were underway or under consideration. ${ }^{24}$ None use the full ASM of all industries. Instead, they use a 25-industry prototype of these data covering 1954-1961 (and later 1963) with around 1,800 establishments. (These data will be the subject of the next section.) The challenges in bringing together multiple years of the full ASM were no doubt great, particularly with the computer technology of the time. Conklin speaks to some "serious obstacles to the achievement of a completely or even moderately satisfactory basic file." Among them are omissions and data error. Even when these were discovered during processing, because

\footnotetext{
${ }^{24}$ The other projects include ones that examine investment functions; potential output in relation to actual shipments; changing patterns in the use of materials (by plant age); demand for fixed investment; productivity and disemployment; factors affecting wage changes; optimal scale, merger, and integration; economics of scale and technical change in manufacturing; and efficiency of new plants as compared with older plants in the same industry. To date, we have only found documents on one or maybe two of these (Jordan 1965, Klotz 1970). Kallek (1975) refers to a Bureau of Labor Statistics "methodological study to explore whether plants with high productivity levels could serve as a guide to projecting future productivity increases of an industry." She may be referring to Klotz (1970), but it is not clear.
} 
"the cost of correcting computer tapes is relatively great ... in a good many instances these corrections were not carried back to the basic tapes or were incorrectly recorded. Another and more serious problem is that with mergers, changes in corporate structure, company name, etc., the identification number of plants has changed over the years with the result that frequently it is not mechanically feasible to bring the records together in the computer. All of these limitations are more pronounced for earlier years than for the period since 1958."

Conklin does mention that "plans for the immediate future involve consolidating the records for large establishments which have changed identification numbers and correcting large data errors in the tapes. The task of correcting records and making other modifications will probably take another year or two." Elsewhere he states that "several years of effort have already been expended on the project and the end is not yet in sight." 25 Recounting the endeavor nearly 20 years later, Conklin (1982) remarks:

On the face of it, it would appear feasible to carry corrections to the micro records as originally taped. There were many (maybe too many) ways that plants could be matched. In addition to industry and geographic codes, Social Security employer identification numbers - alpha numeric company numbers and permanent plant numbers - were on all plant records. After the mid-1950's, nearly all Annual Survey records were collected annually for the previous year as well as for the current year on the same report form. This overlap system of reporting increased the efficiency of the sample design by yielding estimates by differencing from the previous year rather than by directly estimating tables. It was assumed that the overlap would be very helpful in matching plants. The creation of a clean micro file was by its nature not a primary Bureau goal, and as a secondary objective, it simply did not work out well. This experience was frustrating 20 years ago, 15 years ago, and apparently has been since then.

Kallek (1975), then Associate Director for Economic Fields at the Census Bureau, discusses the usefulness of business microdata for economic research and the reasons why the development of such data (and analyses) had so far faltered. She essentially reiterates the challenges mentioned by Conklin (1964), before concluding:

The major lesson learned from the 1960's time-series effort is that it is almost impossible to reconstruct an historical file of individual establishment records. The tracing of identification numbers for individual establishments and the ex post facto

\footnotetext{
${ }^{25}$ Willis Jordan, however, writing in 1965, suggested that the project was only underway "for about 2 years."
} 
correction of data fields pose processing problems which are almost impossible to overcome.

If the Bureau is to provide the ability for microdata analysis, the concept must be built into its operating system, and research efforts must be undertaken here at the Bureau which will permit optimum manipulation of the data.

In the proceedings to a January 1982 conference discussing a new effort to longitudinally-link data from the ASMs and CMs - the effort that led to the longitudinal manufacturing microdata that CES has housed and made available for decades - Kallek offers this account of the ITS project's final days:

In the 1960s, an initial attempt was made to construct a time series file of manufacturing establishments but was aborted in the latter part of the decade because of budget stringencies that occurred at that time. The potential value of this file was discussed at length with data users. So it was with great reluctance that the staff at the [Census] Bureau suspended work on the early project and stored the results in our files without any extensive exploitation of them.

The DSARs mentioned earlier indicate that the data were mothballed in the winter of 1968-69.

Kallek (1982) also offers a detailed discussion of the challenges leading to this project's

shutdown in 1968, which we think is well worth transcribing in its entirety:

The early attempts to match the ASM files using the 1954 census as a starting point proved both promising and frustrating. The early match was undertaken based on census identification numbers. While a significant portion of the establishments had retained their identification numbers for several years, many others' identification numbers had been changed. There was really no way of linking such establishments except by laborious search of the records of the mailing directory. In those days, the method of tabulating the ASM required concurrent key punching of two successive years of data appearing on a single shuttle form. Thus, the linkage of ID numbers used in different years was not critical in order to measure year-to-year change. Some of the largest establishments in the ASM were used in various studies in defense planning and had been assigned a permanent plant number to identify them in each ASM, and these helped resolve some of the unmatched records. But the initial match indicated a very large number of cases where identification number had been changed because of ownership changes. Also there were many cases where a company decided to split its reporting into two documents or consolidate data for two establishments onto one document. Where such managerial decisions do not seriously affect the industry and geographic tabulations, the Census Bureau concurs in order to minimize reporting burden. Thus, the early match led to a significant amount of time and effort to research the larger unmatched establishments. This 
experience led to the modifications in our processing that placed greater responsibility on the directory to document reasons ID numbers changed and link old and new numbers. It also led us to introduce into out tabulations the concept of a permanent number that would be assigned to an establishment throughout its life in the ASM. This tabulation number became critical not only to the directory controls but to a new method of tabulation and editing.

When several years of data were put side-by-side for establishments which were matched, deficiencies in these data appeared. There were unexplained gaps in data items or imputations where it seemed a report was not received for a specific year. There were indications that that the data had been changed in the process of the editing from what was originally reported without an indication in the file as to why the figures had been changed. Quite frequently, the linking of data over time indicated unexplainable changes in level of the data that impaired comparability. The whole process indicated the editing and review process could be tightened up and improved if some of the advantage of the time series review could be introduced. We began to edit the current year's annual survey against as reference tape of previous years' reported data. Under these circumstances, the permanent number of the establishment became even more critical. In the process of reviewing the data in the time series file, we found that it was possible to introduce year-to-year comparability edits that would lead to more consistent data and also to develop the analyses of frequency distributions of various types of operating ratios.

The ASM profited from the early time series work both in its housekeeping operation and in its editing and tabulating techniques. However, through the years, as we plunged deeper and deeper into the development of the file, we found that we had serious problems with managing a file of the magnitude of the time series. We were faced with problems of how to increase the file each successive year and introduce retroactive corrections. We also faced the problems associated with modifications in the annual survey processing and sample control that took place during census years and when new samples were selected after the census. In short, as a result of our need to treat the annual survey and the data for establishments as a continuum, we learned to better handle the annual survey and our census directory operations. Thus, we felt keenly the necessity to discontinue further work on the file in 1968 because of budget restrictions. For all its deficiencies and additional cleanup work needed in the file, we felt we were nearing the point where systematic experimentation could be carried out. We were also beginning to cope with the problems associated with the successive updating of the file.

There is an old proverb that states, "The mountain was in labor and a mouse was born," and to some extent this proverb comes to mind when we think of our experience with the time series file. Inevitably comes the question, "With all of the time, expense, and thought that went into the development of the aborted 1954 to 1964 file, what productive use was made of the file?" Unfortunately, in absolute terms, little; but probably a bit more than many realize.

Kallek then cites Conklin (1964) and Jordan (1965), both of which use the more limited 25industry ITS prototype, which we describe in the next section. Schaffer (1968), on the other 
hand, clearly employs longitudinally-linked data that spans the manufacturing sector. ${ }^{26}$ That the end date for this analysis is 1957, for a paper published in 1968, may be telling. Finally, Kallek also mentions "experimental studies by Professor Griliches to study scale of operations; by Leonard Weiss to study efficiencies of scale, productivity, and the impact of mergers; and the National Planning Association to study capital output relationships.” We have not (yet) found any of these particular studies.

Kallek (1982) goes on to say:

The file was not exploited to the extent that it should have been, primarily because the Bureau devoted so much effort to its development that it has no resources for developing procedures that would permit it to be routinely accessed without a significant expenditure of staff time to assist the researchers. The amount of review required and the correction of defects and errors were both time consuming and costly. But one of the more important reasons for not exploiting it was that techniques were not available to routinely review the data for disclosures. There was significant concern about whether some of the special mathematical techniques for analysis would disclose data or possibly foreclose the use of data for other studies. Discussions on several occasions were held with individual researchers and with various advisory groups as to how these concerns could be resolved. It was evident that for maximum usefulness, the researcher should have sufficient flexibility to review interim output so that he could modify his research project if he felt that the final required tabulations could not be determined without this type of experimentation. A paper later on in this program deals with the problems of disclosure.

The years have passed all too swiftly as it seems, so it comes as a shock to realize that the last entry of data into the file was for 1964. Consequently, when the possibility of reactivating the time series files with the cooperation of the National Science Foundation and Dr. Ruggles was presented to us, all concerned felt that wisdom demanded that we start anew rather than to try to bring the old file up-todate. The present project which will be described by Mr. Govoni is forward looking. It looks to developing a time series file beginning with 1972 data and developing the procedures for routinely adding successive years as time goes by. If this file can be brought to fruition and used effectively in analysis, there may be some value in the future to put the 1954 to 1964 file in a state that it could be joined and linked with the new file. The longer we have to wait, the more obsolete the older tapes become in light of changing computer technology. [Emphasis added.]

\footnotetext{
${ }^{26}$ Schaffer examines the decreasing share of production workers in total manufacturing employment, using the ASMs of 1954 and 1957. He says very little about the origins of the data. His ultimate sample consisted of just 8,001 establishments.
} 
Of course the data on these tapes came within a few months of being lost forever. It is not clear whether Kallek, who died in 1983, would have imagined that it would be almost 30 years before anyone would attempt to link these old files to the "modern" files of manufacturing microdata.

\subsection{The many ITS files of 1954-1964 ASMs}

It is with this backdrop, and Kallek's sobering assessment of the state of these files, that we undertake our initial exploration. The first step is to convert the files from their raw format in which they were recovered from the Unisys Clearpath into SAS datasets. To assist us, there is a record layout for all but 2 of the 37 recovered files. ${ }^{27}$ In particular, there are two record layouts that apply to these files. The first, hereafter called ITS-1, applies to 34 files and is shown in Appendix D. ITS-1 is titled "Industrial Times Series Detail Record" and contains establishment identifier information and ASM data items. The second record layout, which we will call ITS-2, applies only to a single file (with over 750,000 observations) and is shown in Appendix E. The ITS-2 layout is titled "Industrial Time Series - Finder File Prep." This layout contains just select key variables for each establishment. ${ }^{28}$ We do not examine the file read in by the ITS-2 layout in this paper, but we note this file could potentially be useful information for linking establishments longitudinally.

Beyond the likely record layout, very little is known a priori about the contents of these files. ${ }^{29}$ Table 5 lists the 34 files that were made into SAS datasets using the ITS-1 layout, the number of observations in each file, and the associated DSAR. We see that the number of

\footnotetext{
${ }^{27}$ We think the information for the remaining two files was in DSAR 68-130, which we have not been able to locate. It is clear that neither of the record layouts we do have are appropriate for this file. More investigation and analysis will be necessary to identify the layout of this file. These two files combined have 937,798 observations.

${ }^{28}$ Note the top row of the ITS-2 layout is a "header" record providing column headings for the data below.

${ }^{29}$ Moreover, until we start using and proving in the data, we will not know whether using the ITS-1 record layout to read in the data produces reasonable results.
} 
records per file ranges from just a couple of hundred to over a hundred thousand. It is not clear how any of the files, and the records in these files, relate to one another. Table 6 lists each DSAR, the total number of observations in files associated with the DSAR, and the description provided in the DSAR. As one can see, the descriptions of the files are cryptic at best. A detailed exploration of the files will (eventually) be necessary to determine how (if) they fit together.

\subsection{A more detailed look at the DSAR 69-068 files}

As an initial step of what will likely be a complicated endeavor, we chose a set of files that appears to have the proper number of records. We chose the set of files that correspond to DSAR 69-068, with its 686,279 observations. ${ }^{30}$ We find that the files include data for 11 years (1954-1964), but also include 47,538 records with year equal to 1911. After some cogitation and careful study, we came to realize that these "1911" records in fact contain data from the MC-D11 form (Census of Manufactures Supplementary Inquiries for 1957). ${ }^{31}$ Outside of this issue, the year range of 1954-1964 is consistent with Kallek's (1982) description of these files. Govoni (1982), however, writing in the same conference proceedings, mentions that "large portions of the ASM file were successfully matched for the years 1954-1962 ... [but] many potential matches were not resolved." It is not clear whether "1962" was a typo, or whether Govoni had doubts about the quality of links involving 1963 and 1964.

These files contain nearly all of the information collected on the ASM forms of the time. (For facsimiles of these surveys forms, see Appendixes F, G, and H.) For each year (1954-

\footnotetext{
${ }^{30}$ DSAR 68-091, with 690,989 records, is another promising candidate. According to Table 6, both of these are from "ITS127", however the description seems to suggest that DSAR 69-068 may includes some corrections, while DSAR 69-091 is "ITS127 Input."

${ }^{31}$ A minor change to the ITS-1 record layout (shown in Appendix D) is necessary to read in the MC-D11 records. In particular, the "FLAGS" field at the end of line 1 must be split into three separate fields.
} 
1964), the data include numerous output measures, including total value of shipments, adjusted and unadjusted value added, various inventories (total, finished products, work-in-progress, materials), and details at the product level, including value shipped and (for 1958-1964) quantity shipped. The data also include employment measures, including total employment, production workers (by quarter), and man-hours of production workers (by quarter). In addition to payroll measures, including total payroll and the salaries and wages of production and non-production workers, these data include various other production costs, including the costs of materials and supplies, fuels, electricity, contract work, and so forth. The data also include details on capital expenditures (total, equipment, structures, new, and used) and kilowatt-hours of electricity purchased, generated, and sold/transferred. Other notable time-varying variables include 4-digit SIC industry code, state and county codes, sample weight, and various identification numbers. For years 1963 and 1964, the ASM form was revised to include four additional variables: gross book value of capital assets, rental payments on structures, rental payment on equipment, and capital retirements. Since gross book value of capital is measured at the end of year, the files actually contain values for 1962 as well. ${ }^{32}$

In addition to these annual variables, the files contain measures of activity at certain points in time. As noted earlier, data from the 1957 MC-D11 survey is contained in these files. (For a facsimile of this survey form, see Appendix I.) This includes information on depreciable assets in 1957, including the gross book value of capital assets, accumulated depreciation, depreciation, and retirements. Also included are items on employer payments in 1957 for old age and

\footnotetext{
${ }^{32}$ Gross book value of capital assets has positive values in 1962-1964 for 90-99\% of establishments. Rental payments on structures has positive values in 1963-1964 for about $40 \%$ of establishments. Rental payments on equipment have positive values in 1963-1964 for close to 30\% of establishments. Capital retirements have positive values in 1963-1964 (for about 60\% of establishments). For reasons we don't quite yet understand, positive values for these variables also exist in 1959. While for capital assets, equipment rental, and retirements, the incidence of positive values is less than $2 \%$, for structure rental it is over $80 \%$. Information in this footnote is based solely on DSAR 69-068.
} 
survivors insurance, unemployment insurance, workmen's compensation premiums, and private pension plans, health plans, life insurance, stock purchase plans, savings plans, and so forth. Survey items also include 1957 expenditures on maintenance and repairs, insurance premiums, rental payments, and tax payments. ${ }^{33}$

Table 7 contains the full list of variables and definitions. Variable names were created by us, and are subject to change in the future. The available variables are also summarized in Table 2. Note that, with the exception of a number of key variables, we have not verified that all variables are filled with non-missing values in all years, let alone sensible values.

Setting aside the MC-D11 data, we are left with 638,741 records. ${ }^{34}$ Table 8 shows the number of observations, the number of observations with positive payroll (SW) and employment (TE), and the number of observations suggested by each year's ASM publications. ${ }^{35}$ For most years, the number of observations in these files exceed the numbers mentioned by the respective ASM publications. The two exceptions are 1954 (with 39,667) and 1957 (with 47,780). The 1954 CM publication makes no mention of how many ASM cases there were in that year, though we might expect it to be between 52,000 and "about 45,000", which are the numbers mentioned in the 1953 and 1955 ASM publication, respectively. Jordan (1965) states that there are around 45,000 records in 1954 (and 60,000 in 1961). To the extent that the counts do not match those stated in the publications, recall that this is just one set of recovered files. The other sets of files

\footnotetext{
${ }^{33}$ As noted in U.S. Bureau of the Census (1961): "Form MC-D11, Selected Costs and Assets of Manufacturing Establishments, collected data on some of the cost items which account for the difference between value added as defined in the Census of Manufactures and national income originating in manufacturing. ... The MC-D11 survey for 1957 ... compiled data on several cost items not deducted from value added. These costs amounted to $\$ 15.4$ billion in 1957."

${ }^{34}$ We'll note that not all MC-D11 ID values can be successfully merged to other ID values in the data. Nearly $98 \%$ of MC-D11 ID values can be matched to 1957 ASM ID values. There are just over 1,000 MC-D11 ID values that cannot be matched to 1957 ASM ID values. Several hundred of these can be matched to ID values in other years, but there are over 600 MC-D11 ID values in the DSAR 69-068 data that cannot be matched to any of the ASM ID values from DSAR 69-068.

${ }^{35}$ For the purposes of this paper, ID-year duplicates are left in the data; less than $0.3 \%$ of observations in the DSAR 69-068 data are ID-year duplicates. Further examination is necessary to determine if the ID-year duplicates in the data contain duplicate information or are actually different establishments.
} 
might have different counts and/or may have establishments not in this file. And the files

discussed in Section 5 are yet another source of data covering these same years. Regarding 1954 in particular, the records here can and should be compared to the prior year data contained in the 1955 ASM file discussed in Section 5.

As another early check, we attempt to aggregate a few key variables (including payroll, employment, and value of shipments) using the data and sample weights found in these files. For the most part, national totals are in the right ballpark. There are some variables missing in certain years. For example, unadjusted value added and quarterly production worker values are missing for $1954-1958$ and $1960-1961 .^{36}$ Recall that all of these exercises have been done using just observations from DSAR 69-068. Results could be different using data from a different DSAR or combining data from various DSARs.

We also undertake a few preliminary longitudinal-linking exercises with these files. In particular, we attempt to longitudinally link adjacent years of these files together, as well as link these files to the longitudinally-linked manufacturing microdata that currently exists at CES. There are multiple establishment identifier variables here in these files: ID (current year), OLDID (prior year), TN (tab number), and PPN (permanent plant number). All of these variables may provide important information for longitudinally linking establishments. ${ }^{37}$ However, for this initial exercise we will simply use the variable ID. As in the "modern" files, ID is 10-digit variable that uniquely identifies establishments with an embedded firm identifier

\footnotetext{
${ }^{36}$ Note that it appears that unadjusted value added values are all zero/missing in 1954-1958 and 1960-1961 and adjusted value added values are all zero/missing in 1954-1957. The value added numbers that do exist produce reasonable national numbers suggesting this missing value added data is probably not the result of a file read-in error. However, the possibility of a file read-in error should be investigated. Quarterly production worker values also appear to be zero/missing in 1954-1958 and 1960-1961. Additionally, it is clear that there are problems with a few variables in select years as we see some ridiculously large tabulated values. More investigation will be required to determine the underlying problem(s).

${ }^{37}$ We look at how often ID differs from OLDID. In most years, ID differs from OLDID for less than half of one percent of observations. However, in some years the percent of observations for which ID is not equal to OLDID is larger: 1959 (3.6\%), $1962(5.5 \%)$, and $1964(1.8 \%)$.
} 
(first 6 characters for a multi-unit firm). Table 9 shows match rates on both an unweighted and employment-weighted basis.

In terms of linking adjacent years of these ASMs, match rates are generally high (most above $90 \%$ ) with some notable exceptions. The CM year, 1958, has a relatively low match rate to 1957 and 1959 . Note, however, that 1958 has many more observations than surrounding years and that more than 90 percent of 1957 and 1959 ASM plants can be matched to 1958. It is possible that in 1958, we have both plants from the 1954-1958 ASM panel and plants from the 1959-1963 ASM panel. There is a similar, but much less pronounced, issue in 1963 - another CM year. We'll note that the matches seen here do not appear to be spurious. Conditional on achieving a match, county and 4-digit SIC industry match rates are generally around $99 \%$ (for year pairs that do not entail geography or industry coding changes).

Table 9 also contains match rates of these annual ITS files to the existing longitudinallylinked microdata - in particular, the CMs of 1963 and 1967. We see that the match rates decline as we move away from 1963 - ranging from an unweighted rate of $47 \%$ in 1954 (i.e., $47 \%$ of 1954 IDs can be found in the $1963 \mathrm{CM}$ file) to virtually $100 \%$ in $1963 .^{38}$ On an employmentweight basis, the match rate is $56 \%$ in 1954 . We certainly expect match rates to decline as we move further back in time, since a non-trivial number of establishments will have died in the interim. However, there are certainly broken establishment identifier links. In the future, we will attempt to make use of the additional establishment identifier variables on the file along with characteristics matching (e.g., 4-digit SIC, county, size class) to improve longitudinal linkages. ${ }^{39}$

\footnotetext{
${ }^{38}$ It is more difficult to assess the quality of the ID links to the CM files using geographic and industry information since the geography and industry information on the existing CM files have been revised for consistency with later files (and corrected for select problems).

${ }^{39}$ We'll note that just over two hundred additional matches are found using identifier TN. Besides OLDID and PPN, we'll note that the final nine digits of the ID variable for single-unit firms is the firm's EIN, which can be used to match these cases to the $1967 \mathrm{CM}$ - provided they survived that far.
} 
The previously mentioned file, read in by the record layout named "Finder File Prep" (ITS-2, see Appendix E), may also be key.

Finally, to get an idea of how this group of files can be linked to the ASM files recovered for 1966-1972, we link the 1964 ITS ASM data to the 1966 ASM data discussed in Section 2. We get a match rate of 55\% using simple ID linking. This low rate is not necessarily surprising since a new panel of establishments was chosen for the wave beginning in 1965. The matched cases are likely from "certainty companies" while the unmatched ones are likely smaller, noncertainty cases.

\section{The longitudinally-linked ASM data for 25 industries for 1954-1961}

The data in this group were recovered from the Unisys Clearpath in October 2009. The source of these data were the 4 tapes and 4 files associated with Data Storage Action Request 79120 , of which 4 were successfully recovered, but only 3 have discernable information (at least so far). ${ }^{40}$ The title given to these data on this DSAR was the " 25 Industry Time Series". In the previous section, we discussed the broader context around these particular files. For better or worse, we've come to call these the "ITS prototype" files.

Twenty-five industries were chosen for this endeavor. As described by Conklin (1964): "For the most part these industries are heavily capitalized, the establishments tend to be large and, therefore, intensively sampled in the Annual Survey of Manufactures. Most of the larger industries in SIC Group 33, Primary Metals, are included; otherwise the selection is widely scattered." Besides the limited scope, the prototype had one other very key difference with the

\footnotetext{
${ }^{40}$ This DSAR was executed in April 1979, after UNISERVO III-A tapes associated with DSAR 67-149 were copied to UNISERVO VIII-C 9 track tapes. This earlier DSAR appears to no longer exist.
} 
data discussed in the previous section: by design, it guaranteed longitudinally-consistent establishment identifiers. As Conklin put it:

The basic data were organized not by the mechanical association of computer tapes but rather by going back to the original report forms and transcribing and punching selected data items on a clerical basis prior to converting the time series to computer tapes. From the point of view of the Census Bureau the objective of this 25-industry experiment are threefold: (1) To create a relatively small record that can be used for testing various kinds of data rearrangements and analyses of the types described earlier; (2) To develop some examples of analytical results as a means of communicating with other agencies of Government, universities, research organizations, and the business community so that they could help us in reaching decisions as to the general dimensions of the overall project; and (3) To establish a basis for evaluating the effectiveness of the computer matching techniques and to set standards as to the amount of clerical or professional work that would be desirable in correcting the computer matched records.

A considerable amount of effort has been invested in reviewing, completing, correcting, and matching the plant records for the 25 -industry study. It has been possible to accomplish this because relatively few (about 2,500) establishments are involved. While some errors remain it is hoped that the file will suffice for the purposes intended.

At the time Conklin was writing, the data already covered 1954-1961, and we have evidence that 1962 and 1963 were eventually added as well. Conklin also states that "for 15 industries, data for 1947 and for the annual surveys prior to 1954 [i.e., 1949-1953] have been added to the record....However, some of the establishment records are incomplete for the earlier years."

As noted in the previous section, Conklin himself used these data in constructing his experimental tables and charts, and the paper includes an appendix describing the data, including lists of the 25 industries and of the variables. At least a few other researchers also used this ITS prototype. Jordan (1965) presents results using a new, experimental measure of plant capacity. The ultimate goal of this line of research was "to incorporate a measure of performance potential in the basic computer record for every Annual Survey of Manufactures establishment." For three of the 25 industries, Krishna (1967) estimates plant-level production functions and examines the 
issue of economies of scale. ${ }^{41}$ Klotz (1970), in a fairly lengthy monograph, also examines productivity, and in particular, whether CES production functions fit the plant-level data better than Cobb-Douglas functions, whether large plants are more efficient than smaller ones, and whether, as plant size increases, there are ranges of increasing, constant, and decreasing returns to scale. Besides being interesting in their own right, all four of these papers are useful in demonstrating how the variables available in the ITS can be used to derive other meaningful variables. ${ }^{42}$ And Jordan, Krishna, and Klotz all have lengthy discussions on the measurement of capital stock and capital services. Each details how he constructed his capital measures, using both ITS and other data, and the limitations inherent in these measures. ${ }^{43}$ These papers are also useful as sources of information about possible deflators. Outside of these four studies, we have found no others that have used the ITS prototype, and none of the several mentioned in Conklin (1964).

As with the files discussed in the previous section, little is documented about the files and how they relate to one another. Four files were successfully recovered, but only three have discernable information (at least so far). In the DSAR, they are named FIRSTOUTPUT, MENDOUTPUT, and TS54EOUTPUT. ${ }^{44}$ The DSAR states, as Conklin (1964) suggested, that

\footnotetext{
${ }^{41}$ This may well be the first Ph.D. dissertation to use confidential manufacturing microdata from the Census Bureau. Decades later, the two of us would follow in Krishna's footsteps. His access to these data, however, was very different. At the University of Chicago, Krishna wrote a FORTRAN program, that he tested on fabricated data, that identified and removed outliers, performed the necessary transformations to construct regressors and regressands, and computed various matrices "of sums of squares and sums of products of deviations from the means of the variables, for each industry" as well as some constant terms. He sent this program (along with some grant money) to the Census Bureau, which executed the program on its UNIVAC 1107 and sent the resulting matrices (on magnetic tape as well as paper printouts) back to Krishna. With this output, Krishna then ran his regressions using the Brookings Institution's IBM 7040.

${ }^{42}$ See, for example, pages 13-18 of Klotz (1970).

${ }^{43}$ Klotz (1970) is different from the other two researchers in that he does not attempt to construct annual capital measures, instead performing cross-sectional analyses using 1957 and 1963, because of the availability of gross book value of capital in those two years.

${ }^{44}$ The fourth file was named TEDS26OUTPUT. The DSAR states that "outputs from TEDS26 program are binary unformatted tapes." In contrast, the "outputs from FIRSTA, MEND, and TS54E programs are FORTRAN formatted tapes."
} 
these files were "intended primarily as a test deck for various kinds of time series tabulations and edits." The DSAR also includes two pages, photocopied directly from the appendix of Conklin (1964), listing the 25 industries and some of the variables included, and including some other basic information. Two unique record layouts are included in the DSAR - one for FIRSTA and MEND, the other for TS54E. We include the latter in Appendix J. This record layout appears to be a superset of the former. ${ }^{45}$

Briefly, for each year (1954-1961), these ITS prototype files contains basic measures of establishment activity, including output (value of shipments, adjusted value added, inventories, specialization ratio), employment (total, production workers, total manhours, peak manhours), payroll (total, production workers), cost of materials, and capital expenditures (total, new structures). In addition, the files contain measures of activity at certain points in time, including value of shipments by 5-digit product (1961), gross book value of capital assets (1957), accumulated depreciation (1956), depreciation (1957), retirements (1957), costs of fuels and electricity $(1954,1961)$, horsepower usage $(1954)$, payments for employee pension \& legallyrequired insurance plans (1957), insurance premiums \& property taxes (1957), among others. ${ }^{46}$ Other time-invariant characteristics include the 4-digit SIC industry code in 1958, state \& county codes, and birth $\&$ death years. The full list of variables and definitions appears in Table 10. Variable definitions were created with help from Conklin (1964), Jordan (1965), Hanna (1959), and U.S. Bureau of the Census $(1957,1961)$. Variable names were created by us, and are subject to change in the future. The available variables are also summarized in Table 2.

The three files that were recovered are very similar, but not identical. Table 11 contains some basic information about them. The files are very close in terms of the number of unique

\footnotetext{
${ }^{45}$ The differences between the TS54E layout and that for FIRSTA/MEND appear to be limited to the 19 flags at the end line 1 and the four derived variables at the end of line 4 on page 2 .

${ }^{46}$ The variables from 1956 and 1957 come from Form MC-D11, discussed in the previous section.
} 
plants (ID values), with 1,808 in FIRSTA and 1,807 in MEND and in TS54E. The overlap among these ID values is very high, but not perfect, with 1,802 IDs in common across all three files. We see that the number of ID-year observations varies across these files. We find that there are some duplicate ID-year observations in FIRSTA (just 1) and especially in TS54E $(1,948)$. FIRSTA's one duplicate is an exact duplicate in all variables, while TS54E contains 1,705 ID-year observations that are an exact duplicate of another observation in all variables (except for the inconsequential SEQ_TYPE2 variable). Thus there are $243(=1948-1705)$ observations in TS54E that have duplicate ID-year values, but are not exact duplicates for all data items. It turns out that the duplicate pairs differ only in the value of their flags and derived items, mainly SC57 and SUMCE_ASSETS. ${ }^{47}$ In terms of the comparability of data items between files, it is again high but not perfect. For example, of the 1,802 IDs and 14,415 IDyears in common to FIRSTA and MEND, 417 ID-years have at least one difference. These 417 observations belong to 145 unique plants. Much more understanding is needed to construct a gold standard version of the ITS prototype (or to recognize that one of these files is already the ultimate version). ${ }^{48}$

Until that time, and for the purposes of this paper, we use the data contained in the FIRSTA file, realizing that the numbers may/will vary if one of the other files is used. With that caveat, Table 12 presents the sample size, by industry, and compares it to the total number of establishments in the industry, according to $1958 \mathrm{CM}$ publications. We see that the ITS prototype has about half of the universe of establishments in these industries, and about threequarters of the larger establishments (with 20 or more employees). Table 13 shows the coverage

\footnotetext{
${ }^{47}$ In these cases, we should be able to compute the derived variables ourselves and remove the incorrect observations.

${ }^{48}$ To gain some understanding of the differences between these files, we can look to completed survey forms available on microfilm, which we have begun to do. We can also examine the questionable cases, as they appear in the (full) ITS, described in the previous section.
} 
of the ITS prototype sample relative to the universe, in terms of establishments, value of shipments, total employees, and capital expenditures in $1958 .^{49}$ Depending on the industry, the ITS prototype has between $7 \%$ to $100 \%$ of the plants in an industry, with a median of $61 \%$. On an activity-weighted basis, however, the ITS prototype has $85-100 \%$ of these industries, with a median of $97-99 \%$ coverage. ${ }^{50,51}$ The ITS prototype certainly appears to have all the establishments "that matter". In Table 14, we speak to these 25 industries vis-à-vis the manufacturing sector as a whole. According to published statistics, while these 25 industries collectively accounted for just over $1 \%$ of manufacturing establishments in 1958, they had $11 \%$ of value added, $8 \%$ of employment, and about $25 \%$ of capital expenditures. ${ }^{52}$ This sample of 1,808 tracks these numbers fairly closely.

For each of these 1,808 establishments, we have data for 1954-1961. It is worth noting that we do not have data for 1962 and 1963 in any of the files, despite evidence that such a version of the ITS prototype once existed (Krishna 1967, Klotz 1970). We also note that there is no data here from before 1954, as described by Conklin (1964) rather explicitly. Curiously, of the studies we have found so far that employed ITS data, none use or even mention these older data. It is not clear what became of them, or why we (only) have an ITS prototype file of this particular vintage.

In any event, we explored whether these 1,808 large establishments can be linked longitudinally to the existing longitudinally-linked manufacturing microdata that we currently

\footnotetext{
${ }^{49}$ Here we restrict out attention to "active" establishments, where employment or value of shipments is nonzero in 1958.

${ }^{50}$ The one exception here is SIC 3362 (Brass, bronze, copper castings). Klotz (1970) excludes this industry from his analyses.

${ }^{51}$ This is consistent with Jordan (1965) who states that on an "unweighted basis, the sample cases accounted for over 95 percent of the universe." He goes on to say that "because of this high coverage, no attempt was made ... to weight estimates for small establishments." This is somewhat a moot point since there is no weight variable in these files. Presumably most of these cases would have a weight close to or equal to 1.00 anyway.

${ }^{52}$ As previously noted, capital-intensive industries were deliberately chosen for this prototype.
} 
have. To do so, we matched the only plant ID variable present in the ITS prototype (reported to be the 1961 ID variable) to the variable ID (not PPN) in the 1963 CM. The simple match rate is about $83 \%$, and about $93 \%$ on an activity-weighted basis. The (unweighted) match rate varies by 4-digit SIC industry from $69 \%$ to $100 \%$, with a median of about $82 \%$. We are fairly confident that these are more than just spurious matches: Of the matched cases, over $93 \%$ share the same 4-digit SIC, about 97\% share the same county, and about 91\% share the same 4-digit SIC and county.

More work can and should be done to understand the $17 \%$ of cases that did not match. Are these establishments that closed, or did the ID number change (a broken link)? For each unmatched case, can we find a (unique) establishment in the $1963 \mathrm{CM}$ that is in the same 4-digit SIC, same county, and (perhaps) same employment size class? If so, those might be the same establishment.

Even without any significant additional work, the ITS prototype has two immediate uses. First, it can potentially be used to make sense of the "full" ITS, described in the previous section. Indeed, the ITS prototype has already been useful to us in that regard. A simple ID-match with the "full" ITS (a) helped us verify our hunch that the year=1911 cases contained data from the 1957 MC-D11 survey, and (b) revealed the record positions of a number of the MC-D11 variables - enough for us to use the survey form itself to determine the remaining MC-D11 variables and their positions. And since the ITS prototype has unquestioned longitudinal links, by virtue of its construction, it can potentially shed light on the state of the longitudinal linking that was attempted and abandoned in the "full" ITS. The second immediate use is for eight more years of microdata on a number of enormous manufacturing establishments. To the extent that some of them are still alive today, their data would span over a half century (1954-2009), with 
only eight missing years at this point $(1962,1964-66,1968-71)$. With some effort, their data for these years can be found in the files described in Sections 2 and 3.

As interesting as the ITS prototype data may be, the data described in the previous two sections obviously have significantly more potential and should be the immediate focus of future efforts.

\section{The individual ASMs of 1953 and 1955-1956}

The data in this group were recovered from the Unisys Clearpath by Alfred Nucci in April $2006 .{ }^{53}$ The sources of these data were the 3 tapes and 3 files associated with Data Storage Action Requests 79-138, 79-140, and 79-139. ${ }^{54}$ An unfortunate aspect of these particular files is that their record layouts no longer exist. Nevertheless, we have made significant progress in making proper datasets for at least 1955 and 1956. The keys to deciphering the long string of numbers in a record proved to be (1) the image of the punch card in the appendix of the ASM publication for the respective year (see Appendix K), and (2) the microfilm of completed ASM survey forms for the period 1954-1958 (discussed in a later section). Meanwhile, deciphering the 1953 file has proven much more difficult because we do not have the benefit of microfilm covering this year, we have not yet found an establishment identifier that allows linking to other years of data, and the punch card image for 1953 has thus far proven insufficient to identify the location of all variables in the file. ${ }^{55}$ In addition, the 1953 data appears to have only 23,804

\footnotetext{
${ }^{53}$ As noted in Section 2, Nucci used a different methodology to recover these files from the Unisys mainframe. In January 2010, we extracted these same files using the alternate methodology described in the introduction - as insurance against possible errors. Thus far, we have no reason to believe that there are any errors in the files from 2006.

${ }^{54}$ These DSARs were executed in April 1979, after UNISERVO II-A "Hi-pack" tapes associated with DSAR 59015, 60-022, and 59-016 were copied to UNISERVO VIII-C 9 track tapes. These earlier DSARs no longer exist.

${ }^{55}$ We think we have successfully identified several variables based on the punch card, including an establishment identifier, state code, county code, industry code, payroll, and employment. Further work could potentially identify additional variables (e.g., by attempting to use the data to replicate published totals for an industry heavily
} 
unique observations. This is significantly less than the approximately 52,000 observations expected (based on the 1953 ASM publication). For these reasons, we postpone further exploration of the 1953 file.

Table 2 summarizes the variables contained in the 1955 and 1956 files. Note that both of these files also include prior year data on all the same variables. For both of these years (and their prior years), the data include output measures, including total value of shipments and various inventory measures (total, finished products, work-in-progress, materials). The data also include employment measures, including total employment, production workers, and man-hours of production workers. In addition to payroll measures, including total payroll and the salaries and wages of production and non-production workers, these data include various other production costs, including the costs of materials and supplies, fuels, electricity, contract work, and so forth. The data also include details on capital expenditures (total, equipment, structures, new, and used) and kilowatt-hours of electricity purchased, generated, and sold/transferred. Other notable variables include 4-digit SIC industry code, state and county codes, sample weight, and ID. It should also be noted that there are a small number of continuous variables that currently remain unidentified, as well as a number of categorical variables. Other establishment identifiers may be here. Meanwhile, there are also a few variables on the punch card (see Appendix K) that have not been identified in the microdata, including panel group code, card number, prior year industry, and product class. Note that, with the exception of a number of key variables, we have not verified that all variables are filled with non-missing values in both years, let alone sensible values.

dominated by certainty cases with weight 1.00). Meanwhile, the establishment identifier present in the 1953 data is only 9 digits long - not 10 digits, as in later years. 
Table 15 shows the number of observations, the number of observations with positive payroll and employment, and the number of observations suggested by each year's ASM publications. ${ }^{56}$ As discussed earlier, the number of establishments in the 1953 file is less than half of the expected number. Because the 1953 data has not been read in completely, there may be some chance (however unlikely) that there is data for more than one establishment in each line of data. Meanwhile, the 1954 count is based on the number of plants in the 1955 ASM file with positive prior year employment and payroll. While the $1954 \mathrm{CM}$ publication makes no specific mention of how many ASM cases there were in the year, we expect it to be between 52,000 and "about 45,000", which are the numbers mentioned in the 1953 and 1955 ASM publication, respectively. Jordan (1965) states that there are around 45,000 records in 1954. This is quite a bit larger than the 37,788 found here. Recall that the 1954 file from the ITS, discussed in Section 3, is also smaller than expected. The number of observations in the 1955 files is also smaller than expected, while the number in the 1956 file is fairly close to the expected number. The counts for each of these files are all lower, by several thousand, than the counts seen for the same years in Table 8 for the ITS.

In exploring these 1955 and 1956 ASM files, we discovered that there are a number of industries missing. In particular, in 1955, nine expected 4-digit SIC industries in the range SIC 2011-2026 are missing along with industries in Ordnance and accessories (SIC 19--). In 1956, these same industries are missing plus seven others in the range SIC 2027-2036. The missing industries in SIC 19 and 20 were not unexpected since the DSARs mention tapes whose data

\footnotetext{
${ }^{56}$ Here, observations that were exact duplicates across all variables have been removed from these datasets, while ID-year duplicates with different data in any variables are retained.
} 
could not be salvaged. ${ }^{57}$ Meanwhile, all states are represented (except then-territories Alaska and Hawaii).

To evaluate the reasonableness of the data in these files, we made some attempts to weight and tabulate the microdata and compare to the results to published totals, at the 4-digit SIC level. The distribution of differences is certainly centered close to zero, but a significant number of industries have differences substantially different from zero (see Ladner 2008). This may be indicative of statements made by several commentators (cited above) that corrections to records were often not carried back to back to the (microdata) tapes. Complicating this effort further, we discovered records with identical IDs, sometimes (but not always) with identical values for variables. Furthermore, nearly a quarter of observations in 1955, and nearly $9 \%$ in 1956 , have a weight of zero. (In turn, many of those with zero weight in 1955, have a weight of one in 1956.) It is not precisely clear what the situation is here. ${ }^{58}$

Much of this activity occurred in 2007 and 2008 without the benefit of knowledge and information we have since acquired, including the ITS data (and paper) files. Revisiting and recontemplating these files will be worthwhile and necessary, as they may help us understand the ITS files and may serve as complements to those files. ${ }^{59}$ ID match rates between these 1955 and 1956 files and those in the ITS are fairly high, considering we are missing blocks of data/industries in these files. We find that over $75 \%$ of IDs in the 1955 ITS file match to the

\footnotetext{
${ }^{57}$ In particular, DSAR 79-140 (1955 ASM) notes that "Tape HC1707 was omitted from run - unable to salvage tape, data on tape not written in standard language. Tape was to be data for cut 19-21, reel 1 of 4." And DSAR 79139 (1956 ASM) notes "Tape HM33757 was omitted from this run. Tape was rejected - Unable to salvage tape. Tape contained data for Industry cut 19-21, reels 1/5 and 2/5 (4000 records)."

${ }^{58}$ One thing to recognize is that the published totals in non-CM years are not simply a weighting of ASM microdata, as we attempt here. Rather, a (weighted) year-over-year change is estimated with microdata and applied to prior year totals, originating from the prior CM and moved forward.

${ }_{59}$ We may also now have more knowledge and information to allow us to better decipher the file containing the 1953 ASM.
} 
1955 file here, and about $89 \%$ of IDs in the 1956 ITS file match to the 1956 file here. ${ }^{60}$

Conditional on an ID match, the match rates for the values of 4-digit industry, state, payroll, employment, and shipments are all relatively high, between 95 and 99 percent.

\section{The Ruggles Files (1954-1959 ASM)}

The data in this group were recovered from the Unisys Clearpath in February 2010. The source of these data were the 2 tapes associated with Data Storage Action Request 79-147. ${ }^{61}$ The title given to these data on this DSAR was the "Ruggles Sorted Year Pairs / Ruggles Run Main File" and the file names mention the 1954-1959 ASM. ${ }^{62}$ Unfortunately, the DSAR we have does not contain a record layout, and its predecessor (65-094) has not been found. About all we know at this point is from Conklin (1964):

The most extensive project is one being carried on as a joint venture of the Social Science Research Council and the Census Bureau. Much of the pioneering thought on the use of the [Industrial Time Series] file and of the development techniques for matching records stems from this (the Ruggles) project which will cover the years 1954 through 1959. This study, entitled The Behavior and the Characteristics of Manufacturing in the United States, 1954-1959, uses the Annual Survey of Manufactures computer tapes for all industries for the years 1954-1959 and supplementary data for 1957 on nonpayroll labor costs, cost of maintenance and repair, insurance, rent, taxes and depreciation, book value and retirements of depreciable assets. The study is a micro-analysis dealing with economic behavior and characteristics at the establishment level rather than at the industry level. It is aimed at the exploration of (a) price-cost behavior, (b) wage behavior, (c) productivity and growth behavior, and (d) investment and net margin behavior.

\footnotetext{
${ }^{60}$ In 1955 , nearly $25 \%$ of the establishments in the ITS file that do not match to the 1955 file here are in industries 1911-2027. In 1956, close to 70\% of the non-matched observations are in industries 1911-2037. About $95 \%$ of the IDs in the 1955 and 1956 files here can be matched to the corresponding files in the ITS. Here, the non-matched observations do not appear to be heavily concentrated in specific industries.

${ }^{61}$ This DSAR was executed in April 1979, after UNISERVO III-A tapes associated with DSAR 65-094 were copied to UNISERVO VIII-C 9 track tapes.

${ }^{62}$ Richard Ruggles was a professor of economics at Yale University from 1946 to 1985, and his wife Nancy Ruggles was long affiliated with the United Nations Statistical Office. They were leaders in the field of national accounting and early advocates for the use of microdata, and the cross-sectional- and longitudinal-linking of such data. They were also the force that initiated the longitudinal manufacturing microdata that CES has today.
} 
We have not yet been able to locate the named study, or one like it. The lack of a record layout has, so far, kept us from exploring these files. ${ }^{63}$ Some of the other sources of data described in this paper may prove very helpful in eventually deciphering these data.

\section{Microfilm of completed survey forms from the 1954-1958 ASMs and the 1958 CM}

Ten years ago, CES came to acquire 325 rolls of $16 \mathrm{~mm}$ microfilm on open reels containing images of completed survey forms from the 1954-1958 ASMs as well as the 1958 CM. In November 2010, we discovered and acquired 226 more such rolls, for a total of $551 .^{64}$

In exploring this microfilm, we find at least three different types of respondent cases. ${ }^{65}$

First, there are establishments that were required to report full census detail, because they were above a given size in terms of number of employees. These establishments received a "standard form" - the first two pages of which included the same data items, regardless of industry, while the remaining pages (upwards of 6 additional pages) differed by industry or industry group, with detailed inquiries on individual products shipped, individual materials consumed, and other items (e.g., types of operation and equipment). There were almost 200 different standard forms, to accommodate the approximately 425 manufacturing industries. A second type of respondent was establishments that were in the ASM panel from 1954-58. Here, the 2-page ASM "shuttle" form (see Appendix F), with columns and data for each year from 1954 to 1958, was followed by

\footnotetext{
${ }^{63}$ Difficulties in reading and recovering these files also required an unorthodox approach which yielded 107 files of partial data, using various character set assumptions. A note on the DSAR states that the "data on original tape was not written in standard language."

${ }^{64}$ In November 2010, we also came to acquire 93 microfilm cartridges from the $1967 \mathrm{CM}$ and 77 microfilm cartridges associated with a variety of surveys - mainly ASMs from the 1970s it seems. Without a microfilm reader that can accommodate cartridges, we have not viewed any of this microfilm. Since we already have microdata for these particular surveys and years, we consider this set of microfilm out of scope to the current discussion. We will note, however, that the $1967 \mathrm{CM}$ microfilm could be useful in creating a mapping between establishment name \& address and other Census Bureau establishment identifiers, which would be helpful for linking to outside sources of data or even historical Census data also on microfilm.

${ }^{65}$ In June 2009, we acquired via GSA surplus a Bell \& Howell ABR-2000 microfilm reader/printer with motorized control. Prior to this acquisition, we used the microfilm/reader available in the Census Bureau library.
} 
pages 3 and on from the "standard form" for the industry. Finally, establishments below the given employment cutoff (generally 4 to 10 employees, depending on the industry) received a short 2-page survey form without much detail. There were 20 different short forms used, each covering a 2-digit SIC group. In certain industries, where smaller establishments were common and accounted for a substantial portion of an industry's activity, a modified short form with some additional inquiries was used. We do not know (or do not recall at this point) whether the microfilm includes any of the other survey forms associated with the $1958 \mathrm{CM}$, including those for manufacturing plants under construction, central administrative offices and auxiliaries, class of customer, industrial water use, and the MC-D11 (discussed previously). We do know that survey forms from the 1958 Census of Mineral Industries are contained on this microfilm.

There are other notable things about this microfilm. First, by luck, we discovered a small form called an "Economic Census Schedule Pulling Request" on which a Census Bureau employee had recorded the industry code, state/county, and employer identification number of a survey form that must have been removed from the batch for whatever purpose. The form was signed October 21, 1966, suggesting that the imaging of these survey forms occurred quite some time after the $1958 \mathrm{CM}$. (It also suggests that at least one survey form may be missing from this set of microfilm. ${ }^{66}$ ) Another fact worth noting is that the forms tend to be batched by industry and state/region. We had an intern record the industry and state of both the first and last survey form on each roll, which has given us some (albeit very limited) ability to find survey forms of cases we see in the microdata. This also led us to discover that the some of the rolls are exact copies of each other. At this point, we have not attempted to determine how many unique rolls

\footnotetext{
${ }^{66}$ This missing case happens to be in the ITS prototype. Interestingly, the signature on the pull request is "Katz", who is also the person that prepared the record layout for the ITS prototype, dated August 16, 1967. The pull request appears on the roll we have labeled \#159.
} 
there are among these 551. We'll also note that some rolls consist of a single stream of images, while others consist of a double stream. ${ }^{67}$

We have pondered and investigated what it would take to make this into electronic data. As part of our investigation, we spoke with experts at the National Archives and Records Administration (NARA) as well as three contractors. To start, a digital image must be taken of each page on the microfilm. If nothing else, this would provide a long-term storage solution and prevention from loss from decay or disaster. To make this long string of images minimally usable, the pages of a single form must be associated with one another, and the form would be indexed - at a minimum, perhaps by form number/type, state, and 4-digit SIC industry. In this case, optical character recognition is not practical; indexing must be performed by human. With the proper software (and enough labor), this indexing could occur in-house. Once indexed, the form images are then at least searchable, so that a researcher interested in a particular industry could, in principal, find all the relevant survey forms and key in the required data. Of course, the ultimate goal would be to have all the data from all forms keyed in. Relative to the costs up to this point, keying in an entire Census of Manufactures is likely extraordinarily expensive.

Certainly the biggest interest in this microfilm, from our perspective, is the possibility of having (electronic) data on the entire universe of manufacturing establishments in 1958 - the CM before the oldest CM we currently have (1963). With these records, one could explore industry dynamics, such as plant entry and exit, which one simply cannot do with ASM cases alone. A big unknown at this point is whether the microfilm actually contains the nearly 300,000

\footnotetext{
${ }^{67}$ In the original set of 325 rolls, 187 have a single stream, while 138 are double stacked.
} 
manufacturing establishments in existence in 1958. Back-of-the-envelope calculations suggest that it is possible. ${ }^{68}$

Even if the microfilm is incomplete, there is no doubt that there is a significant amount of (new) data here. Even for cases that we have data for in electronic form, there is even more data to be had here, including the value and quantities of products produced (at the 8-digit product level), intrafirm transfers by 8-digit product, cost and quantities of materials used and fuels consumed, special inquiries, and obviously any write-in information. (See Table 2 for a summary.) In essence, any variable and any data on any standard form, ASM form, short form, and modified short form will obviously be here. Note that name, address, EIN, and other establishment identifiers on these forms are important for linking these records to other data on these establishments, including earlier data.

Even if the microfilm is not digitized in the foreseeable future, it can be - and has been an extremely useful resource in making sense of the electronic files described in the previous sections. For example, without the microfilm, prospects for figuring out the record layout for the 1955 and 1956 ASM files (discussed in Section 5) would be bleak. In this case, we printed out some random ASM forms from the microfilm, located the plant ID, searched the raw data for that plant ID string, and with the completed survey form in front of us we could puzzle out the location and length of the vast majority of variables. We have also used the microfilm to make sense of the ITS prototype - in particular, for gaining insight into the differences between the

\footnotetext{
${ }^{68}$ For the initial batch of 325 rolls, we had an intern determine how many contained a single versus a double stream of images. We also had him count the total number of pages on a couple of randomly chosen rolls. From that, and setting aside the fact that the rolls are sometimes of different lengths, we estimated approximately 1.2 million pages, which seemed to us to be the right order of magnitude. Present in that total, however, are forms from the Census of Mineral Industries and possibly other (supplemental) manufacturing surveys. We also later discovered that the set of 325 rolls had duplicates among them. But then we also later acquired 226 additional rolls of microfilm containing the $1958 \mathrm{CM}$. Casual inspection revealed that at least some of these are duplicates of those in the first set. Without more work, we simply do not know how many unique rolls we have, which is currently the biggest hindrance to a more accurate estimate of the number of page images.
} 
FIRSTA, MEND, and TS54E files. For one example, we could see exactly how the definitions of SPEC58 and SPEC differed between FIRSTA and MEND (and the definitions that appear on the record layout). In addition to the ITS, we suspect that the microfilm might also prove very useful in shedding light on the Ruggles files, described in the previous section.

We'll note briefly that in addition to this microfilm held by CES, NARA maintains microfilm copies of completed CM survey forms from 1947 to potentially as far back as 1820 (see NARA 1964, 2011). ${ }^{69}$ Unfortunately, we have not found any evidence that any microfilm from the 1954 CM still exists, either at the Census Bureau, or held on its behalf at NARA, or in the public domain at NARA. The microfilm from the $1947 \mathrm{CM}$ - the next nearest one - is, we are told, on acetate film and in a very fragile state. ${ }^{70}$ Preservation and restoration of the microfilm would probably be necessary before anything could be done with it. Meanwhile, the microfilm of the biennial CMs from 1929 into the 1930s have been used by a number of researchers (e.g., Foss 1981; Bresnahan and Raff 1991; Bertin, Bresnahan, and Raff 1996; Raff 1998). Some of these data have recently been made available electronically. ${ }^{71}$ Conklin (1982) mentions another source of information that may certainly worth searching for in the Census Bureau's archive:

The background of the consideration [of a microdata file of individual plant data] was in the late 1940's; there was 'rediscovered' in the Industry Division of the Census Bureau a file of $5 \times 8$ cards relating to the biennial census of manufactures

\footnotetext{
${ }^{69}$ Data on manufacturing was first collected in 1810 (Micarelli 1998).

${ }^{70}$ At the time we were investigating this, in 2007, NARA did not know exactly where this microfilm was being stored. But staff at both NARA and the Census Bureau had distinct memories of the accessioning, and the condition of the film, dating from "perhaps a decade ago." An accessioning in the late 1990s would be consistent with the "50 year rule" the Census Bureau had used to honor the confidentiality of business data.

${ }^{71}$ In particular, panelized data for the automotive and textile industries from the CMs of 1929-1935 have recently been made available through the Interuniversity Consortium for Political and Social Research (ICPSR). See Raff and Bresnahan (ICPSR31761-v1). In addition, these data have been linked with industry data on automobile characteristics to create hedonic prices for the automotive industry from 1906-1941 (Raff and Trajtenberg, ICPSR31762-v1). Digitization and panelization of establishment-level data from the 1929-1935 CMs has been completed for several other industries, including cigarettes, steel, tin cans, rubber tires, petroleum, glass, soap, linoleum and sugar refining. These data are expected to be available from ICPSR in the near future. We thank Maggie Levenstein for this information.
} 
from 1929 to 1939. Each card contained for an individual plant the records of employment, payrolls, cost of material, value of shipments, and value added for 1929 and each odd-numbered year in the 1930's. As I remember it some 35 years ago, the file was duplicated with one set organized geographically by industry and the other industry by geography. The file serves as an important check on the completeness of the census, but the primary purpose was to determine whether publication would involve disclosure. It was called the 'yes-no' file. I do not know whether is still exists, but I do know that it was tantalizing to realize that here was a massive micro record of manufacturing during the great depression. To attempt to organize and analyze it with existing equipment (there was not even Univac I) was far beyond our resources. Also, it wasn't in our job descriptions. But the 'yes-no' files did encourage some of us to try a few years later to plan for a micro file for the Annual Survey of Manufactures.

\section{Conclusion}

Our analyses show that longitudinally-linked microdata on manufactures, covering 1954 to the present, appear possible though very challenging. With the exception of a few years with fewer cases than we would expect (particularly 1953 and perhaps 1954), and 1965, for which we have no data at all, it appears possible that we have data on all ASM establishments over this period. The biggest challenge, will be constructing longitudinal links from these ASM files to the existing longitudinally-linked microdata - in particular, the CMs of 1963, 1967, and 1972. The naïvest of matching algorithms yields match rates of $75 \%$ to $96 \%$ for the ASM files in the 1960s and early 1970s. On an employment-weighted basis, these rates are $86 \%$ or better. Match rates decline, however, monotonically, as the time to the $1963 \mathrm{CM}$ increases - falling to just $48 \%$ in 1954 (and 56\% on a weighted basis), though substantially better for select industries thanks to the ITS prototype. These match rates can be improved upon through the use of multiple establishment identifiers and by other means (such as characteristics matching), but the task will prove challenging. Adding to the challenge is the tangle of (undocumented) files from 1954-

1964. There are also the sobering (if sometimes vague) assessments offered by commentators 
from decades ago that led to the abandonment of these files in the late-1960s along with all efforts to longitudinally link them — assessments that still held currency over a decade later when these files were explicitly ignored in favor of the more modern ASM and CM files, in an effort that was the basis for the longitudinally-linked manufacturing microdata we have today. Obviously, much more work needs to be done. However, we see tremendous value in extending the manufacturing microdata series back into time. Better still if data contained on the microfilm of the $1958 \mathrm{CM}$ (and the earlier CMs) can also be incorporated. With these "new" data, new lines of research become possible, and many others can be revisited. 


\section{References}

Atrostic, B.K., Randy A. Becker, Todd Gardner, Cheryl Grim, and Mark Mildorf. "Recovery of Historical U.S. Census Bureau Microdata: Success to Date," in 2009 Research Report: Center for Economic Studies and Research Data Centers, November 2010. Available at http://www.census.gov/ces.

Becker, Randy A. "County Coding in the Annual Survey of Manufactures of the 1950s," Center for Economic Studies mimeo, August 2009.

Bertin, Amy L., Timothy F. Bresnahan, and Daniel M.G. Raff. "Localized Competition and the Aggregation of Plant-Level Increasing Returns: Blast Furnaces, 1929-1935," Journal of Political Economy, 104(2), 241-266, April 1996.

Bresnahan, Timothy F. and Daniel M.G. Raff. "Intra-Industry Heterogeneity and the Great Depression: The American Motor Vehicles Industry, 1929-1935," Journal of Economic History, 51(2), 317-331, June 1991.

Conklin, Maxwell R. "Time Series for Individual Plants from the Annual Survey of Manufactures and Related Data," Census Bureau mimeo presented at a joint session of the American Economic Association and the American Statistical Association on December $30,1964$.

Conklin, Maxwell R. "Keynote Address," in Proceedings of the Workshop on the Development and Use of Longitudinal Establishment Data, U.S. Bureau of the Census, 1982.

Foss, Murray F. "Long-Run Changes in the Workweek of Fixed Capital," American Economic Review, 71(2), 58-63, May 1981.

Foster, Lucia, John Haltiwanger, and Namsuk Kim. "Gross Job Flows for the U.S. Manufacturing Sector: Measurement from the Longitudinal Research Database," Center for Economic Studies Discussion Paper, 06-30, 2006.

Govoni, John P. "Methodological Problems Related to Time Series File Developed from Census of Manufactures / Annual Survey of Manufactures Data," in Proceedings of the Workshop on the Development and Use of Longitudinal Establishment Data, U.S. Bureau of the Census, 1982.

Hanna, Frank A. The Compilation of Manufacturing Statistics. Washington DC: U.S. Bureau of the Census, 1959.

Jordan, Willis K. "The Measurement of Performance Potential in Manufacturing Establishments," Bureau of the Census, Working Paper No. 18, 1965.

Kallek, Shirley. "Potential Application of Census Bureau Economic Series in Microdata Analysis," American Economic Review, 65(2), 257-262, May 1975. 
Kallek, Shirley. "Objectives and Framework," in Proceedings of the Workshop on the Development and Use of Longitudinal Establishment Data, U.S. Bureau of the Census, 1982.

Klotz, Benjamin P. Productivity Analysis in Manufacturing Plants. BLS Staff Paper 3, 1970.

Krishna, K. L. Production Relations in Manufacturing Plants: An Exploratory Study. Ph.D. dissertation, Department of Economics, The University of Chicago, 1967.

Ladner, Justin. "Initial Construction and Analysis of Historical Annual Survey of Manufactures Microdata, 1955-1971.” Unpublished CES Technical Note, 2008.

Micarelli, William F. "Evolution of the United States Economic Censuses: The Nineteenth and Twentieth Centuries," Government Information Quarterly, 15(3), 335-377, 1998.

National Archives and Records Administration. Preliminary Inventory of the Records of the Bureau of the Census (Record Group 29). Washington, DC: General Services Administration, 1964.

National Archives and Records Administration. Records of the Bureau of the Census (Record Group 29). <www.archives.gov/research/guide-fed-records/groups/029.html $>$ (accessed August 30, 2011).

Raff, Daniel M.G. "Representative Firm Analysis and the Character of Competition: Glimpses from the Great Depression," American Economic Review, 88(2), 57-61, May 1998.

U.S. Bureau of the Census. U.S. Census of Manufactures: 1954, Vol. 1, Summary Statistics. Washington, DC: U.S. Government Printing Office, 1957.

U.S. Bureau of the Census. U.S. Census of Manufactures: 1958, Vol. 1, Summary Statistics. Washington, DC: U.S. Government Printing Office, 1961. 
TABLE 1

Sources of the 1966-1972 ASM Files Recovered by Alfred Nucci in May 2006

\begin{tabular}{|c|c|c|c|c|c|}
\hline Year & Reel number & DSAR & Title and subtitle of DSAR & File name & Comments \\
\hline 1966 & 021754 & $78-136$ & 1967 ASM: 1967 ASM Register Prep & IN67ASM*ASMRGPREPOUT & $\begin{array}{l}\text { File name and DSAR description } \\
\text { doesn't necessarily suggest final } 1966 \\
\text { data. }\end{array}$ \\
\hline 1967 & 021756 & $78-137$ & 1967 ASM: 1968 Final Edited PY & IN67ASM*68FNEDTPYOUT & \\
\hline 1968 & 021763 & $78-129$ & 1968 ASM: 1968 Final Edited PY & IN68ASM*69FNEDTPYOUT & Subtitle is misleading. May be a typo. \\
\hline 1969 & 021760 & $78-139$ & 1969 ASM: 1968 Final Edited CY & IN69ASM*69FNEDTCYOUT & \\
\hline 1970 & 021773 & $78-132$ & 1971 ASM Finals - 1970 Data: PY Edited & IN71ASM*70FNEDTPYOUT & $\begin{array}{l}\text { Unlike other years, records carried over } \\
\text { onto a second tape (reel \#130834). It } \\
\text { appears that this second tape, with } \\
4,132 \text { records, was not read/copied by } \\
\text { Nucci. We recovered data from this } \\
\text { second tape in November } 2009 \text { but have } \\
\text { not yet incorporated these additional } \\
\text { records. }\end{array}$ \\
\hline 1971 & 021775 & Unknown & & IN72ASM*72MERGERGOUT & $\begin{array}{l}\text { File name doesn't necessarily suggest } \\
\text { final } 1971 \text { data. }\end{array}$ \\
\hline 1972 & 021793 & Unknown & & IN73ASM*72FNEDTPYOUT & \\
\hline
\end{tabular}


TABLE 2

Summary of Variables in Newly Recovered Manufacturing Microdata

\begin{tabular}{|c|c|c|c|c|c|}
\hline & $\begin{array}{cc}\text { ITS } & \\
\text { (25 industries) } & \end{array}$ & $\begin{array}{l}\text { Microfilm of } \\
\text { survey forms }\end{array}$ & $\begin{array}{c}\text { ITS } \\
\text { (All industries) }\end{array}$ & $\begin{array}{l}\text { Individual } \\
\text { ASMs }\end{array}$ & $\begin{array}{c}\text { Individual } \\
\text { ASMs }\end{array}$ \\
\hline Years & $1954-61$ & $1954-58$ & $1954-64$ & $\begin{array}{c}1955-56 \\
\text { (and 1954*) }\end{array}$ & $1966-72$ \\
\hline \multicolumn{6}{|l|}{ BASICS } \\
\hline Industry (4-digit SIC) & • & • & - & - & - \\
\hline State \& county & • & • & • & • & • \\
\hline Place & & & & & $?$ \\
\hline Weight & & $?$ & - & - & - \\
\hline Name $\&$ address & & • & & & \\
\hline EIN & & $\bullet$ & & & \\
\hline \multicolumn{6}{|l|}{ OUTPUT } \\
\hline Total value of shipments & - & - & - & - & - \\
\hline Total inventories & & - & - & - & - \\
\hline Finished products inventories & - inc. 1953 & - & - & - & - \\
\hline Work-in-progress inventories & - inc. 1953 & - & - & - & - \\
\hline Materials, supplies, fuels, etc. inventories & & - & - & - & - \\
\hline Value added (adjusted or unadjusted) & • & & • & & • \\
\hline \multicolumn{6}{|l|}{ LABOR } \\
\hline Total employees & • & • & • & • & • \\
\hline Non-production workers & & - & - & - & - \\
\hline Production workers & - & - & - & - & • \\
\hline Production workers, by quarter & & - & - & & - \\
\hline Production worker man-hours, total & - & - & • & • & - \\
\hline Production worker man-hours, by quarter & & - & - & & - \\
\hline Peak quarter man-hours & • & & & & \\
\hline Total payroll & - & - & - & - & - \\
\hline Non-production worker payroll & & • & - & - & - \\
\hline Production worker wages & - & - & - & - & • \\
\hline Legally required supplemental labor costs & & & & & - \\
\hline Voluntary supplemental labor costs & & & & & - \\
\hline Supplemental employee costs & see below & & see below & & \\
\hline \multicolumn{6}{|l|}{ MATERIALS } \\
\hline Total cost of materials, etc. & - & - & - & - & - \\
\hline Materials, parts, containers, supplies, etc. & & • & - & - & • \\
\hline Products bought and resold & & - & - & - & - \\
\hline Cost of fuels & 1954,1961 & - & - & - & - \\
\hline Cost of electricity & 1954,1961 & • & • & - & • \\
\hline Cost of contract work & & $\bullet$ & • & • & • \\
\hline Purchased electric (kwh) & & - & - & - & - \\
\hline Generated electric (kwh) & & - & - & - & • \\
\hline Electricity sold / transferred & & - & - & - & - \\
\hline
\end{tabular}




\section{CAPITAL}

Total capital expenditures

Capital expenditures on new equipment

Capital expenditures on new structures

Capital expenditures, used

Gross book value of assets

1957

Gross book value of assets, structures

Gross book value of assets, equipment

Retirements

1957

Rental payments on structures

Rental payments on equipment

Rental payments on structures \& equipment

Accumulated depreciation

Depreciation

Horsepower of power equipment

\section{OTHER COSTS}

Total expenditure for maintenance \& repairs

Salaries \& wages for maintenance \& repairs

Other costs for maintenance \& repairs

Selected supplementary employee costs

Employer pymts for old age and survivors ins.

Employer pymts for unemployment ins.

Employer pymts for workmen's compensation

Employer pymts for various private plans

Insurance premiums and property taxes

Insurance on property, inventories, etc.

Tax payments on property and inventories

\section{PRODUCT DETAIL}

Products produced (5-digit) \& values

Products produced (5-digit) \& quantities

Resales

Contract work done

Misc. receipts

Products produced (8-digit), values, quants

Intrafirm transfers, by product (8-digit)

Identity of primary (5-digit) product

Specialization in primary product

\section{MATERIAL DETAIL}

Materials used, quantities \& cost

Fuels consumed, quantities \& cost

\section{MISCELLANEOUS}

Prior year data (on above noted items)

Various flags

Birth year, death year

Status/ownership change

Remarks \& analyst notations

Other

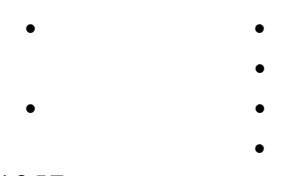

1957, 1962-1964

1957, 1963-1964

1963-1964

1963-1964

1957

1956

1957 
TABLE 3

Establishment Counts in the Individual ASM Files of 1966-1972

\begin{tabular}{|c|c|c|c|}
\hline \multirow{2}{*}{ Year } & \multicolumn{3}{|c|}{ Number of Establishments } \\
\cline { 2 - 4 } & Total & $\begin{array}{c}\text { With Positive } \\
\text { Payroll and } \\
\text { Employment }\end{array}$ & $\begin{array}{c}\text { Published } \\
\text { Information }\end{array}$ \\
\hline 1966 & 66,419 & 62,493 & about 60,000 \\
\hline 1967 & 71,380 & 66,087 & about 60,000 \\
\hline 1968 & 71,994 & 65,948 & about 60,000 \\
\hline 1969 & 71,991 & 68,011 & about 60,000 \\
\hline 1970 & 70,250 & 63,716 & about 65,000 \\
\hline 1971 & 71,584 & 59,985 & about 65,000 \\
\hline 1972 & 75,389 & 68,626 & n/a \\
\hline
\end{tabular}


TABLE 4

Linking the 1966-1972 ASMs to Each Other and to Existing Longitudinal Microdata: Preliminary Match Rates Using ID Only

\begin{tabular}{|c|c|c|c|c|c|c|c|c|c|c|}
\hline \multirow[b]{2}{*}{ Year } & \multicolumn{2}{|c|}{$t-1$} & \multicolumn{2}{|c|}{$t+1$} & \multicolumn{2}{|c|}{$1963 \mathrm{CM}$} & \multicolumn{2}{|c|}{$1967 \mathrm{CM}$} & \multicolumn{2}{|c|}{$1972 \mathrm{CM}$} \\
\hline & Unweighted & Weighted & Unweighted & Weighted & Unweighted & Weighted & Unweighted & Weighted & Unweighted & Weighted \\
\hline 1966 & & & 83.1 & 89.0 & 78.9 & 87.6 & 84.3 & 91.0 & & \\
\hline 1967 & 77.3 & 87.9 & 89.7 & 93.1 & 61.8 & 77.4 & 90.5 & 96.9 & 59.9 & 74.2 \\
\hline 1968 & 88.8 & 94.5 & 99.9 & 99.9 & & & 81.2 & 90.6 & 65.3 & 79.3 \\
\hline 1969 & 99.9 & 99.8 & 58.0 & 85.4 & & & 81.2 & 88.8 & 65.3 & 80.4 \\
\hline 1970 & 59.3 & 84.6 & 82.3 & 88.5 & & & 68.6 & 81.2 & 76.6 & 85.7 \\
\hline 1971 & 80.6 & 94.8 & 34.0 & 65.5 & & & 56.9 & 77.0 & 91.0 & 96.1 \\
\hline 1972 & 36.7 & 64.2 & & & & & 84.3 & 91.0 & 52.1 & 66.7 \\
\hline
\end{tabular}


TABLE 5

The 34 Files Read in Using the ITS-1 Record Layout

\begin{tabular}{ccc}
\hline \hline & Number of & \\
File Number & $\begin{array}{c}\text { Observations } \\
\text { DSAR }\end{array}$ \\
\hline 26221 & 17,991 & \\
26223 & 3,511 & \\
26225 & 90,167 & \\
26227 & 88,035 & \\
26229 & 92,664 & $69-068$ \\
26231 & 112,715 & \\
26233 & 116,848 & \\
26235 & 53,301 & \\
26237 & 48,896 & \\
26239 & 62,151 & \\
\hline 27225 & 743 & $69-069$ \\
\hline 26241 & 91,403 & \\
26243 & 90,884 & \\
26247 & 114,967 & \\
27231 & 117,928 & \\
27232 & 1,643 & \\
\hline 27227 & 196 & \\
27229 & 1,253 & \\
\hline 24982 & 1,053 & \\
27237 & 99,442 & \\
27239 & 88,272 & \\
27241 & 93,210 & \\
27243 & 114,409 & \\
27265 & 117,928 & \\
27267 & 53,986 & \\
27269 & 57,367 \\
27271 & 74,331 & \\
\hline 26205 & 117,928 & \\
26206 & 60,789 & \\
26209 & 111,568 & \\
26211 & 112,868 & \\
26214 & 64,958 & \\
\hline 26202 & 18,667 & \\
18279 & & \\
\hline \hline & & \\
\hline
\end{tabular}


TABLE 6

Number of Observations and Description, by DSAR

\begin{tabular}{c|c|l}
\hline \hline DSAR & $\begin{array}{c}\text { Number of } \\
\text { Observations }\end{array}$ & \begin{tabular}{l} 
Descriptive Information \\
\hline $69-068$
\end{tabular} \\
686,279 & $\begin{array}{l}\text { ITS127 Correction - XPT = Detail without TN corrections; XPTA = detail with TN } \\
\text { corrections; XPTB = deletes and duplicates }\end{array}$ \\
\hline $69-069$ & 743 & ITS Adds - Plant records for 1954-1963 discovered missing on the Finder File \\
\hline $69-070^{*}$ & 416,825 & ITS Detail merged with corrected detail records from ITS127 \\
$69-071$ & 1,449 & $\begin{array}{l}\text { ITS138 - duplicate TNs to be reviewed and corrected and ITS138 limited sample } \\
\text { for future testing }\end{array}$ \\
\hline $69-091$ & 690,989 & ITS127 Input - Parts of file come from ITSTRP, ITS58, ITS60 and ITS135 \\
\hline $69-092$ & 468,111 & ITS160 - Merged and Matched 1954-1964 MA-101 Data \\
\hline $69-093$ & 18,667 & $\begin{array}{l}\text { ITS138 - records with TN changes from correction program are sorted and merged } \\
\text { with adds punched - expanded, sorted, etc. from ITS137 }\end{array}$ \\
\hline $69-096$ & 18,007 & $\begin{array}{l}\text { Sorted and packed TN changes from ITS127 and All correction records from } \\
\text { ITS149 }\end{array}$ \\
\hline \hline
\end{tabular}

* DSAR 69-070 is missing one file that could not be recovered. 
TABLE 7

1954-1964 Industrial Tine Series Files: Variables and Variable Definitions

Variable name

ID

OLDID

TN

PPN

RECNO

YR

SURVYR

SIC4

SIC4 DERIVED

SIC4_PY

CENST

\section{Description}

Establishment identification number (current year). 10-digit. For a plant in a multi-unit manufacturing firm, ID does not begin with 0 , and the first 6 digits are identical for plants belonging to the same firm. For a single-unit plant/firm, ID begins with 0 , and the 10 digit number uniquely identifies firm.

Establishment identification number (prior year). 10-digit. For a plant in a multi-unit manufacturing firm, ID does not begin with 0 , and the first 6 digits are identical for plants belonging to the same firm. For a single-unit plant/firm, ID begins with 0 , and the 10digit number uniquely identifies firm.

Tab number. 6-digit.

Permanent plant number. 5-digit.

Record number. 2-digit.

Year. 2-digit.

Survey year. 2-digit.

Standard Industrial Classification code (tabbed, current year). 4-digit. Major modifications in SIC codes and definitions occurred in 1958. Here, the 1954-1957 data use the previous SIC classification system. See Appendixes A, B, and C of U.S. Bureau of the Census (1961) for 1958 SIC industry codes, definitions, and descriptions of the revisions to industry definitions and code numbers. Appendix C in particular contains a mapping of new to old SIC codes, as well as the number and share of affected establishments, number and share of affected employees, and dollars and share of affected value added.

Standard Industrial Classification code (derived, current year). 4-digit. See SIC4.

Standard Industrial Classification code (tabbed, prior year). 4-digit. See SIC4.

Census state code. 2-digit. The first digit indicates the Census division within the United States (1-9). The second digit indicates the state within the division. Not to be confused with the 2-digit FIPS state code (introduced in 1970). In 1958-1960, establishments in Alaska and Hawaii are coded as 01 and 02, respectively, and as 94 and 95 in 1961-1964. There are a relatively small number of cases with a missing or invalid state code. 
County code. 3-digit. It appears that at least three different coding schemes are in use here. In years 1954-1957, the county code appears to be the one discussed in detail in Becker (2009). Briefly, within a state, the set of counties and county equivalents in existence at that time was ordered alphabetically and assigned a 3-digit code in ascending order, beginning with 001 and using only the 219 codes with digits in a nondecreasing order. (For example, 010, 020, and 021 are invalid codes.) There are two anomalous states. In Texas, the first 54 counties were given a code that is a transformation of the "expected" code. In particular, the leading zero is replaced with a 9 - from 901 (Anderson County) through 999 (Crosby County). Meanwhile, the final 200 Texas counties (alphabetically) were assigned ascending codes, beginning with 001 (Culberson County) and ending with 666 (Zavala County). In Virginia, rather than an alphabetized list of counties and cities commingled, counties appear first, in alphabetical order, followed by the independent cities, in alphabetical order (with a couple of exceptions). Specifically, the 98 counties in existence at the end of 1952 (after the disappearance of both Elizabeth City County and Warwick County in July 1952) appear at the top of the list, in alphabetical order. Next, the 30 independent cities in existence at the end of 1952 appear, in alphabetical order. This is followed by Galax city (formed/added in November 1953) and then Norton city (formed/added in January 1954). Becker (2009) contains a spreadsheet of 3,104 counties that associates the 1954-57 county codes, county names, and the county codes used in the 1963 and 1967 CMs (if the county was still in existence). In years 1958-1962, the county code appears very similar - but not identical - to the county coding scheme used in the 1963 and 1967 CMs. Two major differences were found, involving Virginia and Wisconsin. After some investigation, and with insight from Becker (2009), it appears that the county coding scheme used here reflects the set of counties and independent cities in existence from July 1, 1958 (after Warwick County VA was eliminated) to January 1, 1960 (before South Boston city VA was formed). As such, Menominee County WI (formed on April 29, 1961) exists in the 1963/67 CM county codes but not here. Instead, take the alphabetical list of Wisconsin counties in the 1963/67 CM, eliminate Menominee County, and (re)assign codes, starting at 001 , and increasing in increments of 1 . In the end, all counties from Milwaukee County forward have a county code that is 1 less than that in the respective 1963/67 CM county code. For Virginia, relative to the $1963 / 67$ CM county coding scheme, the following counties do not exist: Chesapeake city (formed on January 1, 1963), Fairfax city (formed on June 30, 1961), Franklin city (formed on December 22, 1961), and South Boston city (formed on January 1, 1960). Meanwhile, Norfolk County still existed (until January 1, 1963, when it consolidated with South Norfolk city to form Chesapeake city). Likewise, Princess Anne County still existed (until January 1, 1963, when it consolidated into Virginia Beach city). And, South Norfolk city still existed (until January 1, 1963, when it consolidated with Norfolk County to form Chesapeake city). Take the alphabetical list of Virginia counties and independent cities in the 1963/67 CM (in cases where a county has the same name as a city, the county appears first), make the above additions and subtractions, and (re)assign codes, starting at 001, and increasing in increments of 1 . The following Stata code can be used to convert this county code to the one used in the 1963/67 CM (COU6367):

gen cou6367=cou

replace cou6367 $=$ cou +1 if state $==35 \&$ cou $>=040$

replace cou $6367=$ cou +1 if state $==54$ \& cou $>=025 \&$ cou $<=037$

replace cou6367 $=$ cou +2 if state $==54$ \& cou $>=038 \&$ cou $<=042$

replace cou $6367=$ cou +3 if state $==54$ \& cou $>=043$ \& cou $<=081$

replace cou $6367=$ cou +2 if state $==54$ \& cou $>=082 \&$ cou $<=096$

replace cou $6367=121$ if state $==54$ \& cou $==097$

replace cou $6367=$ cou +1 if state $==54$ \& cou $>=098$ \& cou $<=110$

replace cou $6367=$ cout 2 if state $==54$ \& cou $==111$

replace cou $6367=025$ if state $==54$ \& cou $==112$

replace cou $6367=$ cou +1 if state $==54$ \& cou $>=113$ 
In years 1963-1964, the county code appears to be identical to the county coding scheme used in the 1963 and 1967 CMs.

SMSA

WT

WT_BINARY

SOURCE

NULL

PW1

PW2

PW3

PW4

TPW

PW

$\mathrm{OE}$

TE

WW

OW

SW

PH1

$\mathrm{PH} 2$

$\mathrm{PH} 3$
Standard metropolitan statistical area code. 3-digit.

Sample weight. 5-digit, with two implied decimal places. Values ranges from 0 (concentrated mainly in 1954 and 1955 ) to 999.9 (relatively few and all in 1958), with a median and mode of 1.00. A small percentage have no value.

Sample weight. 6-digit.

Source. 1-digit. Unknown.

Unknown - labeled as null in record layout. 1-digit.

Production workers during pay period ended nearest March 15th.

Production workers during pay period ended nearest May 15th.

Production workers during pay period ended nearest August 15th

Production workers during pay period ended nearest November 15th.

Sum of PW1, PW2, PW3, and PW4.

Average number of production workers. TWP divided by four.

All other (non-production) workers on March 15th.

Total employment. Sum of PW and OE.

Production worker wages (in $\$ 000$ ).

All other (non-production) employees salaries and wages (in \$000).

Total payroll (salaries and wages) (in \$000). Sum of WW and OW.

Man-hours of production workers in January through March (in 000).

Man-hours of production workers in April through June (in 000).

Man-hours of production workers in July through September (in 000). 
Man-hours of production workers in October through December (in 000).

Total production worker man-hours. Sum of PH1, PH2, PH3, and PH4.

Cost of materials, parts, components, containers, supplies, etc., consumed (in $\$ 000)$.

Cost of resales (products bought and resold withour further manufacture, processing, or assembly) (in $\$ 000$ ).

Cost of fuels consumed (in \$000).

Cost of purchased electricity (in \$000).

Cost of contract work done for plant by others on plant's materials (in \$000).

Total cost of materials, fuels, electricity, contract work, etc. (in \$000). Sum of CP, CR, CF, EE, and CW.

Finished products inventories at end of year (in \$000).

Work-in-progress inventories at end of year (in \$000).

Materials, supplies, fuels, etc., inventories at end of year (in \$000).

Total inventories at end of year (in \$000). Sum of FIE, WIE, and MIE.

New structures and additions to plant (in \$000).

New machinery and new equipment (in \$000).

Used plant and used equipment acquired from others (in \$000).

Total capital expenditures (in \$000). Sum of NB, NM, and UE.

Purchased electricity (in 000 of kWh).

Generated electricity (gross less generating station use) (in 000 of $\mathrm{kWh}$ ).

Electricity sold or transferred to other establishments (in 000 of $\mathrm{kWh}$ ).

Total value of products shipped (in \$000). Sum of appropriate PWV* variables. 
Sales of products bought and resold without further manufacture, processing, or assembly (in $\$ 000$ ). The cost of such products should be in CR.

Total value of shipments (in \$000). Sum of TVPS, RCW, MISC, and VR.

Unadjusted value added (in \$000). “The standard formula for deriving value added by manufacture in 1958 was modified from the one used for earlier censuses. During the earlier period, the measure was obtained by subtracting the cost of materials, supplies and containers, fuel, purchased electric energy, and contract work [see CM above] from the value of shipments for products manufactured plus receipts for services rendered [see TVS above]. This item is referred to as unadjusted value added.... For 1958, this measure of value added was adjusted by taking into account the following items: (a) value added by merchandising operations (that is, the difference between the sales value and cost of merchandise sold without further manufacture, processing, or assembly) plus (b) the net change in finished goods and work-in-process inventories between the beginning and end of the year. The resulting figure is the adjusted value added by manufacture. ... The adjusted value added is superior because it is more comprehensive as an approximation of the net production of goods and services during the period.... Under the earlier concept, the value added in merchandising was omitted on the grounds that it did not accrue as a consequence of manufacturing functions. Under the new (adjusted) concept, the measurement of all activities of establishments defined as primarily manufacturing is accepted as the objective." (U.S. Bureau of the Census 1961) This seems to suggest that UVA $=\mathrm{SUM} P C+\mathrm{RCW}-\mathrm{CP}-\mathrm{CF}-\mathrm{EE}-\mathrm{CW}$, or UVA $=\mathrm{SUM} \mathrm{PC}+\mathrm{RCW}+\mathrm{MSC}-\mathrm{CP}$ $-\mathrm{CF}-\mathrm{EE}-\mathrm{CW}$.

Adjusted value added (in \$000). "The standard formula for deriving value added by manufacture in 1958 was modified from the one used for earlier censuses. During the earlier period, the measure was obtained by subtracting the cost of materials, supplies and containers, fuel, purchased electric energy, and contract work [see CM above] from the value of shipments for products manufactured plus receipts for services rendered [see TVS above]. This item is referred to as unadjusted value added.... For 1958, this measure of value added was adjusted by taking into account the following items: (a) value added by merchandising operations (that is, the difference between the sales value and cost of merchandise sold without further manufacture, processing, or assembly) plus (b) the net change in finished goods and work-in-process inventories between the beginning and end of the year. The resulting figure is the adjusted value added by manufacture. ... The adjusted value added is superior because it is more comprehensive as an approximation of the net production of goods and services during the period.... Under the earlier concept, the value added in merchandising was omitted on the grounds that it did not accrue as a consequence of manufacturing functions. Under the new (adjusted) concept, the measurement of all activities of establishments defined as primarily manufacturing is accepted as the objective." (U.S. Bureau of the Census 1961) This seems to suggest that AVA $=\mathrm{TVS}-\mathrm{CM}+\Delta \mathrm{FIE}+\Delta \mathrm{WIE}$.

Product made in the establishment. In 1954-57, the first 5 digits contain a product class code number, and the 6th digit is empty. From 1958 and on, the first 5 digits contain a product class code number, and the 6th digit contains either a 0 to indicate quantity or a 1 to indicate value. 
PQV1

$\downarrow$

PQV40

TAE

BR

MR

TRT

REPTOT57

REPSW57

REPOTH57

EINS_OASI57

EINS_UI57

EINS_WC57
In 1954-57, the value of product PC1 shipped (in \$000). From 1958 and on, if the 6th digit of PC1 contains a 0 , quantity of product PC1 shipped (see instructions for unit of quantity). From 1958 and on, if the 6th digit of PC1 contains a 1, value of product PC1 shipped (in \$000). $\downarrow$

(There are 40 variables to accommodate up to 20 quantities and 20 values.)

Gross book value of buildings, structures, machinery, equipment, and other depreciable fixed assets at end of year. Only available for 1962, 1963, and 1964.

Rental payments (or equivalent charges) for use of buildings and structures (in \$000). Excludes payment for land. Only available for 1963 and 1964.

Rental payments (or equivalent charges) for use of transportation, production, and office equipment (in \$000). Only available for 1963 and 1964.

Retirements (in \$000). Only available for 1963 and 1964.

Total expenditure for maintenance and repairs in 1957 (in \$000). Sum of REPSW57 and REPOTH57. Includes own expenditures for repair materials and supplies, salaries and wages, and the cost of work done by outside contractors. Includes the costs charged to current expense accounts, such as cleaning, repair of office equipment and plant machinery, painting, repair of structures, maintenance of grounds, etc. Excludes expenditures which are charged to a capital account or to a depreciation reserve. Includes expenditures made on leased property or facilities owned by Government agency. From Form MC-D11.

Salaries and wages paid to own employees for maintenance and repair activities in 1957 (in \$000). From Form MC-D11. See also REPTOT57.

Other maintenance and repair costs in 1957 (in \$000). Includes purchased materials and supplies used in maintenance and repairs, and maintenance and repair services purchased from other business establishments. From Form MC-D11. See also REPTOT57.

Employer payments for (legally required) old age and survivors insurance in 1957 (in \$000). From Form MC-D11.

Employer payments for (legally required) unemployment insurance - state and federal - in 1957 (in \$000). From Form MC-D11.

Employer payments for (legally required) workmen's compensation premiums, and state temporary disability payments (Rhode Island, California, New York, New Jersey), in 1957 (in \$000). From Form MC-D11. 
EINS_PRIVATE57 Employer payments or allocations for private pension plans, health and welfare plans, life insurance, stock purchase plans, thrift savings plans, and supplemental unemployment compensation plans, in 1957 (in \$000). See form for substantial more details. From Form MC-D11.

INS57 Insurance premiums accrued or paid to others in 1957 (in \$000). Includes insurance on structures, equipment, and inventories; liability insurance; theft insurance; window breakage; etc. Excludes insurance reported in EINS_OASI57, EINS_UI57, EINS_WC57, and EINS_PRIVATE57. From Form MC-D11.

RENT57

Rental payments to others in 1957 (in \$000). Includes payments for structures and equipment. From Form MC-D11.

TAX57

Tax payments (or charges) in 1957 on land, structures, equipment, and inventories (in \$000). Excludes all other taxes, such as income taxes, sales taxes, excise taxes, and permit fees. From Form MC-D11.

ASSETS57 Gross book value of structures, equipment, and other depreciable or depletable fixed assets on December 31 , 1957 (in \$000). From Form MC-D11. The book value represents the actual cost of the assets at the time of purchase including all costs incurred in making the asset usable (such as transportation and installation).

CUMDEP57

Accumulated depreciation and depletion to December 31, 1956 (in \$000). From Form MC-D11. See Chapter 9 of U.S. Bureau of the Census (1961) for additional details and definitions.

DEP57

Depreciation and depletion charged in 1957 (in \$000). From Form MC-D11. See Chapter 9 of U.S. Bureau of the Census (1961) for additional details and definitions.

RET57 Retirements in 1957 (in \$000). From Form MC-D11. Undepreciated value of fixed assets retired from use.

\section{FLAGS \& OTHER}

FSPLIT1 A block of flags appearing at the end of line 1 of record layout, first word. Unknown.

FSPLIT2 A block of flags appearing at the end of line 1 of record layout, second word. Unknown.

FSPLIT3 A block of flags appearing at the end of line 1 of record layout, third word. Unknown.

FLAGS2 A block of flags appearing at the end of line 3 of record layout. Unknown.

FLAGS_RA A block of flags associated with the rent and asset variables in 1962 (TAE, BR, MR, TRT). Unknown.

CCS1

CCS2

$\mathrm{CCS} 3$

CCS4

ITS CCS Code 1. 2-digit. Unknown.

ITS CCS Code 2. 2-digit. Unknown.

ITS CCS Code 3. 2-digit. Unknown.

ITS CCS Code 4. 2-digit. Unknown. 
CCS5

CCS6

FILLER1

FILLER2

FILLER3

FILLER4

FILLER5

FILLER6

FILE
ITS CCS Code 5. 2-digit. Unknown.

ITS CCS Code 6. 2-digit. Unknown.

Source file number from DSAR 79-089. 6-digit. Constructed by Becker \& Grim. 
TABLE 8

Establishment Counts in the Individual ASM Files of 1954-1964

(DSAR 69-068 only)

\begin{tabular}{|c|c|c|c|}
\hline & \multicolumn{3}{|c|}{ Number of Establishments } \\
\cline { 2 - 4 } Year & Total & $\begin{array}{c}\text { With Positive } \\
\text { Payroll and } \\
\text { Employment }\end{array}$ & $\begin{array}{c}\text { Published } \\
\text { Information }\end{array}$ \\
\hline 1954 & 39,667 & 39,523 & n/a \\
\hline 1955 & 49,325 & 49,113 & about 45,000 \\
\hline 1956 & 49,430 & 49,146 & about 45,000 \\
\hline 1957 & 47,780 & 47,446 & about 50,000 \\
\hline 1958 & 74,775 & 74,118 & about 60,000 \\
\hline 1959 & 61,754 & 58,614 & about 60,000 \\
\hline 1960 & 61,569 & 57,764 & about 60,000 \\
\hline 1961 & 63,156 & 58,035 & about 60,000 \\
\hline 1962 & 61,977 & 57,902 & n/a \\
\hline 1963 & 63,820 & 62,673 & about 60,000 \\
\hline 1964 & 65,488 & 61,398 & \\
\hline
\end{tabular}


TABLE 9

Linking the ITS Files to Each Other and to Existing Longitudinal Microdata: Preliminary Match Rates Using ID Only

\begin{tabular}{|c|c|c|c|c|c|c|c|c|}
\hline \multirow[b]{2}{*}{ Year } & \multicolumn{2}{|c|}{$t-1$} & \multicolumn{2}{|c|}{$t+1$} & \multicolumn{2}{|c|}{$1963 \mathrm{CM}$} & \multicolumn{2}{|c|}{$1967 \mathrm{CM}$} \\
\hline & Unweighted & $\begin{array}{c}\text { Employment- } \\
\text { weighted }\end{array}$ & Unweighted & $\begin{array}{c}\text { Employment- } \\
\text { weighted }\end{array}$ & Unweighted & $\begin{array}{c}\text { Employment- } \\
\text { weighted }\end{array}$ & Unweighted & $\begin{array}{c}\text { Employment- } \\
\text { weighted }\end{array}$ \\
\hline 1954 & & & 95.4 & 93.7 & 47.7 & 55.9 & 36.9 & 47.3 \\
\hline 1955 & 76.6 & 90.6 & 93.6 & 96.2 & 48.1 & 60.1 & 37.1 & 51.3 \\
\hline 1956 & 93.3 & 96.6 & 93.5 & 97.8 & 50.0 & 62.1 & 38.3 & 52.2 \\
\hline 1957 & 96.7 & 98.9 & 78.4 & 81.0 & 52.5 & 63.3 & 40.2 & 53.2 \\
\hline 1958 & 50.5 & 72.0 & 77.7 & 93.4 & 63.0 & 77.9 & 46.5 & 63.2 \\
\hline 1959 & 93.1 & 99.2 & 92.6 & 97.6 & 66.5 & 81.2 & 48.9 & 66.4 \\
\hline 1960 & 92.9 & 97.2 & 93.4 & 96.8 & 70.8 & 84.3 & 51.7 & 69.2 \\
\hline 1961 & 91.1 & 96.3 & 88.0 & 96.4 & 75.2 & 87.8 & 54.1 & 71.7 \\
\hline 1962 & 89.9 & 94.8 & 84.5 & 92.7 & 84.7 & 92.5 & 60.4 & 75.2 \\
\hline 1963 & 81.8 & 89.6 & 98.1 & 99.1 & 99.9 & 99.7 & 68.3 & 79.6 \\
\hline 1964 & 95.7 & 98.1 & & & 96.1 & 97.9 & 69.1 & 81.3 \\
\hline
\end{tabular}




\section{TABLE 10}

\section{4-1961 Industrial Tine Series “Prototype” 25-Industry Files: Variables and Variable Definitions}

Variable name

STATE

$\mathrm{COU}$

\section{Description}

Establishment identification number (in 1961). 10-digit. For a plant in a multi-unit manufacturing firm, ID does not begin with 0, and the first 6 digits are identical for plants belonging to the same firm. For a single-unit plant/firm, ID begins with 0 , and the 10-digit number uniquely identifies firm.

1958 Standard Industrial Classification code (in 1958). 4-digit.

Census state code. 2-digit. The first digit indicates the Census division within the United States (1-9). The second digit indicates the state within the division. Not to be confused with the 2-digit FIPS state code (introduced in 1970). Among the states that do not appear here are DC, South Dakota, and Vermont; Alaska and Hawaii did not become states until 1959. Invalid codes that appear include ' 2' - which appears it might actually be Hawaii (based on ID match with 1963 CM).

County code. 3-digit. This county code appears very similar - but not identical - to the county coding scheme used in the 1963 and 1967 Census of Manufactures. Two major differences were found, involving Virginia and Wisconsin. After some investigation, and with insight from Becker (2009), it appears that the county coding scheme used here reflects the set of counties and independent cities in existence from July 1, 1958 (after Warwick County VA was eliminated) to January 1, 1960 (before South Boston city VA was formed). As such, Menominee County WI (formed on April 29, 1961) exists in the 1963/67 CM county codes but not here. Instead, take the alphabetical list of Wisconsin counties in the 1963/67 CM, eliminate Menominee County, and (re)assign codes, starting at 001 , and increasing in increments of 1 . In the end, all counties from Milwaukee County forward have a county code that is 1 less than that in the respective 1963/67 CM county code. For Virginia, relative to the 1963/67 CM county coding scheme, the following counties do not exist: Chesapeake city (formed on January 1, 1963), Fairfax city (formed on June 30, 1961), Franklin city (formed on December 22, 1961), and South Boston city (formed on January 1, 1960). Meanwhile, Norfolk County still existed (until January 1, 1963, when it consolidated with South Norfolk city to form Chesapeake city). Likewise, Princess Anne County still existed (until January 1, 1963, when it consolidated into Virginia Beach city). And, South Norfolk city still existed (until January 1, 1963, when it consolidated with Norfolk County to form Chesapeake city). Take the alphabetical list of Virginia counties and independent cities in the 1963/67 CM (in cases where a county has the same name as a city, the county appears first), make the above additions and subtractions, and (re)assign codes, starting at 001, and increasing in increments of 1 . The following Stata code can be used to convert this county code to the one used in the 1963/67 CM (COU6367):

gen cou6367=cou

replace cou6367 $=$ cou +1 if state $==35 \&$ cou $>=040$

replace cou6367 $=$ cou +1 if state $==54$ \& cou $>=025 \&$ cou $<=037$

replace cou6367 $=$ cou +2 if state $==54$ \& cou $>=038$ \& cou $<=042$

replace cou $6367=$ cou +3 if state $==54$ \& cou $>=043 \&$ cou $<=080$

replace cou6367 $=025$ if state $==54$ \& cou $==081$ 
replace cou6367 $=$ cou +2 if state $==54$ \& cou $>=082$ \& cou $<=096$

replace cou $6367=121$ if state $==54 \&$ cou $==097$

replace cou6367 $=$ cou +1 if state $==54$ \& cou $>=098$ \& cou $<=110$

replace cou6367 $=025$ if state $==54$ \& cou $==111$

replace cou $6367=$ cou +1 if state $==54 \&$ cou $>=112$

INV53

Work-in-process inventories plus finished product inventories (end of 1953). See also INV.

ENERGY61

Costs of fuels plus electricity (1961).

ENERGY54 Costs of fuels plus electricity (1954).

HP54 Horsepower of power equipment (1954). From the 1954 Census of Manufactures. Short forms in 1954 did not include the horsepower inquiry. See U.S. Bureau of the Census (1957) for additional details and definitions.

EINS_TOTAL57 Selected supplementary employee costs (1957). From Form MC-D11. Conklin (1964) labels this "payments for employee pension and insurance plans" and the record layout labels this "Emp. pens. \& ins. pmts". This looks to us to be the sum of selected supplementary employee costs, including (a) employer payments for the following legally required insurance plans: (i) old-age and survivors insurance, (ii) unemployment insurance (state and federal), and (iii) workmen's compensation premiums and selected state temporary disability payments, plus (b) other employer payments or allocations, including those to private pension plans, health plans, life insurance, stock purchase plans, and similar. See Chapter 9 of U.S. Bureau of the Census (1961) for additional details and definitions.

INS_TAX_57 Insurance premiums and property taxes (1957). From Form MC-D11. Conklin (1964) labels this "insurance and taxes" and the record layout labels this "Ins. \& taxes". This looks to us to be the sum of (a) insurance premiums accrues or paid to others (all types of insurance on structures, equipment, inventories, liability, theft, etc.), plus (b) property tax payments paid on land, structures, equipment, and inventories. See Chapter 9 of U.S. Bureau of the Census (1961) for additional details and definitions.

ASSETS57 Gross book value of of depreciable or depletable assets (December 31, 1957). From Form MC-D11. The data encompasses all fixed depreciable or depletable assets on the books of the establishment at the end of 1957. The book value represents the actual cost of the assets at the time of purchase including all costs incurred in making the asset usable (such as transportation and installation).

CUMDEP57 Accumulated depreciation and depletion (to December 31, 1956). From Form MC-D11. See Chapter 9 of U.S. Bureau of the Census (1961) for additional details and definitions.

DEP57

Depreciation and depletion (charged in 1957). From Form MC-D11. See Chapter 9 of U.S. Bureau of the Census (1961) for additional details and definitions.

RET57 Retirements (1957). From Form MC-D11. Undepreciated value of fixed assets retired from use. 
YEAR

WW

SW
Year. 2-digit.

Production worker wages. See also SW and PW.

Total payroll. Total salaries and wages paid to all employees. "It includes all forms of compensation such as salaries, wages, commissions, dismissal pay, all bonuses, vacation and sick leave pay, and compensation in kind, prior to such deductions as employees' Social Security contributions, withholding taxes, group insurance, union dues, and savings bonds.... It should be noted that this definition does not include employers' Social Security contributions, or other nonpayroll labor costs such as employees' pension plans, group insurance premiums, and workmen's compensation."

Production workers. Average number of production workers during the four pay periods ending nearest the 15th of March, May, August, and November. "Workers (up through the working foreman level) engaged in fabricating, processing, assembling, inspection, receiving, storage, handling, packing, warehousing, shipping (but not delivering), maintenance, repair, janitorial, watchman services, product development, auxiliary production for plants' own use (e.g., power plant), record keeping, and other services closely assocated with these production operations." See also TE.

Total employees. Production workers (as defined in PW) plus all other employees on March 15th. "Comprises all full-time and parttime employees.... Included are all persons on paid sick leave, paid holidays, and paid vacations during these pay periods. Excluded are members of the armed forces and pensioners carried on the active rolls but not working during the period. Officers of corporations are included as employees; proprietors and partners of unincorporated firms are, however, excluded from the total... Nonproduction personnel ... [include] those engaged in the following activities: factory supervision above the working foreman level, sales (including driver salesmen), sales delivery (highway truck drivers and their helpers), advertising, credit, collection, installation and servicing of own products, clerical and routine office functions, executive, purchasing, financing, legal, personnel (including cafeteria, medical, etc.), professional, and technical. Also included are employees on the payroll ... engaged in the construction of major additions or alterations to the plant and who are utilized as a separate workforce." See also PW.

Peak quarter man-hours. Maximum of the four quarterly total production worker man-hours. See also PH.

Total production worker man-hours. "It represents all man-hours worked or paid for ... including actual overtime hours.... It excludes hours paid for vacations, holidays, or sick leave..." See also PW.

Total cost of materials, fuels, electricity, resales, and contract work. Includes "(a) the total delivered cost of all raw materials, semifinished goods, parts, components, containers, scrap, and supplies put into production in [the year] or used as operating supplies and for repair and maintenance during that year; (b) the amount paid for electric energy purchased; (c) the amount paid for all fuels consumed for heat, power, or the generation of electricity; (d) the cost of work done by others on materials or parts furnished by manufacturing establishments; (e) cost of products bought and resold in the same condition. The total excludes the cost of services used, such as advertising, insurance, telephone, etc., and research, developmental, and consulting services of other establishments; it 
also excludes overhead costs, such as depreciation charges, rent, interest, royalties, etc.; it excludes materials, machinery and equipment used in plant expansion or capitalized repairs which are chargeable to fixed assets accounts."

Work-in-process inventories plus finished product inventories (end of year). See also INV53.

Capital expenditures on new structures and additions to plant. See also TCE.

Total capital expenditures. "Expenditures made during the year for permanent additions and major alterations to [the plant], as well as for new machinery and equipment purchases, that were chargeable to fixed-asset accounts... and were of a type for which depreciation accounts are ordinarily maintained. Expenditures for machinery and equipment were to include those made for replacement purposes, as well as for additions to plant capacity. Excluded ... are costs of maintenance and repairs charged as current operating expense. Also excluded are expenditures for land and expenditures made by owners of plants and equipment leased to reporting manufacturers." See also NB.

Total value of shipments. “...the received or receivable net selling values, f.o.b. plant, after discounts and allowances, and excluding freight charges and excise taxes. However, where the products of an industry are customarily delivered by the manufacturing establishments ... the value of shipments is based on the delivered price of the goods rather than the f.o.b. plant price.... [I]nclude all items made by or for each establishment from materials owned by it, whether sold, transferred to other plants of the same company, or shipped on consignment. Also included were receipts for contract work and for such miscellaneous activities as sale of scrap and refuse, installation work by manufacturing plant employees, research and development work, and repair work. The net selling value of products made in one plant on a contract basis from materials owned by others was reported by the plant providing the materials. ... In the case of multiunit companies, the manufacturer was requested to report the value of precuts transferred to other establishments of the same company ... (at "the nearest approximation to corresponding commercial values, f.o.b. plant, and not the cost of production."

Adjusted value added. "The standard formula for deriving value added by manufacture in 1958 was modified from the one used for earlier censuses. During the earlier period, the measure was obtained by subtracting the cost of materials, supplies and containers, fuel, purchased electric energy, and contract work [see CM above] from the value of shipments for products manufactured plus receipts for services rendered [see TVS above]. This item is referred to as unadjusted value added.... For 1958, this measure of value added was adjusted by taking into account the following items: (a) value added by merchandising operations (that is, the difference between the sales value and cost of merchandise sold without further manufacture, processing, or assembly) plus (b) the net change in finished goods and work-in-process inventories between the beginning and end of the year. The resulting figure is the adjusted value added by manufacture. ... The adjusted value added is superior because it is more comprehensive as an approximation of the net production of goods and services during the period.... Under the earlier concept, the value added in merchandising was omitted on the grounds that it did not accrue as a consequence of manufacturing functions. Under the new (adjusted) concept, the measurement of all activities of establishments defined as primarily manufacturing is accepted as the objective." This seems to suggest that VA_ADJ $=$ TVS - CM + $\Delta \mathrm{INV}$.

$\mathrm{CM}+\mathrm{SW}$. Derived, not collected. 
Definition appears to vary by file. In the MEND file, this appears to be the 5th digit of the plant's primary product in 1958, which is also the definition that appears on the record layout. In the FIRSTA file, this appears to be the 5th digit of the plant's primary product in that year (which can obviously be different than the primary product in 1958). This alternate definition was discovered through inspection of a small sample of completed survey forms (available on microfilm) for cases with discrepancies in SPEC58 between FIRSTA and MEND.

SPEC

Approximate percentage of TVS accounted for by product indicated by SPEC58. 1-digit. For example, 7 indicates a range of 70-80\%.

\section{PRODUCT CLASS DATA FOR 1961}

Variable names will vary by industry. See Attachment A of record layout. In short, value of shipments is available for all the primary products of a plant's industry and selected secondary products, for year 1961.

OTHER

SEQ_TYPE1 Sequence number, Type 1 file.

SEQ_TYPE2 Sequence number, Type 2 file.

\section{FLAGS (TS54E only)}

\section{BIRTHYEAR Birth year. 2-digit.}

DEATHYEAR Death year. 2-digit.

FLAG_VA See record layout for five possible values. 1-digit.

FLAG CE GBV See record layout for two possible values. 1-digit.

FLAG_DEP_GBV See record layout for two possible values. 1-digit.

FLAG_HP $\quad$ HP54: reported, estimated, partially estimated. 1-digit.

FLAG_SUPP SUPPCOSTS57: reported, estimated, partially estimated. 1-digit.

FLAG_INS_TAX INS_TAX_57: reported, estimated, partially estimated. 1-digit.

FLAG_ASSETS ASSETS57: reported, estimated, partially estimated. 1-digit.

FLAG_54 Report, estimated, partially estimated. 1-digit.

$\downarrow$

FLAG_63 Report, estimated, partially estimated. 1-digit.

\section{CONSTRUCTED VARIABLES (TS54E only)}

SC57 Supplemental costs (1957). Derived, not collected. Appears to be SUPPCOSTS57 + INS TAX 57, except when it is not.

SUM_COSTS Operating costs (1957). Derived, not collected. Appears to be SC57 + CM (in 1957) + SW (in 1957), except when it is not.

SUMCE54 57 Appears to be the sum of TCE from 1954-1957.

SUMCE_ASSETS Appears to be SUMCE54_57 divided by ASSETS57. 
TABLE 11

Basic Information on the Three ITS Prototype Files

\begin{tabular}{|c|c|c|c|c|c|}
\hline Filename & $\begin{array}{l}\text { Number of } \\
\text { observations }\end{array}$ & $\begin{array}{l}\text { Number of } \\
\text { variables }\end{array}$ & $\begin{array}{l}\text { Number of } \\
\text { industries }\end{array}$ & $\begin{array}{l}\text { Number of } \\
\text { unique IDs }\end{array}$ & $\begin{array}{l}\text { Number of } \\
\text { unique ID-YEARs }\end{array}$ \\
\hline FIRSTA & 14,464 & 32 & 25 & 1,808 & 14,463 \\
\hline MEND & 14,456 & 32 & 25 & 1,807 & 14,456 \\
\hline TS54E & 16,404 & 55 & 25 & 1,807 & 14,456 \\
\hline
\end{tabular}


TABLE 12

Industrial Composition of the ITS Prototype Sample

\begin{tabular}{|c|c|c|c|c|}
\hline \multirow[b]{2}{*}{1958 SIC code } & \multirow[b]{2}{*}{ Industry } & \multirow[b]{2}{*}{$\mathrm{N}$} & \multicolumn{2}{|c|}{$\begin{array}{l}\text { Number of establishments } \\
\text { in } 1958 \text { Census of Manufactures }\end{array}$} \\
\hline & & & Total & $\begin{array}{l}\text { With } 20 \text { or } \\
\text { more employees }\end{array}$ \\
\hline 2092 & Soybean oil mills & 68 & 117 & 83 \\
\hline 2271 & Woven carpets and rugs & 31 & 69 & 47 \\
\hline 2272 & Tufted carpets and rugs & 60 & 92 & 72 \\
\hline 2822 & Synthetic rubber & 20 & 18 & 17 \\
\hline 2823 & Cellulosic man-made fibers & 26 & 26 & 26 \\
\hline 2824 & Organic fibers, noncellulosic & 17 & 14 & 14 \\
\hline 2911 & Petroleum refining & 267 & 446 & 313 \\
\hline 3011 & Tires and inner tubes & 69 & 123 & 86 \\
\hline 3241 & Hydraulic cement & 172 & 175 & 170 \\
\hline 3312 & Blast furnaces and steel mills & 253 & 291 & 260 \\
\hline 3313 & Electrometallurgical products & 32 & 37 & 35 \\
\hline 3315 & Steel wire drawing & 67 & 170 & 103 \\
\hline 3322 & Malleable iron foundries & 60 & 82 & 74 \\
\hline 3323 & Steel foundries & 150 & 256 & 216 \\
\hline 3331 & Primary copper & 30 & 30 & 29 \\
\hline 3332 & Primary lead & 13 & 13 & 13 \\
\hline 3333 & Primary zinc & 20 & 20 & 20 \\
\hline 3334 & Primary aluminum & 23 & 20 & 20 \\
\hline 3351 & Copper rolling and drawing & 74 & 105 & 89 \\
\hline 3352 & Aluminum rolling and drawing & 88 & 185 & 129 \\
\hline 3362 & Brass, bronze, copper castings & 47 & 665 & 209 \\
\hline 3391 & Iron and steel forgings & 102 & 301 & 189 \\
\hline 3392 & Nonferrous forgings & 16 & 29 & 20 \\
\hline 3519 & Internal combustion engines & 52 & 112 & 75 \\
\hline \multirow[t]{2}{*}{3612} & Transformers & 51 & 175 & 82 \\
\hline & & 1,808 & 3,571 & 2,391 \\
\hline
\end{tabular}

Source: Number of establishment in 1958 are taken from U.S. Bureau of the Census, U.S. Census of Manufactures: 1958, Vol. 1, Summary Statistics. Washington, DC: U.S. Government Printing Office, 1961. 
TABLE 13

ITS Prototype Sample Coverage in 1958 Relative to 1958 Census of Manufactures Universe

\begin{tabular}{|c|c|c|c|c|c|}
\hline $\begin{array}{l}1958 \\
\text { SIC code }\end{array}$ & Industry & $\begin{array}{l}\text { Number } \\
\text { of "active" } \\
\text { establishments }\end{array}$ & $\begin{array}{l}\text { Value } \\
\text { of shipments }\end{array}$ & $\begin{array}{l}\text { Total } \\
\text { employees }\end{array}$ & $\begin{array}{l}\text { Capital } \\
\text { expenditures }\end{array}$ \\
\hline 2092 & Soybean oil mills & $56 \%$ & $90 \%$ & $87 \%$ & $86 \%$ \\
\hline 2271 & Woven carpets and rugs & $45 \%$ & $98 \%$ & $96 \%$ & $99 \%$ \\
\hline 2272 & Tufted carpets and rugs & $61 \%$ & $91 \%$ & $96 \%$ & $93 \%$ \\
\hline 2822 & Synthetic rubber & $106 \%$ & $103 \%$ & $103 \%$ & $101 \%$ \\
\hline 2823 & Cellulosic man-made fibers & $100 \%$ & $\sim 100 \%$ & $\sim 100 \%$ & $100 \%$ \\
\hline 2824 & Organic fibers, noncellulosic & $93 \%$ & $\sim 100 \%$ & $100 \%$ & $117 \%$ \\
\hline 2911 & Petroleum refining & $56 \%$ & $94 \%$ & $93 \%$ & $97 \%$ \\
\hline 3011 & Tires and inner tubes & $52 \%$ & $99 \%$ & $99 \%$ & $99 \%$ \\
\hline 3241 & Hydraulic cement & $95 \%$ & $99 \%$ & $98 \%$ & $111 \%$ \\
\hline 3312 & Blast furnaces and steel mills & $85 \%$ & (a) & $\sim 100 \%$ & $\sim 100 \%$ \\
\hline 3313 & Electrometallurgical products & $84 \%$ & $98 \%$ & $97 \%$ & $98 \%$ \\
\hline 3315 & Steel wire drawing & $38 \%$ & $86 \%$ & $84 \%$ & $86 \%$ \\
\hline 3322 & Malleable iron foundries & $72 \%$ & $83 \%$ & $85 \%$ & $78 \%$ \\
\hline 3323 & Steel foundries & $58 \%$ & $92 \%$ & $91 \%$ & $96 \%$ \\
\hline 3331 & Primary copper & $97 \%$ & (a) & $101 \%$ & $97 \%$ \\
\hline 3332 & Primary lead & $100 \%$ & (a) & $\sim 100 \%$ & $116 \%$ \\
\hline 3333 & Primary zinc & $100 \%$ & $\sim 100 \%$ & $100 \%$ & $100 \%$ \\
\hline 3334 & Primary aluminum & $100 \%$ & $101 \%$ & $\sim 100 \%$ & $78 \%$ \\
\hline 3351 & Copper rolling and drawing & $69 \%$ & $98 \%$ & $99 \%$ & $113 \%$ \\
\hline 3352 & Aluminum rolling and drawing & $44 \%$ & $95 \%$ & $94 \%$ & $110 \%$ \\
\hline 3362 & Brass, bronze, copper castings & $7 \%$ & $41 \%$ & $36 \%$ & $31 \%$ \\
\hline 3391 & Iron and steel forgings & $34 \%$ & $87 \%$ & $87 \%$ & $79 \%$ \\
\hline 3392 & Nonferrous forgings & $55 \%$ & $101 \%$ & $99 \%$ & $99 \%$ \\
\hline 3519 & Internal combustion engines & $46 \%$ & $95 \%$ & $94 \%$ & $99 \%$ \\
\hline 3612 & Transformers & $26 \%$ & $94 \%$ & $92 \%$ & $248 \%$ \\
\hline
\end{tabular}

Source: Underlying statistics on the 1958 universe are taken from U.S. Bureau of the Census, U.S. Census of Manufactures: 1958, Vol. 1, Summary Statistics. Washington, DC: U.S. Government Printing Office, 1961.

(a) The total value of shipments for these three industries were not published due to the extensive duplication arising from shipments from one establishment to another in the same industry. 


\section{TABLE 14}

\section{Share of U.S. Manufacturing Activity in 1958}

\begin{tabular}{|c|c|c|c|c|c|}
\hline & $\begin{array}{l}\text { Number of } \\
\text { establishments }\end{array}$ & $\begin{array}{l}\text { Adjusted } \\
\text { value added }\end{array}$ & Total employees & Capital expenditures & $\begin{array}{l}\text { Gross book value } \\
\text { of depreciable assets }\end{array}$ \\
\hline ITS Prototype sample $(\mathrm{N}=1,808)$ & $0.61 \%$ & $10.49 \%$ & $7.94 \%$ & $24.0 \%$ & $26.0 \%$ \\
\hline 25 industries in scope to ITS Prototype & $1.20 \%$ & $10.85 \%$ & $8.26 \%$ & $24.1 \%$ & (a) \\
\hline
\end{tabular}

Source: Underlying statistics on the 1958 universe are taken from U.S. Bureau of the Census, U.S. Census of Manufactures: 1958, Vol. 1, Summary Statistics. Washington, DC: U.S. Government Printing Office, 1961.

(a) Published statistics on gross book value of depreciable assets employ the industry classification system in place before the 1958 Standard Industrial Classification scheme. 
TABLE 15

Establishment Counts in the Individual ASM Files of 1953-1956

\begin{tabular}{|c|c|c|c|}
\hline & \multicolumn{3}{|c|}{ Number of Establishments } \\
\cline { 2 - 4 } & Total & $\begin{array}{c}\text { With Positive } \\
\text { Payroll and } \\
\text { Employment }\end{array}$ & $\begin{array}{c}\text { Published } \\
\text { Information }\end{array}$ \\
\hline 1953 & 23,804 & 23,722 & 52,000 \\
\hline 1954 & - & $37,788^{*}$ & $\mathrm{n} / \mathrm{a}$ \\
\hline 1955 & 39,471 & 37,875 & about 45,000 \\
\hline 1956 & 45,909 & 44,467 & about 45,000 \\
\hline
\end{tabular}

* The count shown is the number of establishments in the 1955 file with positive values of prior year payroll and employment. 


\section{FIGURE 1}

Newly Recovered and Existing Microdata on Manufacturers

\begin{tabular}{|lccccc|}
\hline \multicolumn{4}{c|}{ NEWLY DISCOVERED MICRODATA } & & CURRENTLY \\
\hline \begin{tabular}{lllll}
\hline Industrial Time Series \\
(25-industry prototype)
\end{tabular} & $\begin{array}{l}16 \mathrm{~mm} \text { microfilm of } \\
\text { survey form images }\end{array}$ & $\begin{array}{c}\text { Industrial Time Series } \\
\text { (All industries) }\end{array}$ & Individual ASMs & AVAILABLE \\
MICRODATA
\end{tabular}

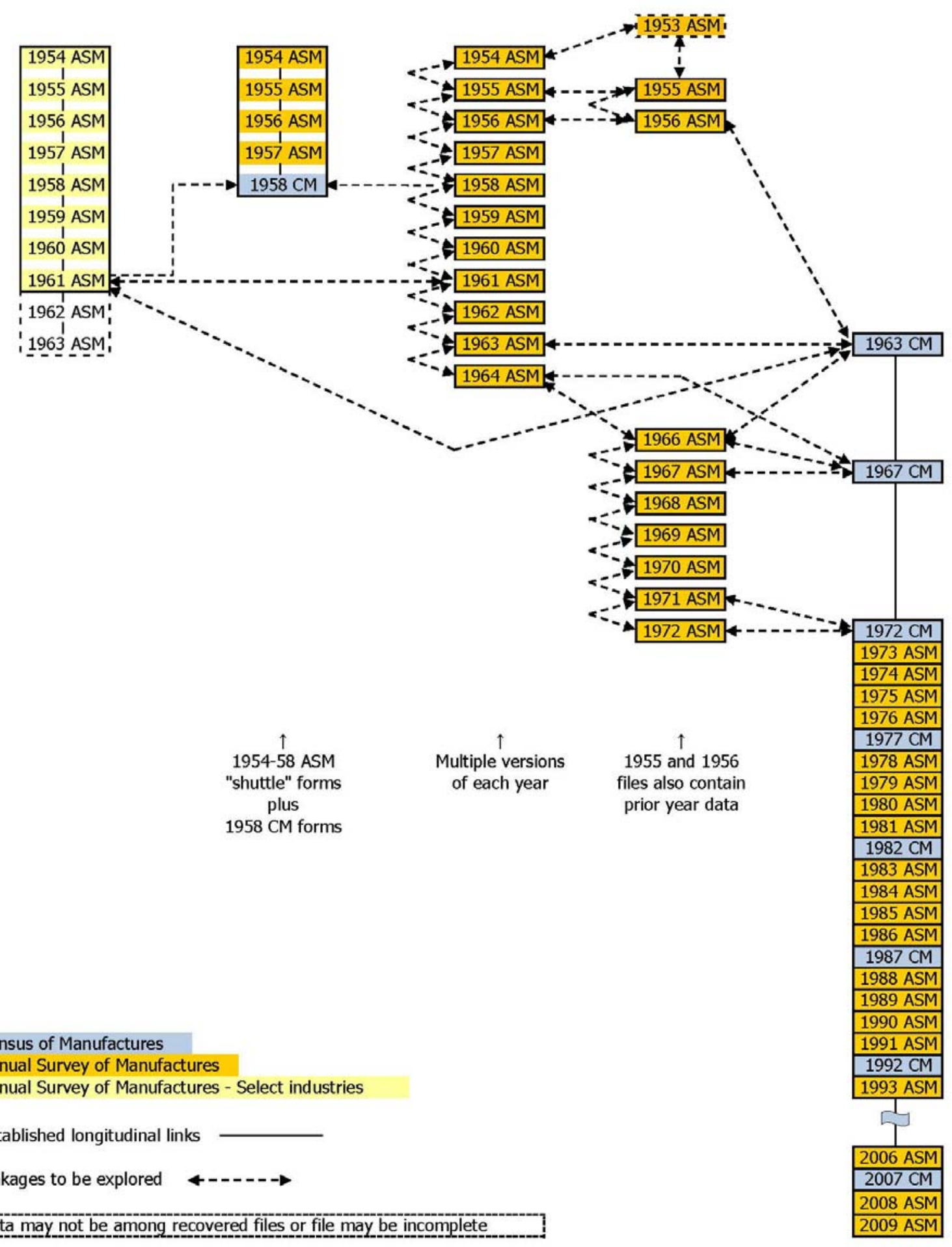




\section{APPENDIX A}

An Attempt to Summarize the Recovered Historical Economic Microdata

Here, we highlight some of the business microdata that were recovered from the Unisys Clearpath mainframe. Note that it is very difficult to summarize this information succinctly, for a variety of reasons, not the least of which is that there are thousands of files, many with only a crude description (if any at all) in the associated paper file (data storage action request). It should also be noted that presence on the list below does not necessarily guarantee that there are usable microdata files. And, in some cases, the lack of a record layout may make recovered data very difficult to use - unless related data and/or record layouts exist. Further details are available upon request.

Meanwhile, for the list of surveys and years that CES currently has and makes available, see http://www.census.gov/ces/dataproducts/.

\section{Manufacturing and Mining}

Census of Manufactures

Special inquiries data

Class of customer data

CAO (auxiliary establishments)

MA-131 (Supplemental Survey of

Materials Consumed)

Location of plants

Ancillary data (e.g., flags, name and address, edit parameters)

Census of Manufactures (Puerto Rico)

Census of Mining

Annual Survey of Manufactures

Main files

ITS (longitudinally-linked ASM estabs)

CAO (auxiliary establishments)

Fixed Base Difference files

MA-175 (Defense, Government)

Defense Mobilization

Ancillary data (flags, parameters, sampling universes, etc.)

Name and address files

Fuel and Electric Energy supplement

MA-452 (Survey of the Consumption of Selected Hydrocarbon, Coal, and Coke Materials)

Survey of Water Use in Manufacturing

Capital Asset and Depreciation Survey

Survey of Industrial R\&D

Survey of Plant Capacity

Pollution Abatement Costs and Expend. Survey

Zvi Griliches project files (includes R\&D, CM)

Lawrence Klein project data

Ruggles project files

Annual Survey of Oil and Gas

\section{Business (i.e., non-manufacturing)}

Census of Business

Census of Retail (various)

Census of Wholesale
1967, 1972, 1977, 1982

1967, 1977

1977

1972

1963

1967, 1972, 1977, 1982

1967, 1972, 1977

1963, 1967, 1972, 1977, 1982

1953-1964, 1966-1971

1954-1961

1974, 1977-81, 1983-86, 1988-91

1974, 1978-85, 1989, 1991

1981-84

1987, 1989

Various years

Various years

1974, 1976

1978-80

1973, 1978, 1983

1967-70

1973-88 (additional data and flags)

$1980,1983 / 84$

1957-1980

1954-59, 1972-81

1974-82

1972

1963, 1967(Puerto Rico), 1972(Capital Expenditure)

1958, 1963, 1967 
Census of Services

Service and Retail Capital Expenditure Survey

Annual Retail Trade Survey

Annual Trade Survey

Services Annual Survey

Annual Wholesale Trade Survey (WATS)

Heating Fuel Survey

Survey of Gallonage Sales of Gasoline

Canned Food Survey

International Trade

Imports (transactions)

\section{Business Register}

SSEL files (various)

County Business Patterns establishment files

Other administrative records files

Enterprise Statistics

\section{Non-employers}

Survey of Minority-owned Business Enterprises

\section{Outlying Areas}

Economic Census

Puerto Rico

Census of Retail

Census of Manufactures

Census of Construction

\section{Transportation}

Commodity Transport Survey (now Commodity Flow Survey)

Domestic and International Transportation of U.S. Foreign Trade

DOT Final GAT-1 and PUT-1

Truck Inventory and Use Survey (public use?)

\section{Construction}

Building Permits

Survey of Housing Starts, Sales, and Completions (HSS)

Progress Reporting

\section{Agriculture}

Census of Agriculture

Census of Agriculture - Puerto Rico

Census of Agriculture - Guam, Virgin Islands

Census of Agricultural Services

Farm Finance Survey

Census of Commercial Fisheries

Census of Irrigation

Census of Horticulture
1963, 1967, 1967(Lawyers), 1967(Capt Exp Med Assets)

1972

1974, 1979-81, 1984-86, 1990

1980, 1982-87, 1990

1987, 1990

1989-90

1979-80

1980-82

1981

1989-90

1974-87, 1989

1976-84

1977-82

1972, 1977

1972, 1977, 1982, 1987

1982

1967

1967, 1972, 1977

1977

1967, 1972, 1977

1976

1977

1970-86, 1989

$1979-83$

1973-83

1964, 1969, 1974, 1978 (+ "Farm Real Estate Survey" and "Hired Labor")

1969, 1978, 1982

1982

1969, 1978

1969 (or 1974?), 1978, 1979(Landlords; Operators)

1967

1969

1979 


\section{APPENDIX B \\ The 1966 Annual Survey of Manufactures Form}

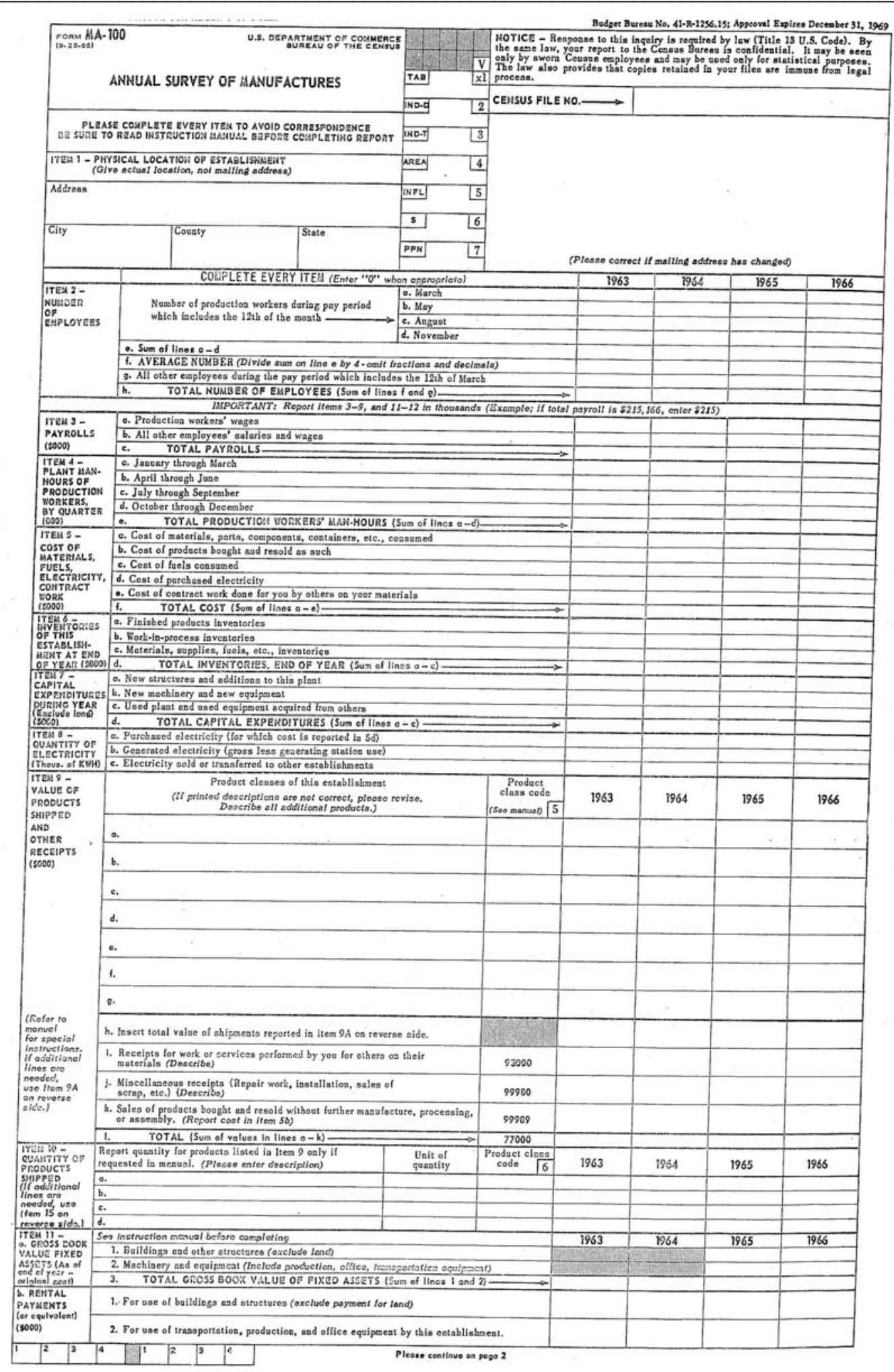




\section{APPENDIX B (cont.)}

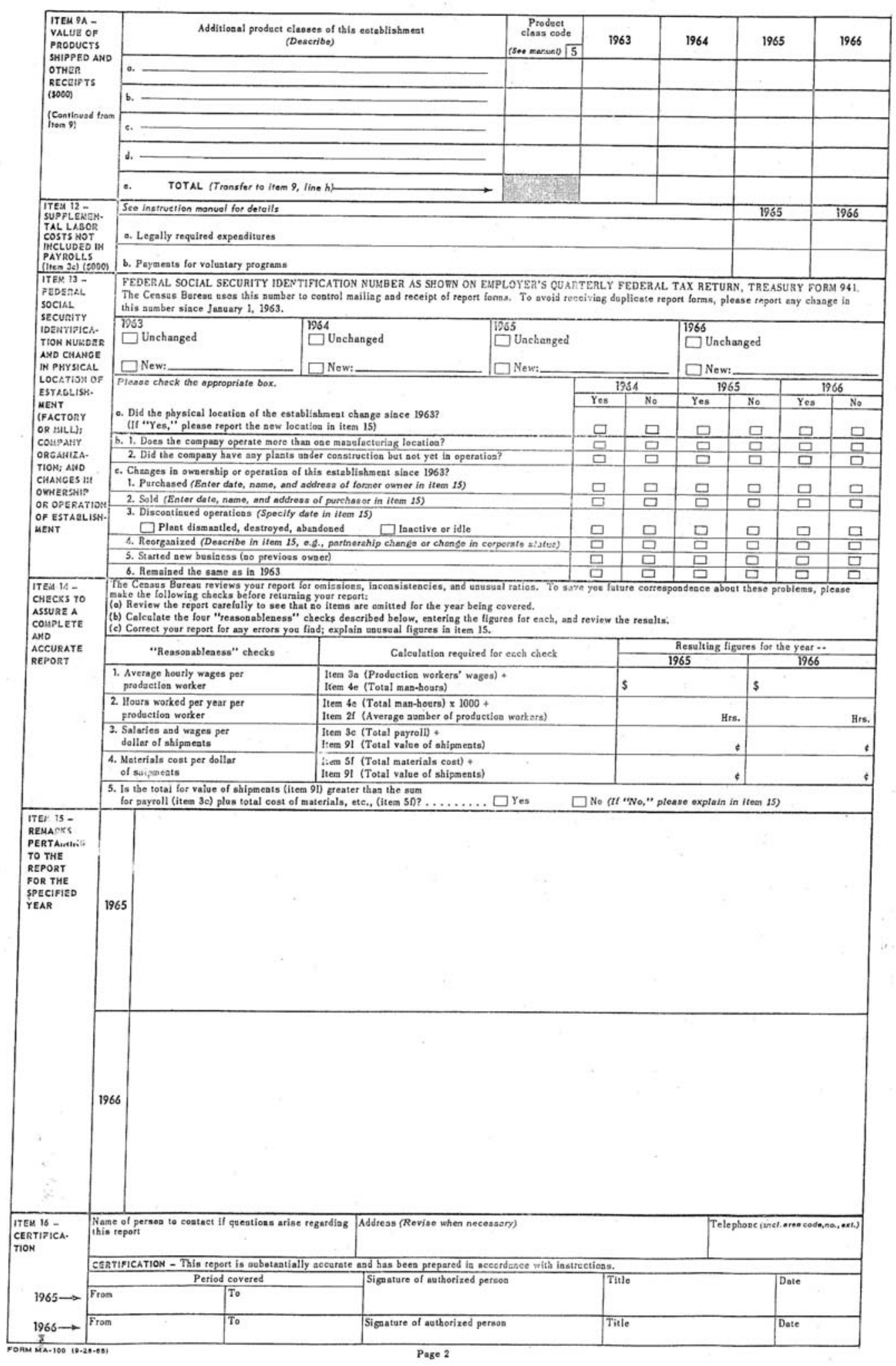




\section{APPENDIX C}

\section{The 1970/71 Annual Survey of Manufactures Form}

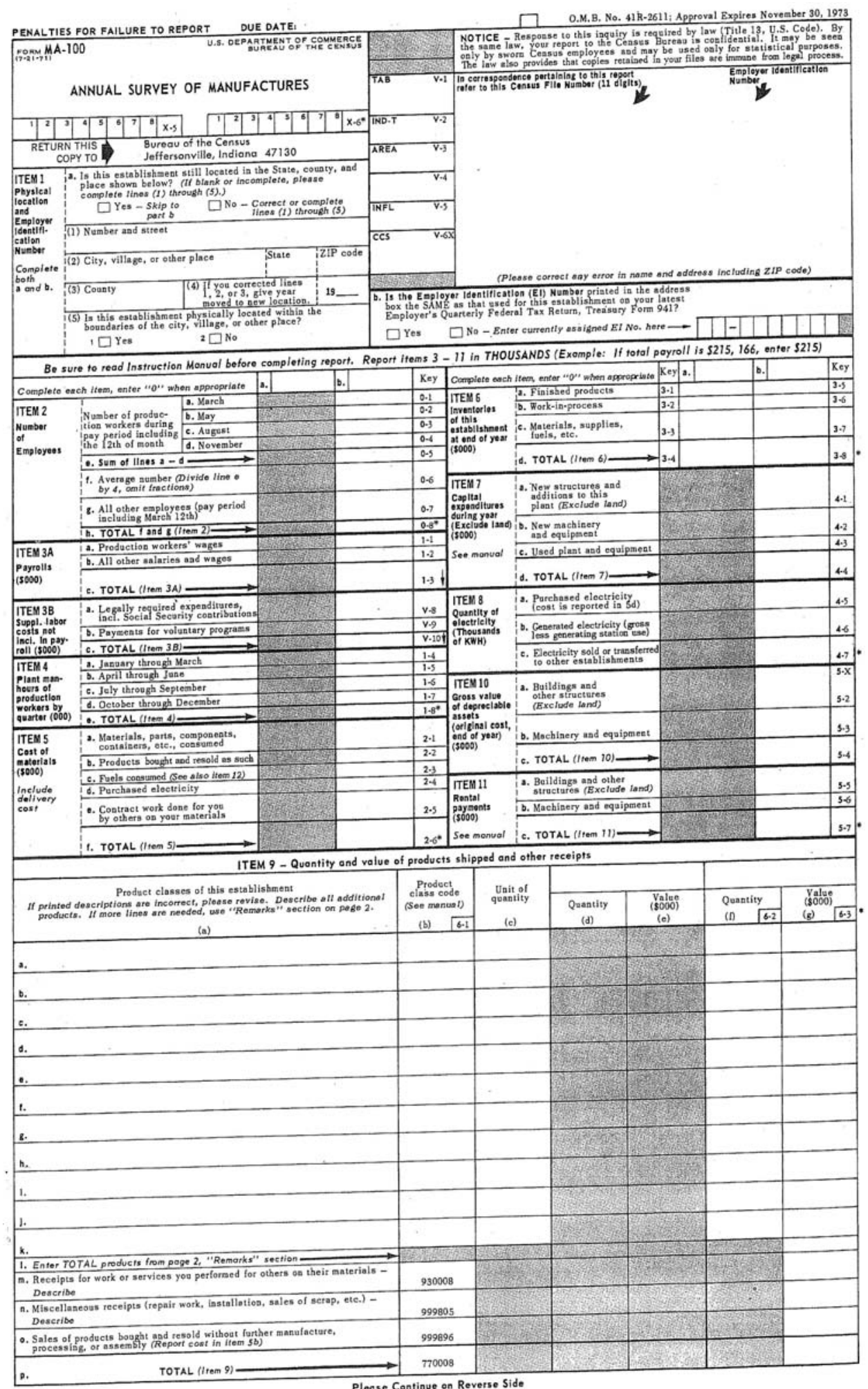




\section{APPENDIX C (cont.)}

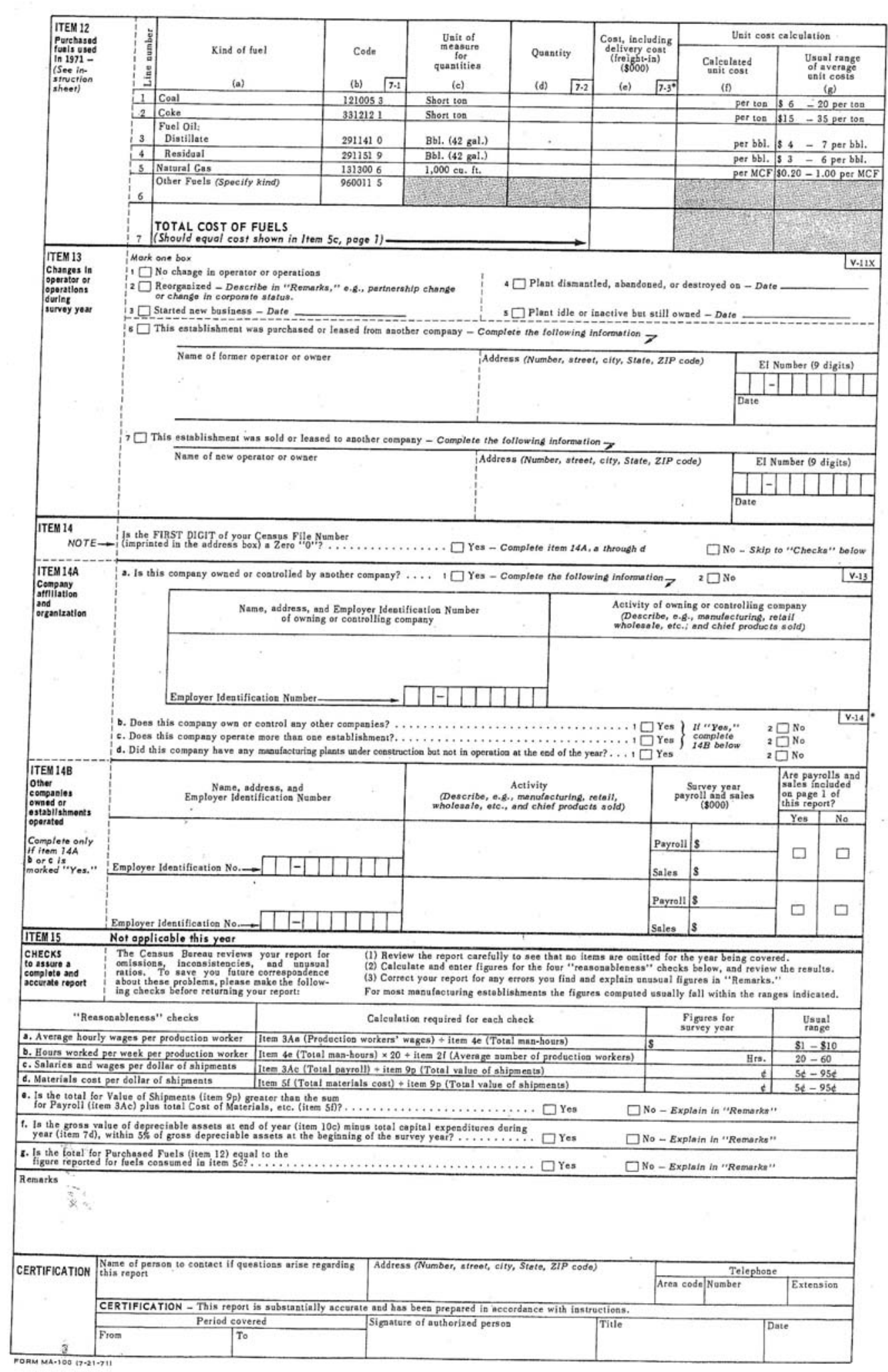




\section{APPENDIX D}

Original Record Layout for 1954-1964 Industrial Time Series Files (ITS-1)

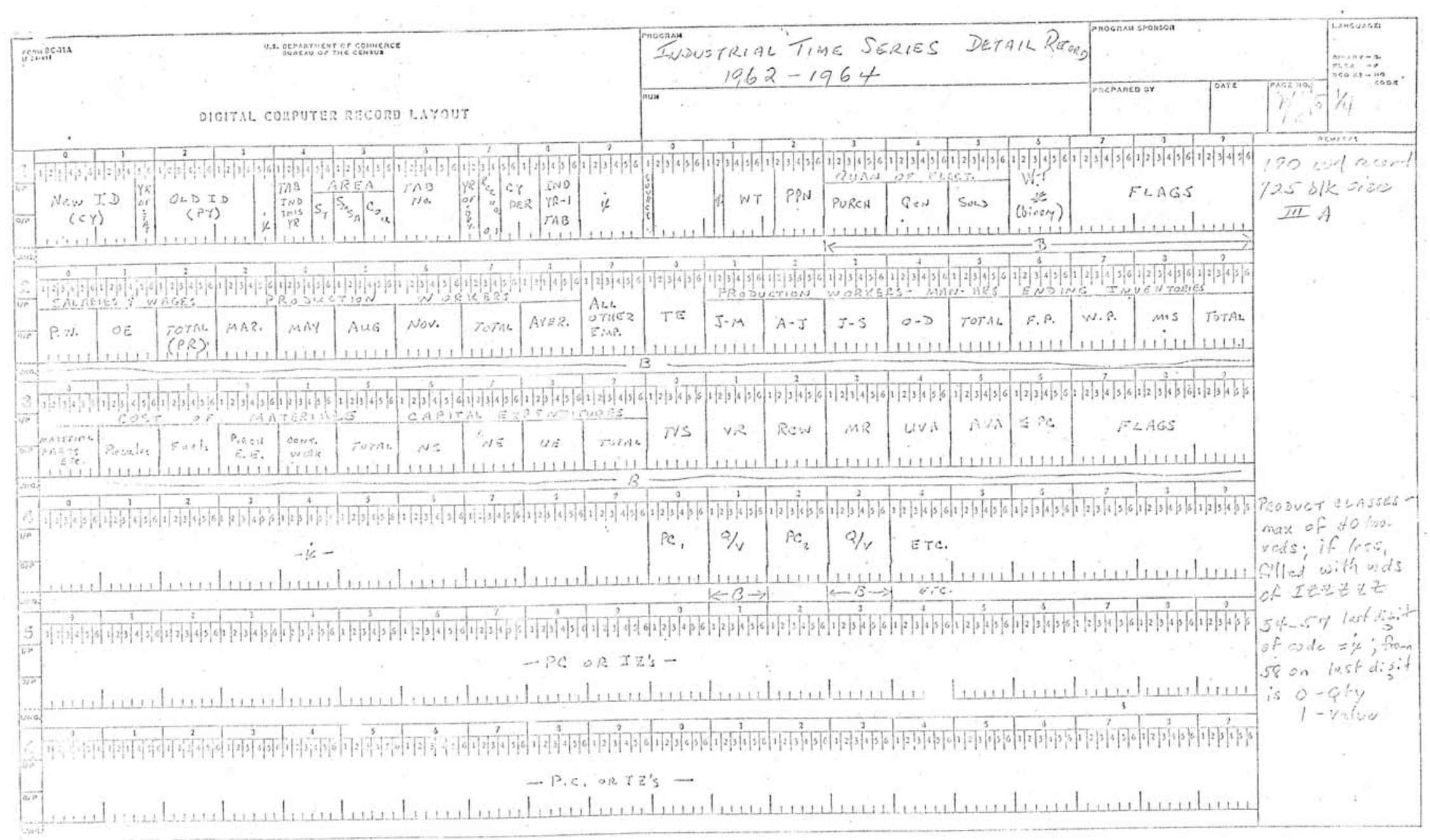




\section{APPENDIX D (cont.)}

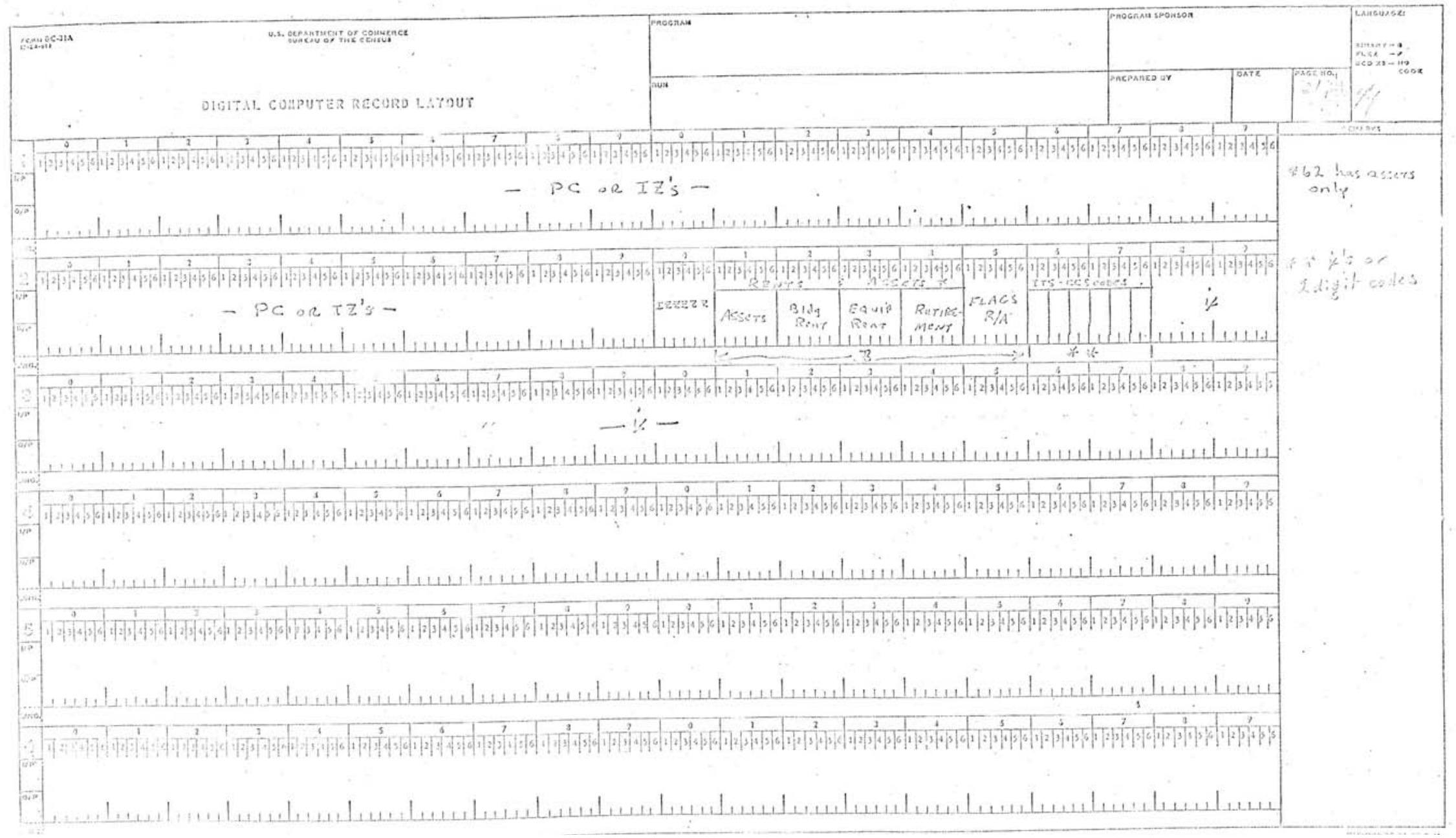




\section{APPENDIX E}

\section{Original Record Layout for 1954-1964 Industrial Time Series Finder File Prep Files (ITS-2)}

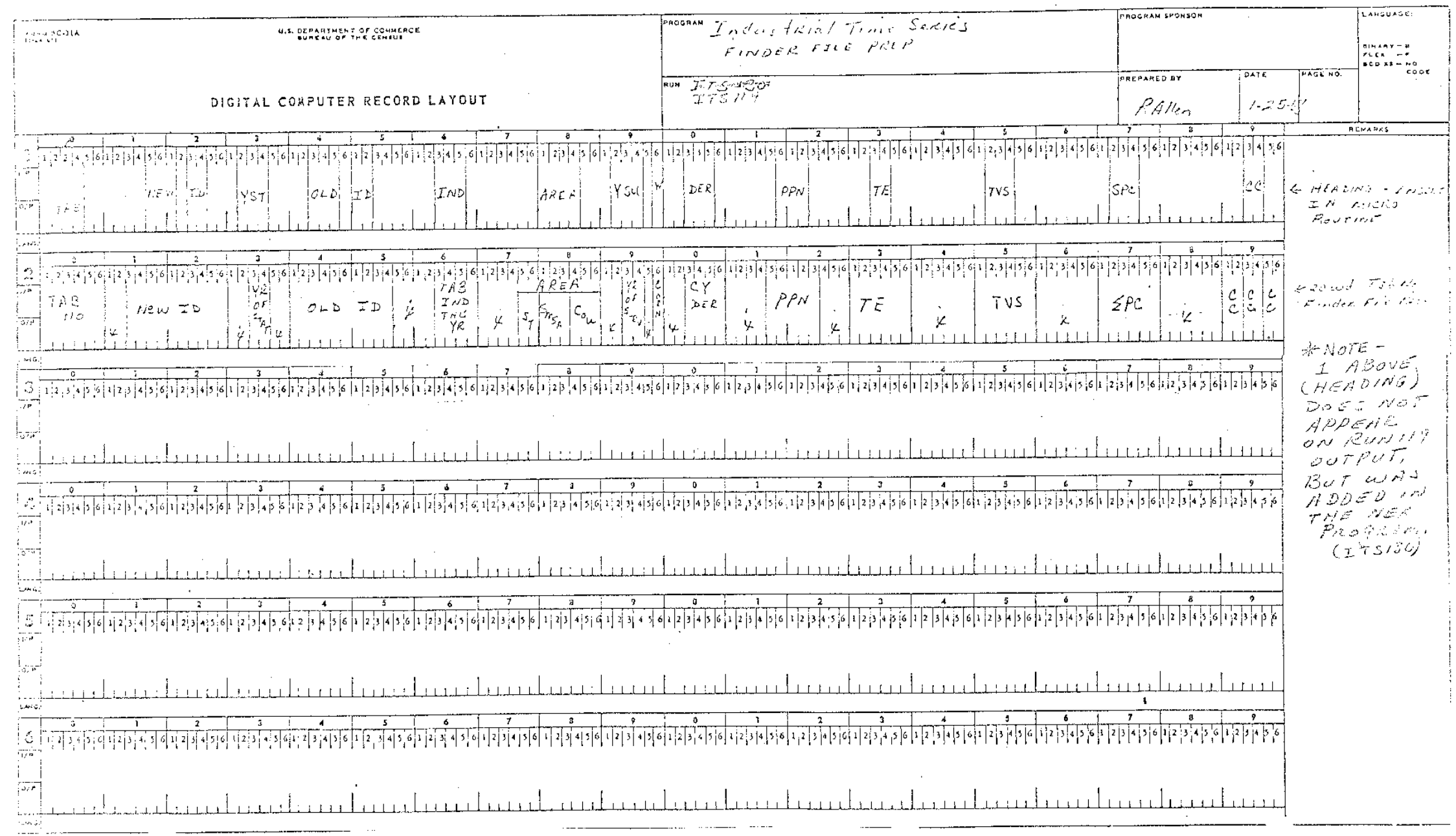




\section{APPENDIX F}

The 1954-1958 Annual Survey of Manufactures “Shuttle Form”

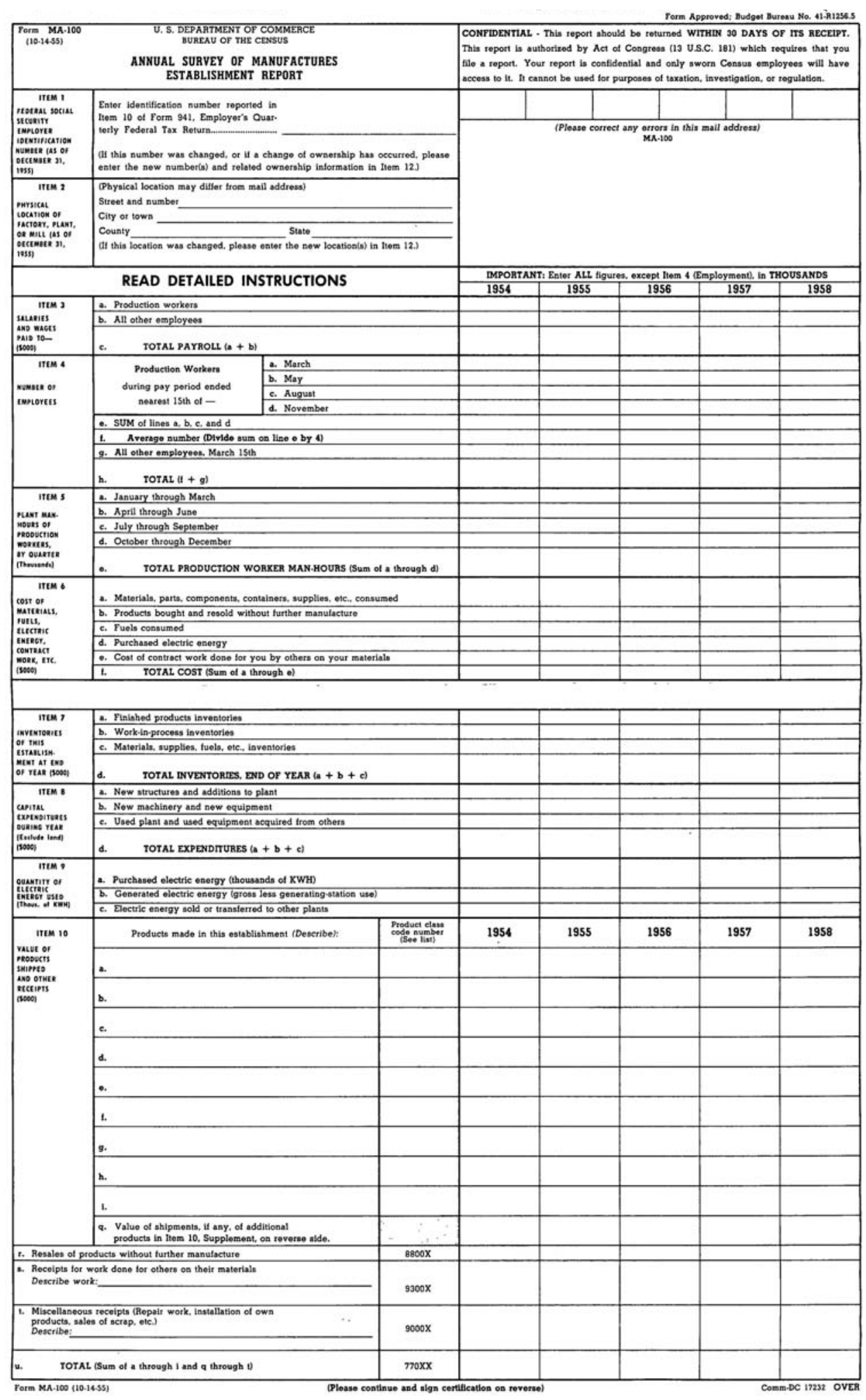




\section{APPENDIX F (cont.)}

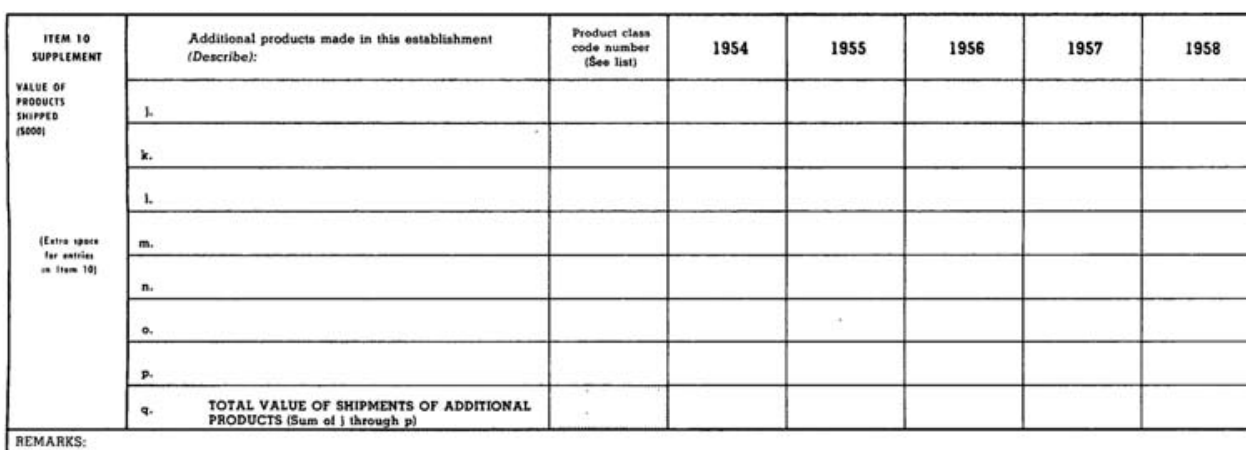

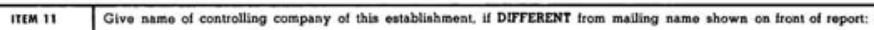

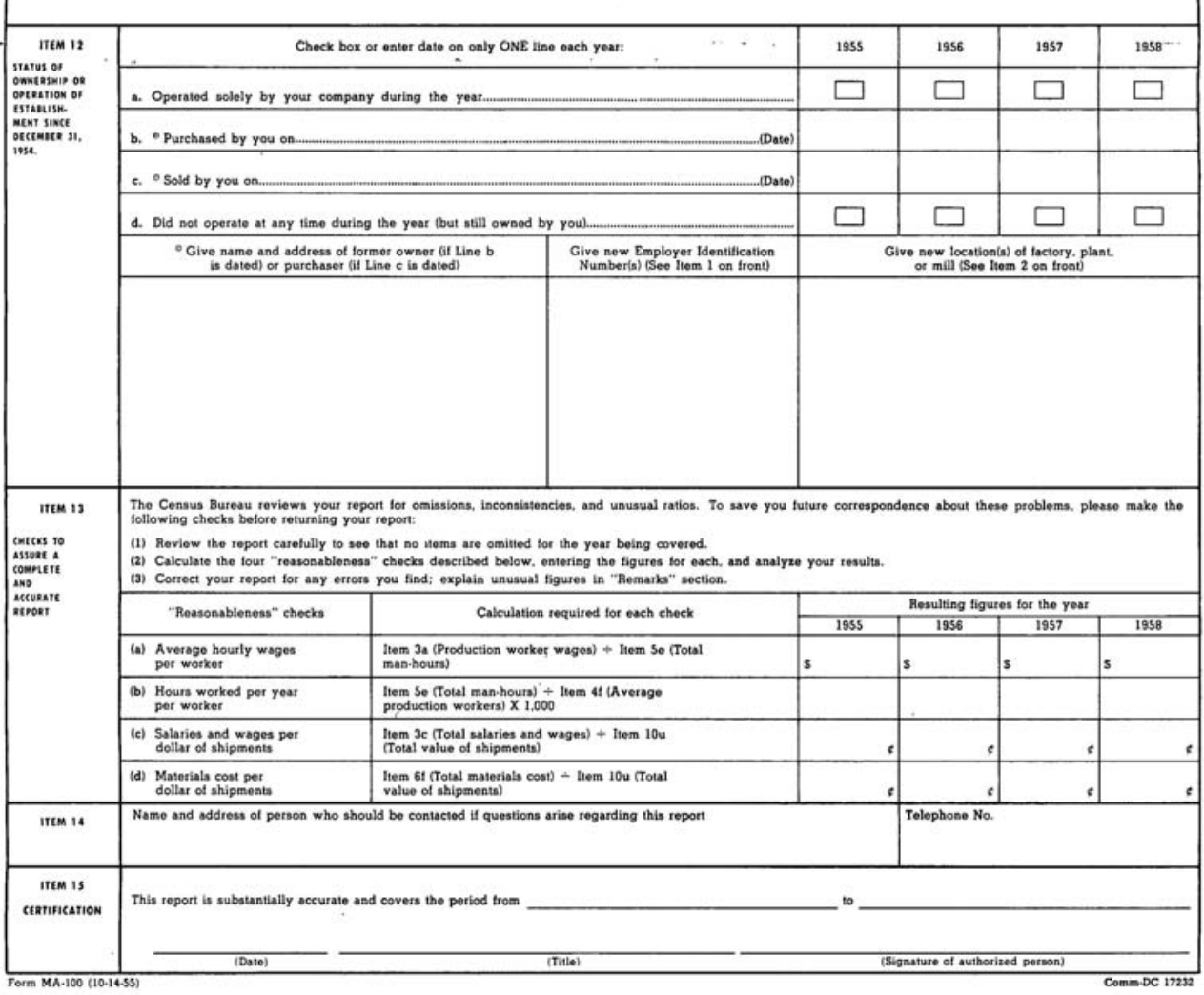




\section{APPENDIX G \\ The 1958-1963 Annual Survey of Manufactures "Shuttle Form"}

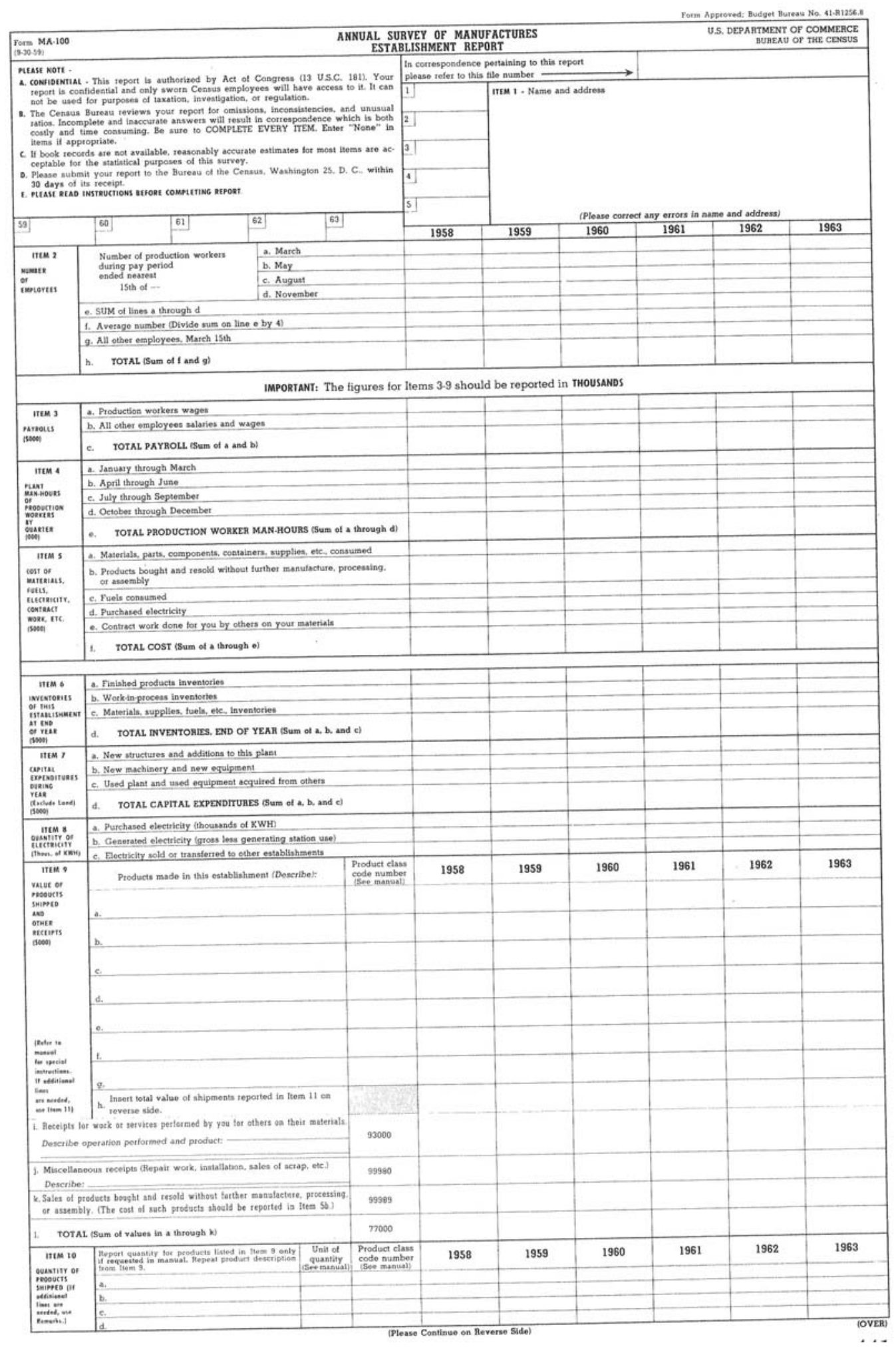




\section{APPENDIX G (cont.)}

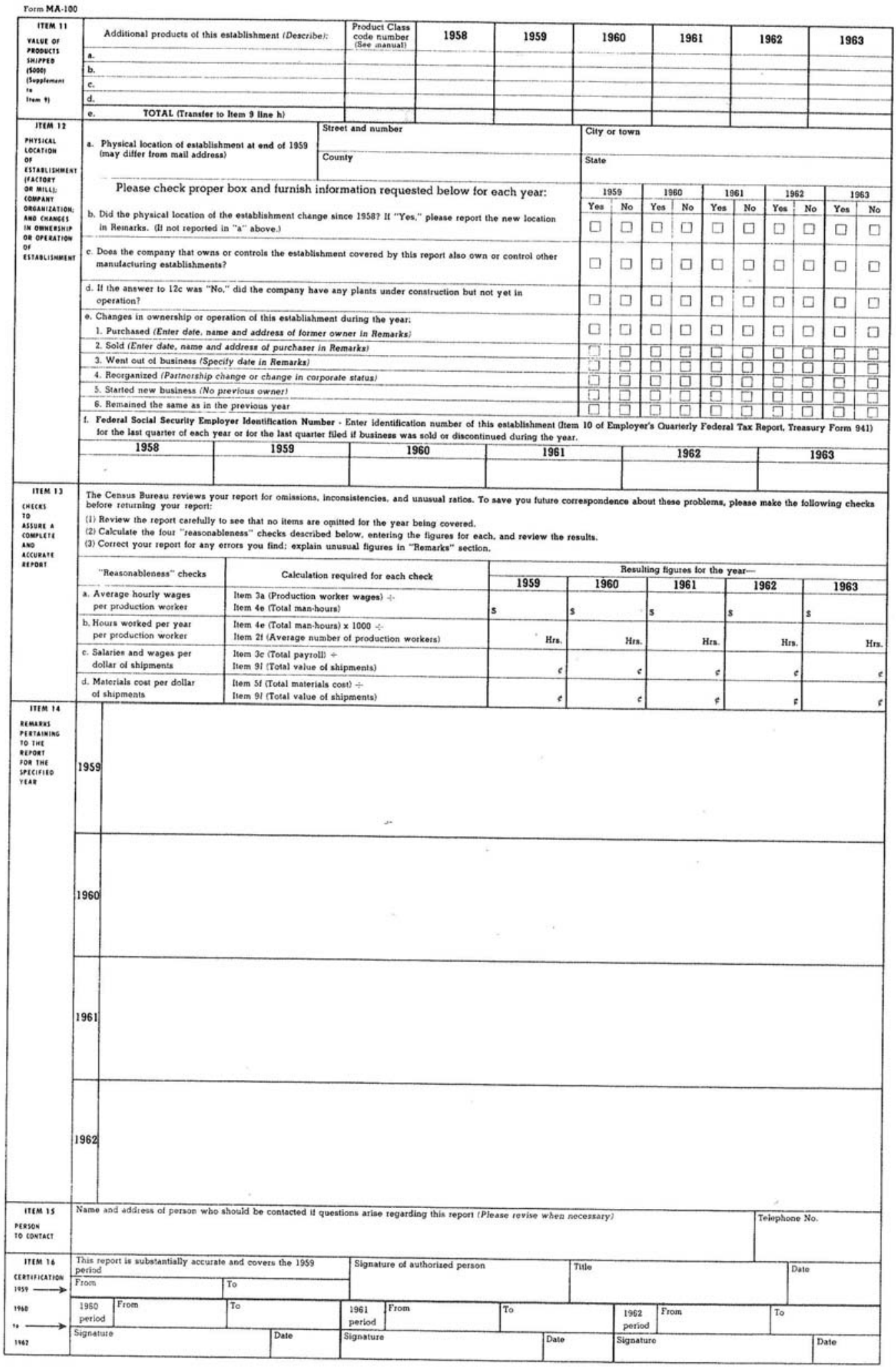




\section{APPENDIX H}

The 1964 Annual Survey of Manufactures Form

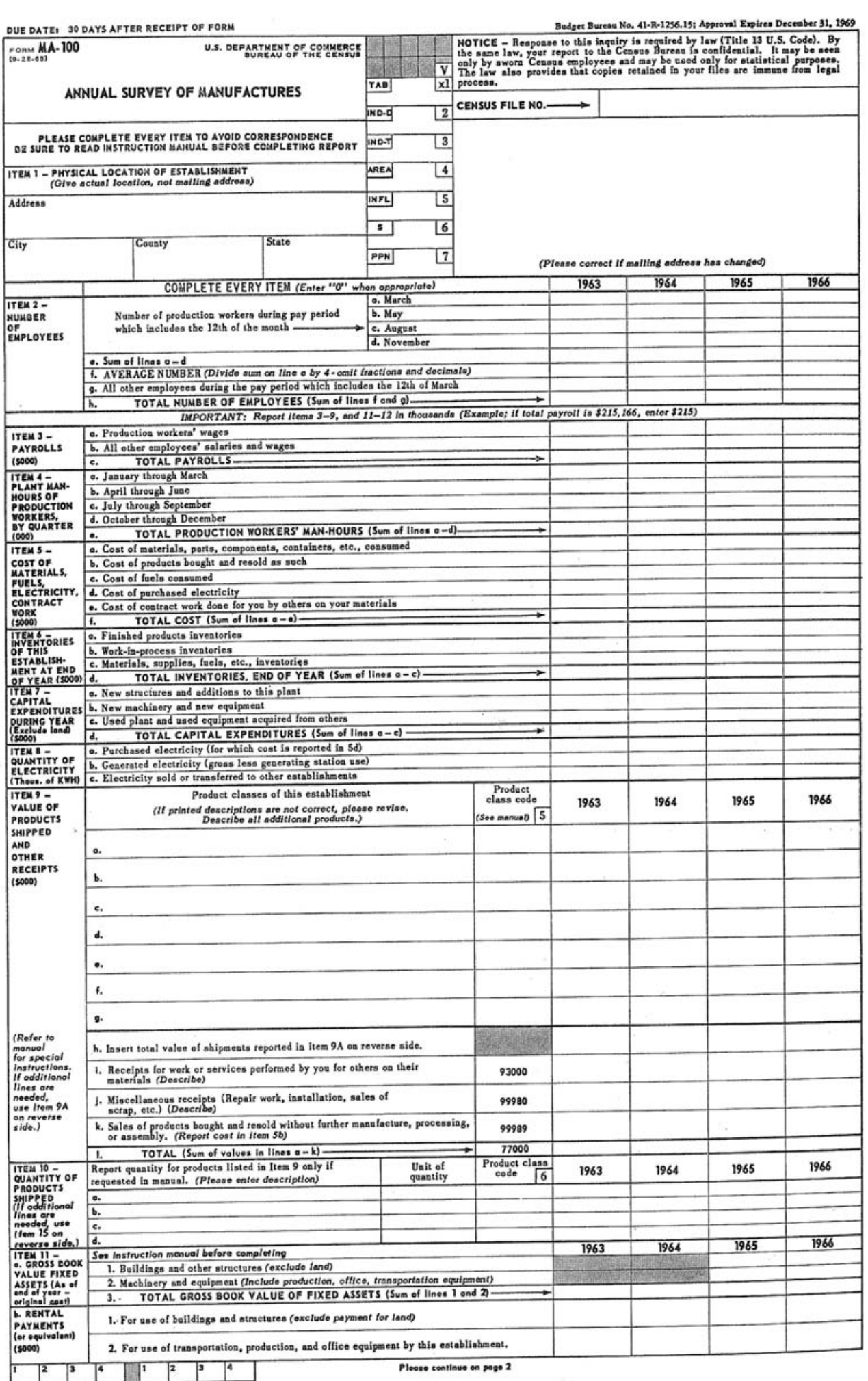




\section{APPENDIX H (cont.)}

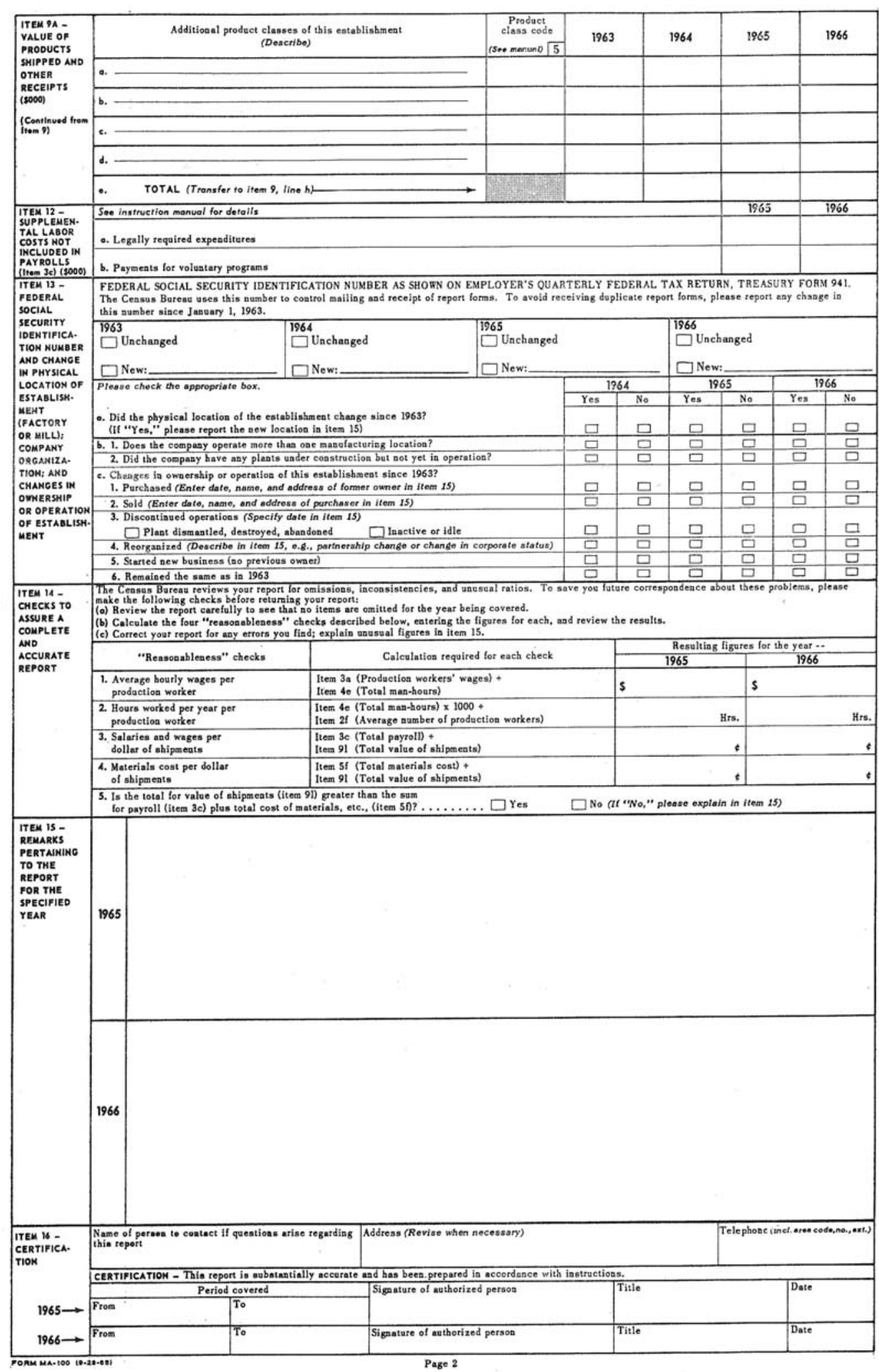




\section{APPENDIX I}

Census of Manufactures Supplementary Inquiries for 1957 (Form MC-D11)

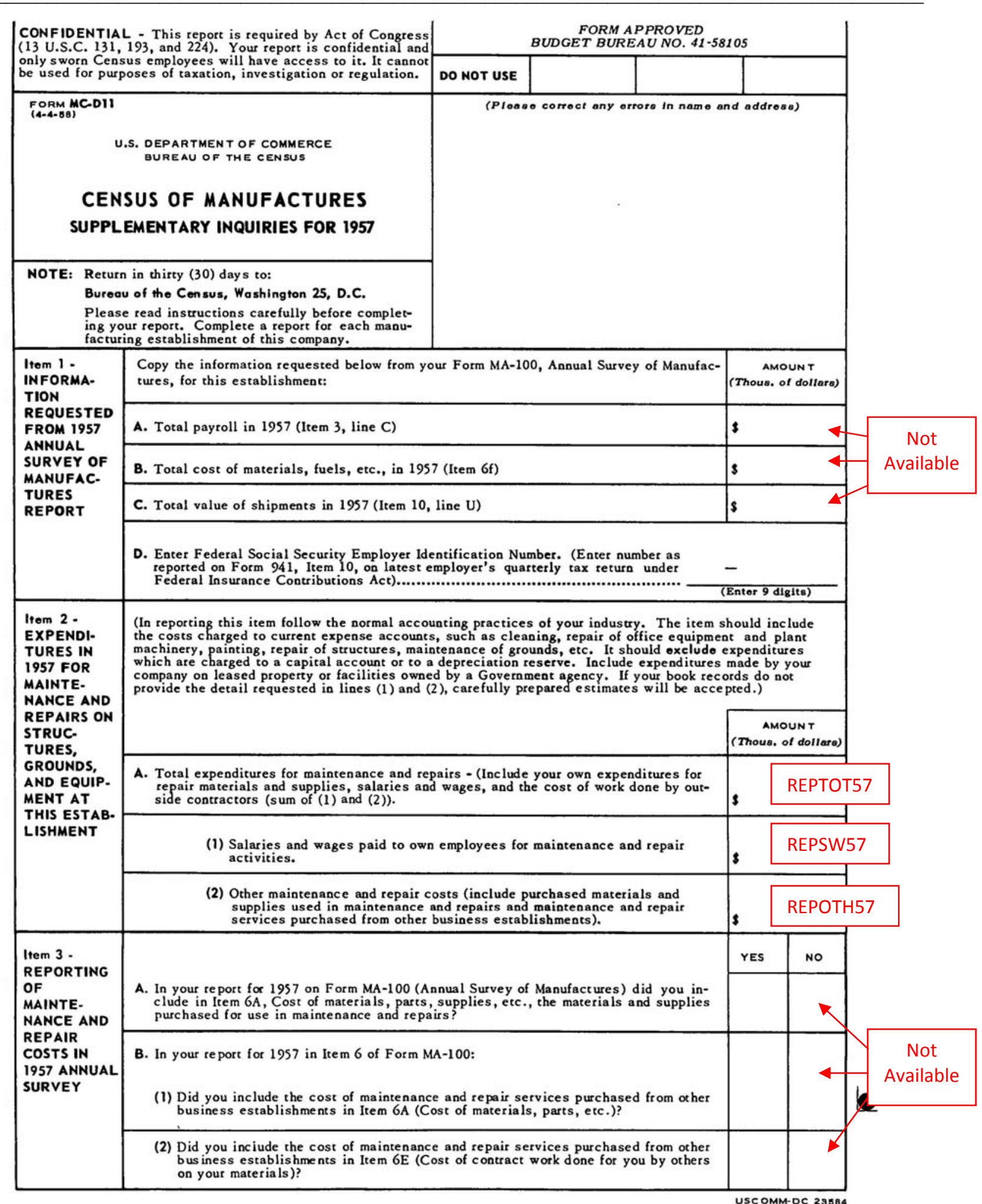




\section{APPENDIX I (cont.)}

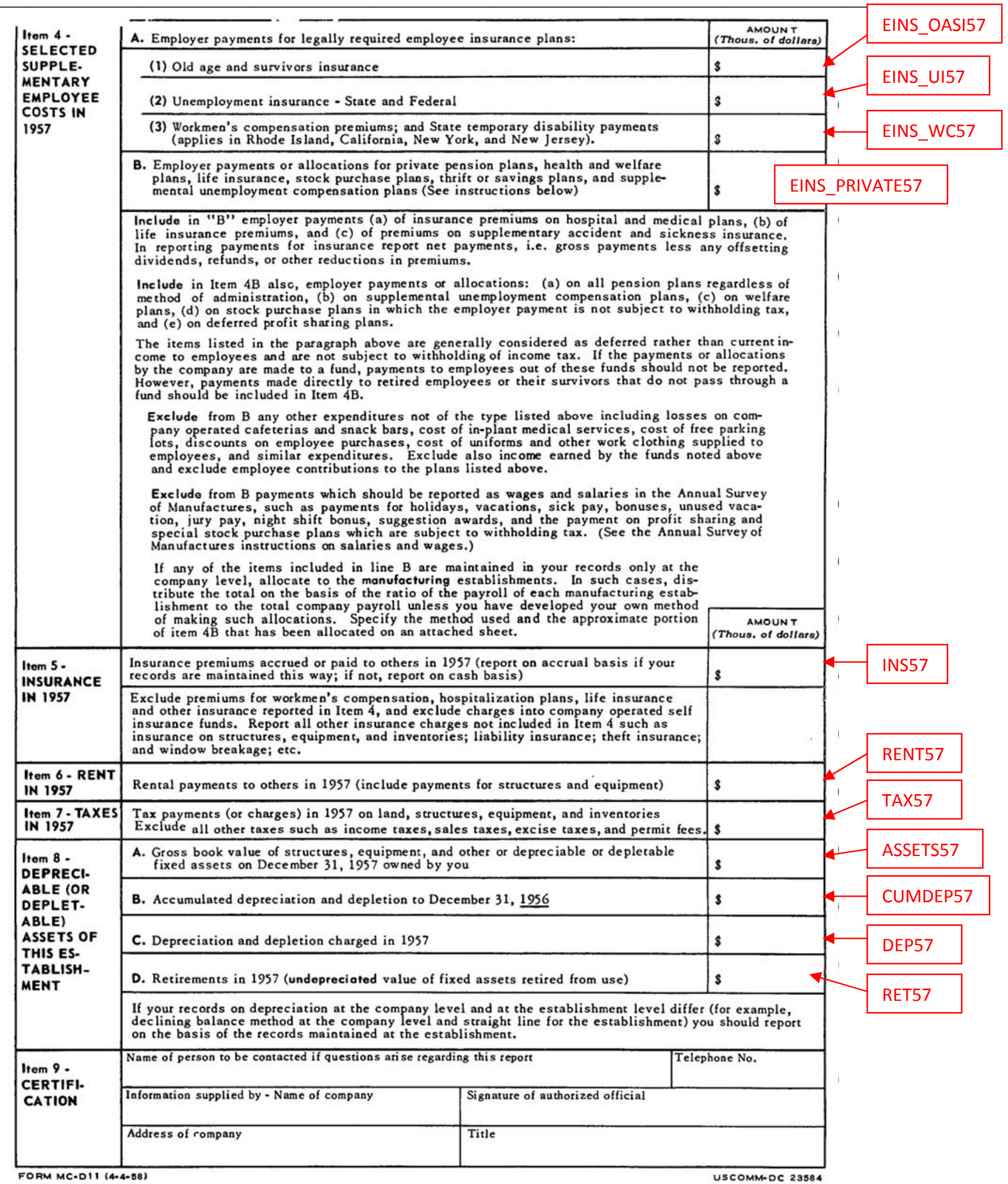




\section{APPENDIX $\mathbf{J}$}

\section{Original Record Layout for 1954-1961 Industrial Time Series 25-Industry "Prototype” Files}

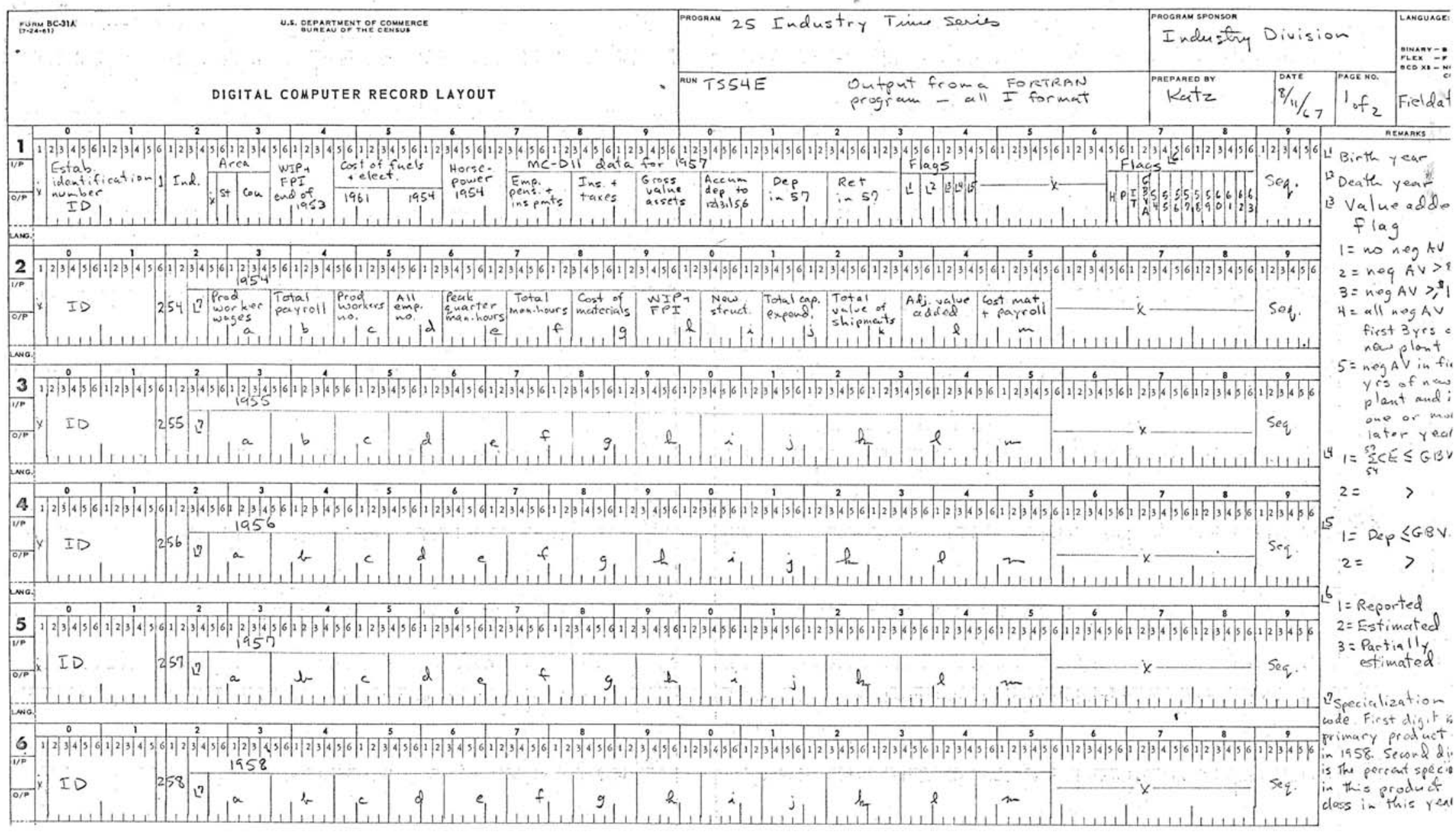


APPENDIX J (cont.)

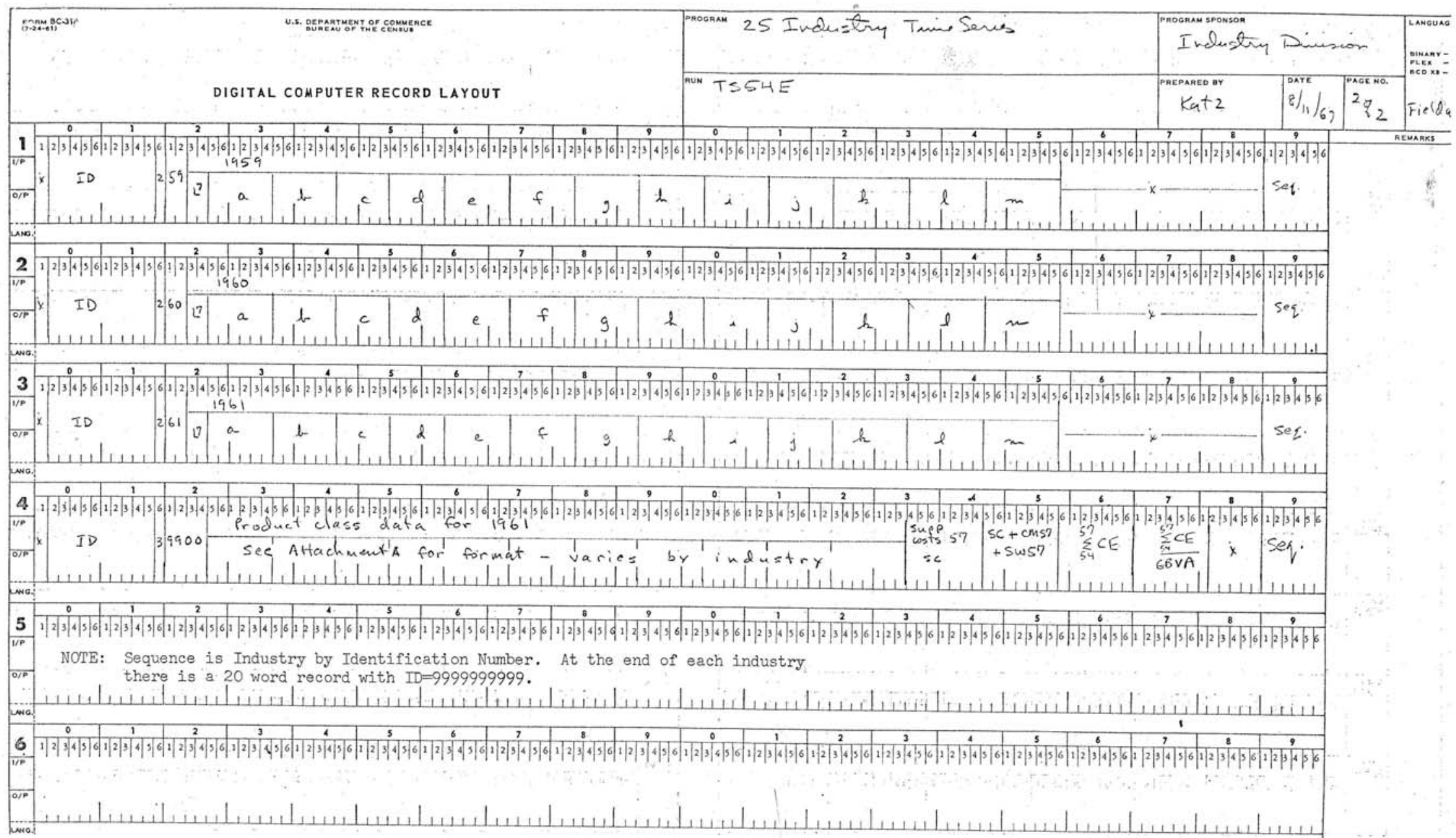




\section{APPENDIX J (cont.)}

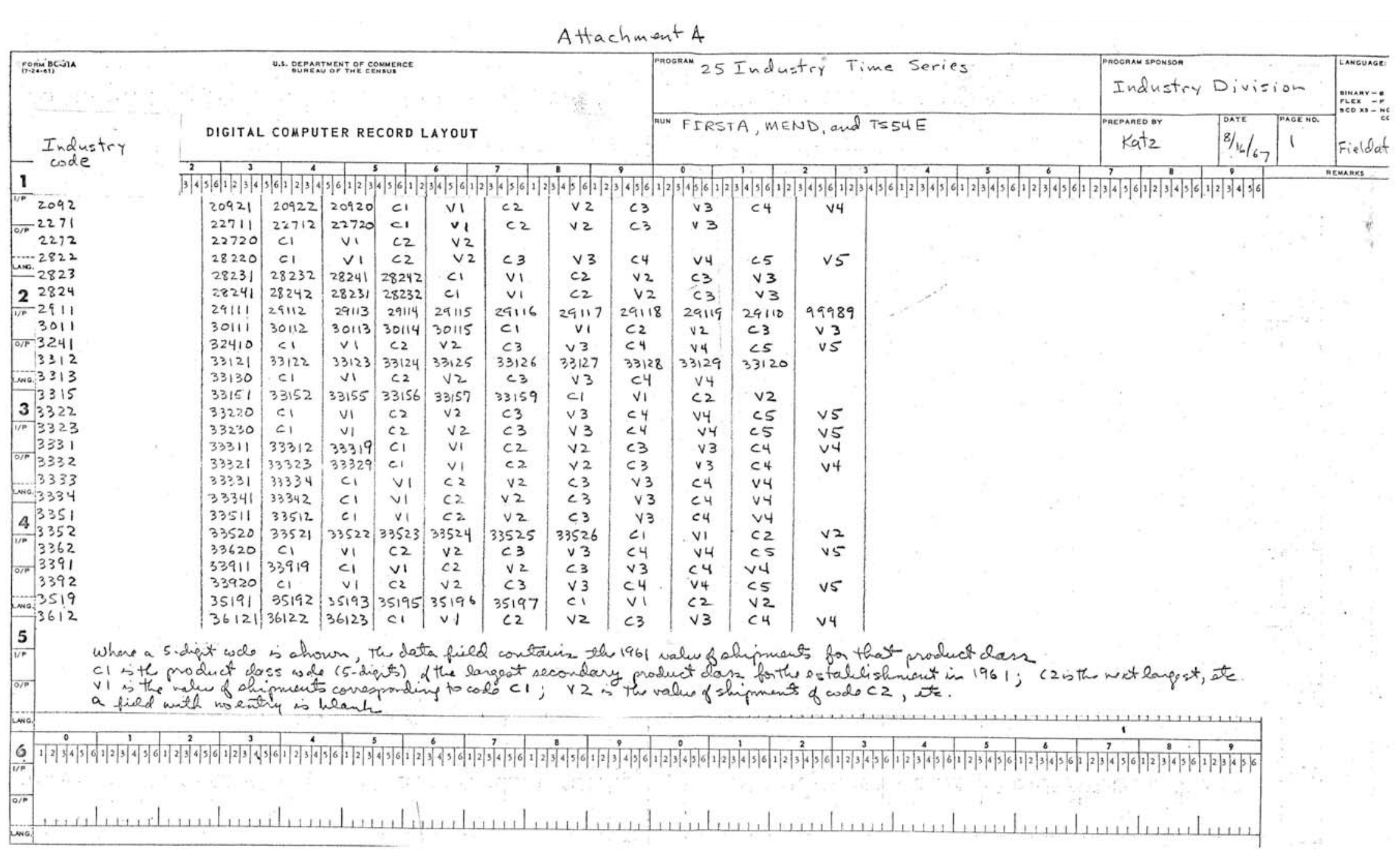

Source: U.S. Bureau of the Census, Data Storage Action Request, Register Number 79-120, April 11, 1979. 


\section{APPENDIX K}

Punch Cards Used in the 1953, 1955, and 1956 Annual Survey of Manufactures

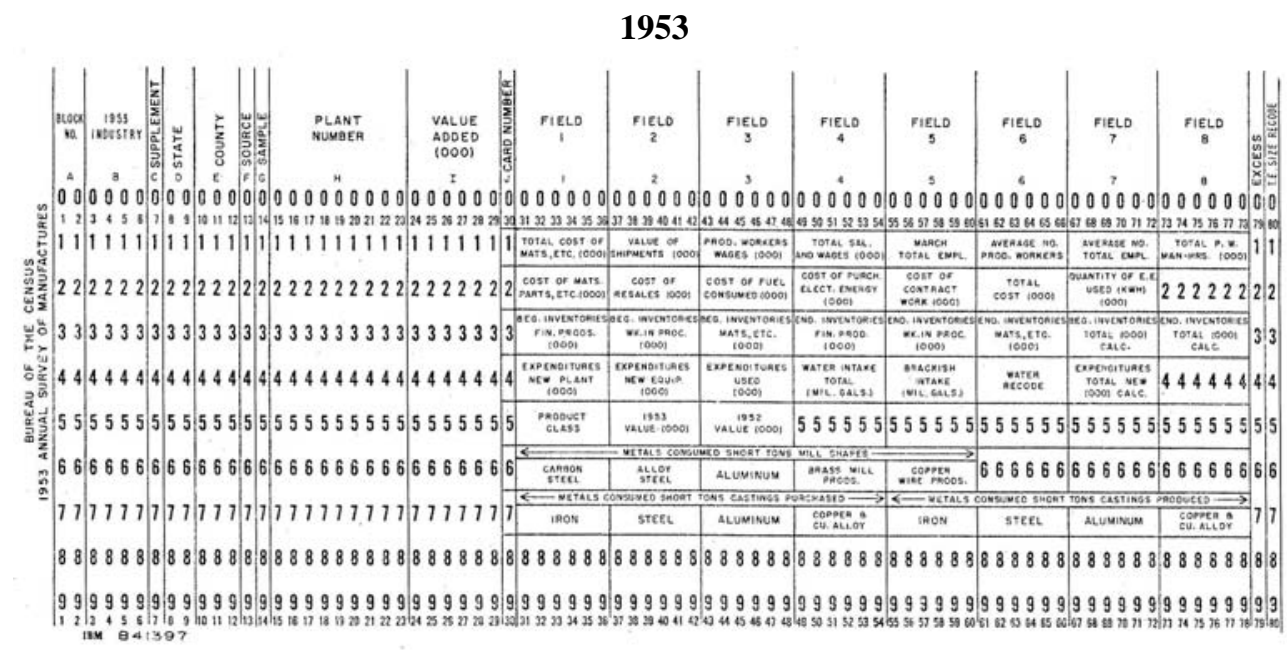

1955

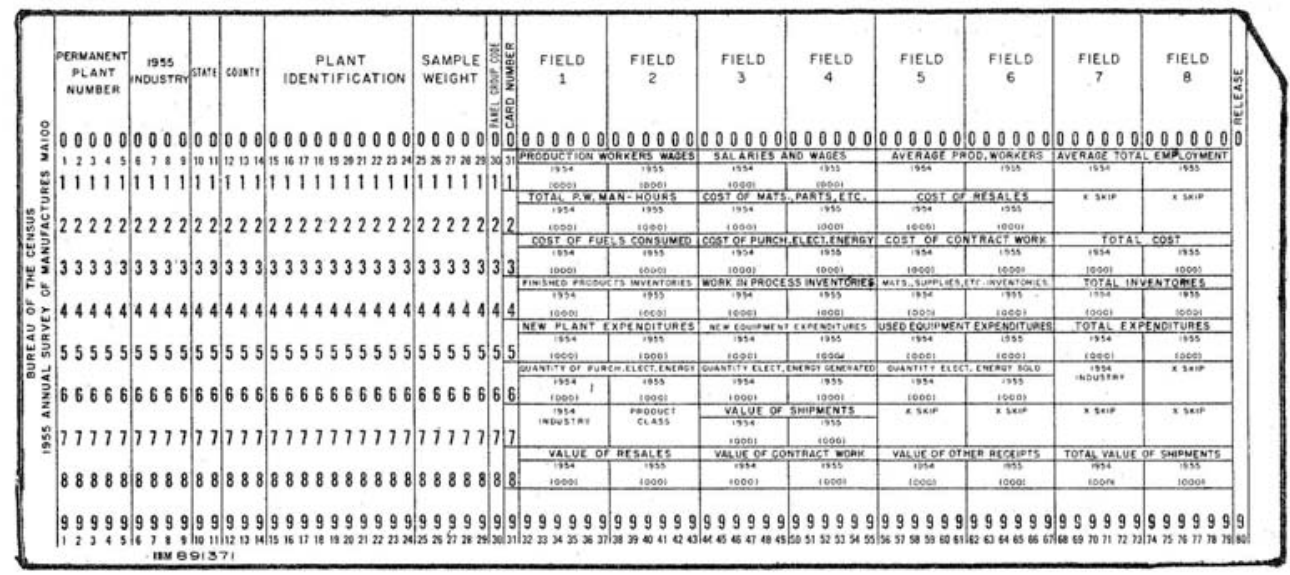

1956

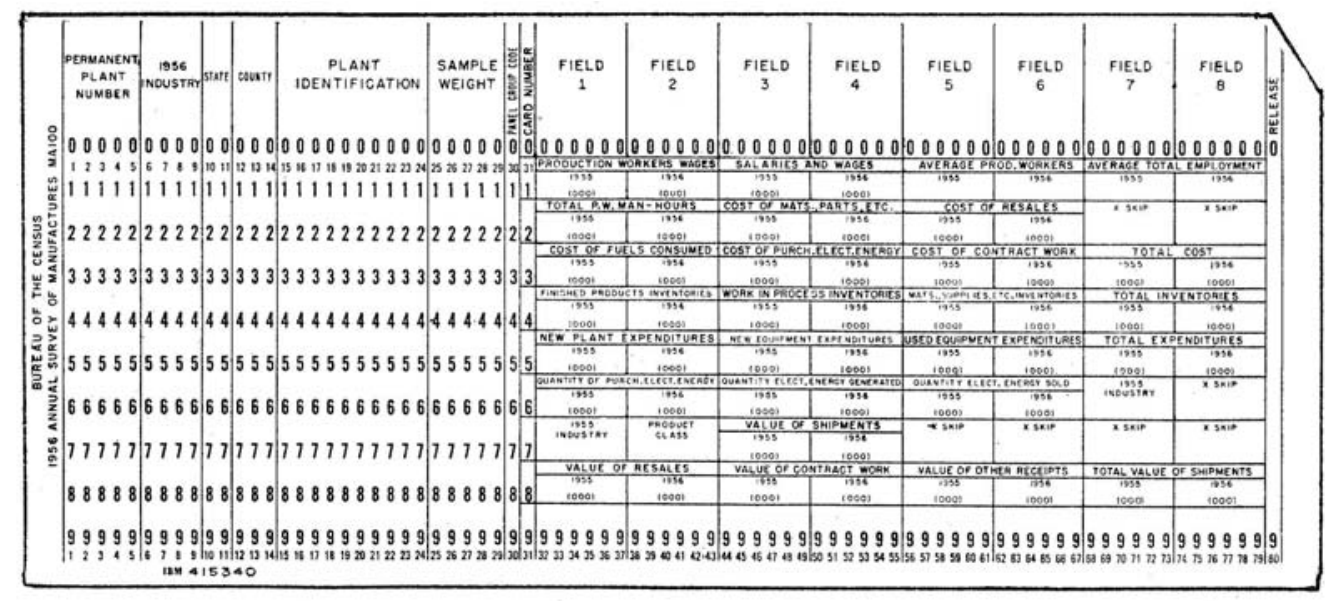

